\title{
Ecological divergence in sympatry causes
}

\section{gene misregulation in hybrids}

13 Classification: Biological Sciences

$14{ }^{1}$ Department of Biology, University of North Carolina, Chapel Hill, NC 27514

$15{ }^{2}$ Department of Integrative Biology and Museum of Vertebrate Zoology, University of

16 California, Berkeley, CA 94720

17 Correspondence: Christopher H. Martin. Department of Integrative Biology and Museum of

18 Vertebrate Zoology, University of California, Berkeley, CA 94720

19 Email: chmartin@berkeley.edu

20 Keywords: RNAseq, gene misregulation, ecological speciation, allele specific expression,

21 Dobzhansky-Muller incompatibility, transcriptomics

22 Word count abstract: 216; Word count main text: 4,145; Figures: 4 


\section{Abstract}

24 Ecological speciation occurs when reproductive isolation evolves as a byproduct of adaptive

25 divergence between populations. However, it is unknown whether divergent ecological selection

26 on gene regulation can directly cause reproductive isolation. Selection favoring regulatory

27 divergence between species could result in gene misregulation in F1 hybrids and ultimately

28 lower hybrid fitness. We combined 58 resequenced genomes with 124 transcriptomes to test this

29 hypothesis in a young, sympatric radiation of Cyprinodon pupfishes endemic to San Salvador

30 Island, Bahamas, which consists of a dietary generalist and two novel trophic specialists - a

31 molluscivore and a scale-eater. We found more differential gene expression between closely

32 related sympatric specialists than between allopatric generalist populations separated by 1000

$33 \mathrm{~km}$. Intriguingly, $9.6 \%$ of genes that were differentially expressed between sympatric species

34 were also misregulated in their F1 hybrids. Consistent with divergent ecological selection

35 causing misregulation, a subset of these genes were in highly differentiated genomic regions and

36 enriched for functions important for trophic specialization, including head, muscle, and brain

37 development. These regions also included genes that showed evidence of hard selective sweeps

38 and were significantly associated with oral jaw length - the most rapidly diversifying skeletal

39 trait in this radiation. Our results indicate that divergent ecological selection in sympatry can

40 cause hybrid gene misregulation which may act as a primary reproductive barrier between

41 nascent species. 


\section{Significance}

51 It is unknown whether the same genes that regulate ecological traits can simultaneously

52 contribute to reproductive barriers between species. We measured gene expression in two trophic

53 specialist species of Cyprinodon pupfishes that rapidly diverged from a generalist ancestor. We

54 found genes differentially expressed between species that also showed extreme expression levels

55 in their hybrid offspring. Many of these genes showed signs of selection and have putative

56 effects on the development of traits that are important for ecological specialization. This suggests

57 that genetic variants contributing to adaptive trait divergence between parental species negatively

58 interact to cause hybrid gene misregulation, potentially producing unfit hybrids. Such loci may

59 be important barriers to gene flow during the early stages of speciation, even in sympatry.

60

61

62

63

64

65

66

67

68

69

70

71

72 


\section{Introduction}

Adaptive radiations showcase dramatic instances of biological diversification resulting from ecological speciation, which occurs when reproductive isolation (RI) evolves as a byproduct of adaptive divergence between populations $(1,2)$. Ecological speciation predicts that populations adapting to different niches will accumulate genetic differences due to divergent ecological selection, indirectly resulting in reduced gene flow. Gene regulation is a major target of selection during adaptive divergence, with many known cases of divergent gene regulation underlying ecological traits (3-7). However, it is still unknown whether divergent ecological selection on gene regulation contributes to reproductive barriers during speciation $(8,9)$.

Hybridization between ecologically divergent populations can break up coadapted genetic variation, resulting in (Bateson) Dobzhansky-Muller incompatibilities (DMIs) if divergent alleles from parental populations are incompatible in hybrids and cause reduced fitness $(10,11)$. DMIs can result in gene misregulation: transgressive expression levels that are significantly higher or lower in F1 hybrids than either parental population. Because gene expression is largely constrained by stabilizing selection, gene misregulation in hybrids is expected to disrupt highly coordinated developmental processes and reduce fitness $(12,13)$.

91 Indeed, crosses between distantly related species show that misregulation is often associated with

92 reduced hybrid fitness in the form of hybrid sterility and inviability (i.e. intrinsic postzygotic

93 isolation) (14-16). DMIs causing these forms of strong intrinsic isolation evolve more slowly

94 than premating isolating barriers and are traditionally modeled as fixed genetic variation between 95 allopatric populations (11).

However, it is unknown whether hybrid gene misregulation also contributes to RI during

97 the early stages of speciation, particularly for populations diverging in sympatry $(9,17,18)$.

98 Either segregating or fixed alleles causing gene misregulation in hybrids could disrupt

99 developmental processes resulting in genetic incompatibilities (intrinsic postzygotic isolation) or

100 reduced performance under natural conditions (extrinsic postzygotic isolation). Emerging

101 evidence suggests that weak intrinsic DMIs segregate within natural populations (19) and are

102 abundant between recently diverged species, reaching hundreds of incompatibility loci within

103 swordtail fish hybrid zones $(20,21)$. Furthermore, hybrid gene misregulation has been reported 
104 at early stages of divergence within a species of intertidal copepod (22) and between young

105 species of lake whitefish (23).

We hypothesized that regulatory genetic variants causing adaptive expression divergence

107 between sympatric species may negatively interact to cause misregulation and reduced fitness in

108 hybrids. Such incompatible alleles could promote rapid speciation because they would

109 simultaneously contribute to adaptive trait divergence and reduce gene flow between populations

$110(18,24,25)$. Here we tested this hypothesis in a young (10 kya), sympatric radiation of

111 Cyprinodon pupfishes endemic to San Salvador Island, Bahamas. This radiation consists of a

112 dietary generalist and two derived specialists adapted to novel trophic niches: a molluscivore $(C$.

113 brontotheroides) and a scale-eater (C. desquamator) (26). Hybrids among these species exhibit

114 reduced fitness in the wild and impaired feeding performance in the lab $(27,28)$. We took a

115 genome-wide approach to identify genetic variation underlying F1 hybrid gene misregulation

116 and found 125 ecological DMI candidate genes that were misregulated, highly differentiated

117 between populations, and strikingly enriched for developmental functions related to trophic

118 specialization. Our findings show that regulatory variation underlying adaptive changes in gene

119 expression can interact to cause hybrid gene misregulation, which may contribute to reduced

120 hybrid fitness and restrict gene flow between sympatric populations.

\section{Results}

123 Trophic specialization, not geographic distance, drives major changes in gene expression 124 and hybrid gene misregulation

125 We sampled two lake populations on San Salvador Island (Crescent Pond and Osprey Lake) in

126 which generalist pupfish coexist with the endemic molluscivore and scale-eater specialist

127 species. We also collected outgroup generalist populations from North Carolina, USA and New

128 Providence Island, Bahamas (Fig. 1A). Wild caught fishes and their F1 offspring were reared in a

129 common laboratory environment. Overall, genetic divergence increased with geographic distance

130 between allopatric generalist populations and was lowest between sympatric populations (Table

$131 \mathrm{~S} 1$; genome-wide mean $F_{s t}$ measured across 13.8 million SNPs: San Salvador generalists vs.

132 North Carolina $=0.217$; vs. New Providence $=0.155$; vs. scale-eaters $=0.106$; vs. molluscivores 
$133=0.056)$. We tested whether isolation by distance explained patterns of gene expression

134 divergence and hybrid gene misregulation while controlling for phylogenetic relatedness using a

135 maximum likelihood tree estimated with RAxML from 1.7 million SNPs (Fig. 1; Fig. S1).

136 Geographic distance among populations was a significant predictor of the proportion of

137 differential gene expression between populations at two days post fertilization ( $2 \mathrm{dpf}$ ) (Fig. 1B;

138 phylogenetic generalized least squares (PGLS); $P=0.02)$. This is consistent with a model of

139 gene expression evolution governed largely by stabilizing selection and drift $(29,30)$. However,

140 at eight days post fertilization ( $8 \mathrm{dpf}$ ), when craniofacial structures of the skull begin to ossify

141 (31), geographic distance was no longer associated with differential expression (Fig. 1C; PGLS;

$142 P=0.18$ ), which was higher between sympatric trophic specialist species on San Salvador Island

143 than between generalist populations spanning $1000 \mathrm{~km}$ across the Caribbean.

144 Geographic distance between parental populations was not associated with gene

145 misregulation in F1 hybrids at either developmental stage (Fig. 1D and E; PGLS; 2 dpf $P=0.17$;

$1468 \mathrm{dpf} P=0.38$ ). 9.3\% of genes were misregulated in specialist F1 hybrids (Fig. 1E; Crescent

147 Pond molluscivore $\times$ scale-eater), comparable to species pairs with much greater divergence

148 times $(16,32)$. Out of 3,669 misregulated genes containing heterozygous sites in F1 hybrids that

149 were homozygous in parents, 819 (22.3\%) showed allele specific expression and were not

150 differentially expressed between parental populations - patterns consistent with compensatory

151 regulation underlying misregulation (Fig. S2-4, Table S2).

153 Genes showing divergent expression between species are also misregulated in their F1

154 hybrids

155 We used two approaches to identify gene misregulation associated with ecological divergence 156 between species. First, we found 716 genes that showed differential expression between San

157 Salvador species that were also misregulated in their F1 hybrids (Fig. 2, Table S3). Nearly all

158 these genes (99.4\%) were misregulated in only one lake population and $69.8 \%$ were only

159 misregulated at $8 \mathrm{dpf}$ in comparisons involving scale-eaters (Fig. 2A-H). Four genes showed

160 differential expression between species and hybrid misregulation in both lake comparisons

161 (trim47, krt13, s100al, elovl7; Table S4). 
Second, we identified genes showing parallel expression divergence in both specialist species relative to generalists that were misregulated in specialist F1 hybrids (Fig. 3). This pattern likely results from parallel expression in molluscivores and scale-eaters controlled by different genetic mechanisms (33). Significantly more genes showed differential expression in

166 both specialist comparisons than expected by chance (Fig. 3A-D; Fisher's exact test, $P<2.7 \times$

$\left.16710^{-5}\right)$. Of these, $96.6 \%(1,206)$ showed the same direction of expression in specialists relative to 168 generalists, which was more than expected under a neutral model of gene expression evolution

169 (Fig. 3E and F; binomial test, $P<1.0 \times 10^{-16}$ ). 45 of the 1,206 genes showing parallel expression 170 divergence in specialists also showed misregulation in specialist F1 hybrids (Fig. 3F). Eight of 171 these genes were severely misregulated to the extent that they were differentially expressed in

172 hybrids relative to all other populations in our dataset. For example, sypll showed significantly

173 higher expression in $8 \mathrm{dpf}$ Crescent Pond molluscivore $\times$ scale-eater F1 hybrids than all other

174 crosses spanning $1000 \mathrm{~km}$ from San Salvador Island, Bahamas to North Carolina, USA $(P=2.35$

$175 \times 10^{-4}$; Fig. 3G). Overexpression of this gene is associated with epithelial-mesenchymal

176 transition, an important process during cranial neural crest cell migration $(34,35)$. Similarly,

$177 s c n 4 a$ showed significantly lower expression in $8 \mathrm{dpf}$ Crescent Pond specialist F1 hybrids than

178 all other crosses $\left(P=5.49 \times 10^{-4}\right.$; Fig. $\left.3 \mathrm{H}\right)$. Mutations in this gene are known to cause

179 paramyotonia congenita, a disorder causing weakness and stiffness of craniofacial skeletal 180 muscles (36).

183 Out of 750 total unique genes identified above as differentially expressed between populations 184 and misregulated in F1 hybrids, 125 (17\%) were within $20 \mathrm{~kb}$ of SNPs that were fixed between 185 populations $\left(F_{s t}=1\right)$ and within $20 \mathrm{~kb}$ windows showing high absolute genetic divergence 186 between populations ( $D_{x y} \geq$ genome-wide $90^{\text {th }}$ percentile; range: $0.0031-0.0075$; Table $\mathrm{S} 1$ ).

187 This set of 125 genes, which we refer to as ecological DMI candidate genes, was significantly 188 enriched for functional categories highly relevant to divergent specialist phenotypes, including 189 head development, brain development, muscle development, and cellular response to nitrogen $190 \quad($ FDR $=0.05 ;$ Fig. 4A, Table S5). 
$26(20.8 \%)$ of these ecological DMI candidate genes showed strong evidence of a hard

192 selective sweep in specialists (negative Tajima's D < genome-wide $10^{\text {th }}$ percentile; range: $-1.62-$

$193-0.77$; SweeD composite likelihood ratio $>90^{\text {th }}$ percentile by scaffold; Table S6 and S7) and 16

194 of these showed at least a two-fold expression difference in F1 hybrids compared to purebred F1.

195 Several ecological DMI candidate genes have known functions that are compelling targets for

196 divergent ecological selection. For example, the autophagy-related gene map $1 l c 3 c$ has been

197 shown to influence growth when cells are nitrogen deprived $(37,38)$. Given that specialists

198 occupy higher trophic levels than generalists, as shown by stable isotope ratios $(\delta 15 \mathrm{~N} ;$ Fig. 5B),

199 expression changes in this gene may be important adaptations to nitrogen-rich diets. Similarly,

200 expression changes in the ten genes annotated for effects on brain development may influence

201 divergent behavioral adaptations associated with trophic specialists, including significantly

202 increased aggression (39) and female mate preferences (40).

Using a genome-wide association mapping method that accounts for genetic structure

204 among populations (41), we found that nine of the 125 genes in differentiated regions were

205 significantly associated with oral jaw size - the most rapidly diversifying skeletal trait in this

206 radiation (GEMMA PIP > 99 ${ }^{\text {th }}$ percentile; Table S8; Fig. S5). For example, we found that $m p p 1$

207 was near 170 SNPs fixed between Crescent Pond generalists and scale-eaters, showed evidence

208 of a hard selective sweep in both populations, and was differentially expressed due to cis-

209 regulatory mechanisms (Fig. 4F-I). F1 hybrids showed a 3-fold decrease in expression of mppl

$210 \quad(P=0.001 ;$ Fig. $4 \mathrm{~F})$. Knockouts of this gene were recently shown to cause severe craniofacial

211 defects in humans and mice (42). The other eight genes significantly associated with jaw size

212 have not been previously shown to influence cranial phenotypes, but some have known functions

213 in cell types relevant to craniofacial development (Table S8). For example, the gene sema6c,

214 which shows strong signs of selection in both scale-eaters and molluscivores (Fig. S6), is known

215 to be expressed at neuromuscular junctions and is important for neuron growth and development

216 within skeletal muscle (43). Expression changes in this gene may influence the development of

217 jaw closing muscles (adductor mandibulae), which tend to be larger in specialists relative to

218 generalists (Fig. 5B). Overall, we found candidate regulatory variants under selection that likely

219 contribute to hybrid gene misregulation and demonstrate that genes near these variants are

220 strikingly enriched for developmental functions related to divergent adaptive traits. 


\section{Discussion}

223 By combining whole genome sequencing with transcriptomic analyses of developing tissues in 224 recently diverged trophic specialists and their F1 hybrids, we provide a genome-wide view of

225 how ecological selection can directly result in genetic incompatibilities causing gene

226 misregulation in hybrids, even in sympatry. Our results are consistent with negative epistatic 227 interactions between alleles from different parental genomes affecting 750 genes (3\% of the

228 transcriptome) that show differential expression between species and misregulation in F1

229 hybrids. 125 of these genes were in highly differentiated regions of the genome containing SNPs

230 fixed between specialists which were enriched for developmental processes relevant to trophic

231 specialization, suggesting that misregulation of these candidate genes in F1 and later generations

232 of hybrids may disrupt the function of adaptive traits and contribute to reproductive isolation

233 between these nascent species.

The negative fitness consequences associated with hybrid gene misregulation are well

235 documented in many systems $(14-16,44,45)$, but most of this research has focused on genes

236 associated with sterility and inviability between highly divergent species (but see (23)). It is clear

237 that these strong intrinsic postzygotic isolating barriers evolve more slowly than premating

238 barriers $(11,46,47)$; however, hybrid gene misregulation may also have non-lethal effects on

239 fitness and performance that could evolve before or alongside premating isolating mechanisms.

240 Additionally, if genes that are differentially expressed between species in developing tissues are

241 important for adaptive trait divergence, then misregulation of those genes could contribute to

242 abnormal phenotypes that are ecologically maladaptive $(18,23,48)$. We previously found

243 extensive gene misregulation specific to craniofacial tissues, which were dissected from

244 generalist $\times$ molluscivore F1 hybrids at an early developmental stage (49). Furthermore, F2 and

245 later generation hybrids showing more transgressive phenotypes exhibited the lowest survival

246 and growth rate in field enclosures across multiple lakes and multiple independent field

247 experiments on San Salvador Island $(27,50)$. In the lab, generalist $\times$ scale-eater F1 hybrids

248 exhibited non-additive and impaired feeding performance on scales (28). Overall, these

249 independent lines of evidence suggest that hybrids among San Salvador Island species suffer

250 reduced performance and survival in both laboratory and field environments, which may result 
251 from misregulation of genes that are necessary for the normal development of their adaptive 252 traits.

If divergent ecological selection on adaptive traits also causes gene misregulation and 254 subsequently reduced performance and survival of hybrids in the wild, then these ecological 255 DMIs may promote rapid speciation, analogous to the mechanism of magic traits (51). For 256 example, whereas magic traits contribute to RI through assortative mating as a byproduct of 257 divergent ecological selection, these ecological DMIs contribute to RI through gene 258 misregulation and reduced hybrid fitness (18). Thus, our results support a mechanism for 259 divergent ecological selection to generate RI as a byproduct since many adaptive traits are 260 expected to evolve by divergent gene regulation that may come into conflict in a hybrid genetic 261 background $(9,18)$.

Mathematical models and simulations suggest that genetic incompatibilities evolve most 263 rapidly under directional selection $(52,53)$, and evolve more slowly under stabilizing selection 264 when compensatory cis and trans variants have opposing effects on expression levels (52). We 265 see evidence for both types of selection driving misregulation. $22.3 \%$ of all misregulated genes 266 showed expression patterns consistent with compensatory regulation, a signature of stabilizing 267 selection (Table S2). However, 26 ecological DMI candidate genes in highly differentiated 268 genomic regions showed strong evidence of hard selective sweeps due to directional selection 269 (Table S6), and more genes may have experienced soft sweeps that were not detected by our 270 methods. Although scale-eaters from Crescent Pond and Osprey Lake form a monophyletic 271 group (Fig. S1), we found little overlap in misregulated genes between lakes (Fig. 2). This may 272 result from selection on Caribbean-wide standing genetic variation that has similar effects on 273 expression, as we showed previously (33), and could reflect polymorphic incompatibilities 274 segregating within species (19). We also see distinct intraspecific differences between lake 275 populations of trophic specialists in pigmentation, maxillary protrusion, and other traits (54), consistent with divergent regulatory variation underlying these adaptive phenotypes. 
our results are consistent with previous observations that hybrid incompatibility alleles are often segregating within populations $(17,19,55,56)$ and that hundreds of genetic incompatibilities can contribute to reproductive isolation between species at the earliest stages of divergence (21). We extend this emerging consensus by showing that gene misregulation can result as a byproduct of divergent ecological selection on a wide range of adaptive traits.

\section{Methods}

\section{Study system and sample collection}

289 We collected 51 wild-caught individuals from nine isolated hypersaline lakes on San Salvador 290 Island, Bahamas, plus outgroup populations across the Caribbean (see supplemental methods). 291 Our total mRNA transcriptomic dataset consisted of 124 Cyprinodon exomes from lab-reared 292 embryos collected between 2017 and 2018. We collected fishes for breeding from two 293 hypersaline lakes on San Salvador Island, Bahamas (Osprey Lake and Crescent Pond); Lake 294 Cunningham, New Providence Island, Bahamas; and Fort Fisher, North Carolina, United States. We performed 11 separate crosses falling into three categories. 1) For purebred crosses, 296 we collected F1 embryos from breeding tanks containing multiple breeding pairs from a single

297 location. 2) For San Salvador species crosses, we crossed a single individual of one species with 298 a single individual of another species from the same lake for all combinations of the three San 299 Salvador species. In order to control for maternal effects on gene expression inheritance, we 300 collected samples from reciprocal crosses for three of the San Salvador species crosses. 3) For 301 outgroup generalist crosses, we crossed a Crescent Pond generalist male with a Lake 302 Cunningham female and a North Carolina female (Table S9).

\section{Sequencing and variant discovery}

305 Genomic resequencing libraries were prepared using TruSeq library preparation kits and 306 sequenced on Illumina 150PE Hiseq4000. We mapped a total of 1,953,034,511 adaptor-trimmed 307 reads to the Cyprinodon reference genome (57) with the Burrows-Wheeler Alignment Tool (58). 308 We extracted RNA from a total of 348 individuals across two early developmental stages (2 days 
post fertilization (dpf) and $8 \mathrm{dpf}$ ) using RNeasy Mini Kits (Qiagen, Inc.). For 2 dpf libraries, we pooled 5 embryos together and pulverized them in a $1.5 \mathrm{ml}$ Eppendorf tube. We used the same extraction method for samples collected at $8 \mathrm{dpf}$ but did not pool larvae. Libraries were prepared using TruSeq stranded mRNA kits and sequenced on 3 lanes of Illumina 150 PE Hiseq4000 at the Vincent J. Coates Genomic Sequencing Center. We mapped 1,638,067,612 adaptor-trimmed reads to the reference genome using the RNAseq aligner STAR with default parameters (59). We did not find a difference between species or outgroup populations for standard quality control measures, (Fig. S7; ANOVA, $P>0.1$ ), except for a marginal difference in transcript integrity numbers (Fig. S8; ANOVA, $P=0.041$ ) driven by slightly higher transcript quality in North Carolina generalist samples relative to other samples (Tukey post-hoc test: $P=0.043$ ). We found no significant differences among San Salvador Island generalists, molluscivores, scale-eaters, and outgroups in the proportion of reads that mapped to annotated features of the Cyprinodon reference genome (Fig. S9; ANOVA, $P=0.17$ ).

We used the Genome Analysis Toolkit (60) to call and refine SNP variants across 58 Cyprinodon genomes and across 124 Cyprinodon exomes. We filtered both SNP datasets to include individuals with a genotyping rate above $90 \%$ and SNPs with minor allele frequencies higher than 5\%. Our final filtered genomic SNP dataset included 13,838,603 variants with a mean sequencing coverage of $8.2 \times$ per individual. We further refined our transcriptomic SNP dataset using the allele-specific software WASP (v. 0.3.3) to correct for potential mapping biases that would influence tests of allele-specific expression $(61,62)$. We re-called SNPs using unbiased BAMs determined by WASP for a final transcriptomic SNP dataset that included 413,055 variants with a mean coverage of $1,060 \times$ across features per individual.

\section{Phylogenetic analyses}

333 In order to determine the relationship between expression divergence, F1 hybrid misregulation, 334 and phylogenetic distance, we estimated a maximum likelihood tree using RAxML (63). We 335 excluded all missing sites and sites with more than one alternate allele from our genomic SNP 336 dataset, leaving 1,737,591 variants across 58 individuals for analyses. We performed ten separate 337 searches with different random starting trees under the GTRGAMMA model. Node support was 338 estimated from 1,000 bootstrap samples. We fit phylogenetic generalized least-squares (PGLS) 
models in $\mathrm{R}$ with the packages ape (64) and nlme to assess whether gene expression patterns were associated with geographic distance among populations after accounting for phylogenetic relatedness among populations and species. We excluded Osprey Lake populations from these analyses because outgroups were only crossed with Crescent Pond generalists.

\section{Population genomics and genome-wide association mapping}

345 If alleles causing gene expression divergence between species affect the development of adaptive 346 traits, and also cause gene misregulation in hybrids resulting in low fitness, we predicted that genomic regions near these genes would be strongly differentiated between species, associated with divergent ecological traits, and show signatures of positive selection. We measured relative genetic differentiation $\left(F_{s t}\right)$, within population diversity $(\pi)$, and between population divergence $\left(D_{x y}\right)$ across 58 Cyprinodon individuals using 13.8 million SNPs (Table S1 and S7). We identified $20 \mathrm{~kb}$ genomic windows significantly associated with variation in oral jaw size across all populations in our dataset (Table S8; Fig. S5). We measured upper jaw lengths and standard

353 length for all individuals in our genomic dataset using digital calipers, fit a log-transformed jaw 354 length by log-transformed standard length linear regression to correct for body size, and used the residuals for genome-wide association mapping with the software GEMMA (41). This program accounts for population structure by incorporating a genetic relatedness matrix into a Bayesian sparse linear mixed model which calculates a posterior inclusion probability (PIP) indicating the proportion of Markov Chain Monte Carlo iterations in which a SNP was estimated to have a nonzero effect on phenotypic variation. We used Tajima's D statistic and the software SweeD (65) to identify shifts in the site frequency spectrum characteristic of hard selective sweeps. We performed gene ontology enrichment analyses for candidate gene sets using ShinyGo (66).

\section{Hybrid misregulation and inheritance of gene expression patterns}

364 We aggregated read counts with featureCounts (67) at the transcript isoform level (36,511

365 isoforms corresponding to 24,952 protein coding genes). Significant differential expression

366 between groups was determined with DESeq2 (68) using Wald tests comparing normalized

367 posterior log fold change estimates and correcting for multiple testing using the Benjamini- 
Hochberg procedure with a false discovery rate of 0.05 (69). We compared expression in F1

hybrids to expression in F1 purebred offspring to determine whether genes showed additive, population $\mathrm{B}\left(\mathrm{F} 1_{(\mathrm{A} \times \mathrm{B})}\right)$, we conducted four pairwise differential expression tests with DESeq2: 1)

374 inheritance was considered additive if hybrid gene expression was intermediate between parental

375 populations and significantly different between parental populations. Inheritance was dominant if hybrid expression was significantly different from one parental population but not the other.

377 Genes showing misregulation in hybrids showed transgressive inheritance, meaning that hybrid gene expression was significantly higher (overdominant) or lower (underdominant) than both

Parallel changes in gene expression in specialists

382 Parallel evolution of gene expression is often associated with convergent niche specialization,

383 but parallel changes in expression may also underlie divergent specialization (33). We looked at 384 the intersection of genes differentially expressed between generalists versus molluscivores and 385 generalists versus scale-eaters to determine whether both specialists showed parallel changes in expression relative to generalists. We asked whether significant parallelism at the level of gene expression in specialists was mirrored by parallel regulatory mechanisms. We predicted that genes showing parallel changes in specialists would show conserved expression levels in specialist hybrids if they were controlled by the same (or compatible) regulatory mechanisms,

390 but would be misregulated in specialist hybrids if expression was controlled by incompatible

391 regulatory mechanisms. We identified genes showing conserved levels of expression in specialist

392 hybrids (no significant difference in expression between F1 purebreds and F1 hybrids) and genes

393 showing misregulation in specialist hybrids. We also identified genes showing misregulation in

394 specialists relative to all other samples in our dataset across the Caribbean. 
Our genomic dataset included every parent used to generate F1 hybrids between populations $(n=$

398 15). To categorize mechanisms of regulatory divergence between two populations, we used custom R and python scripts (github.com/joemcgirr/fishfASE) to identify SNPs that were alternatively homozygous in breeding pairs and heterozygous in their F1 offspring. We counted reads across heterozygous sites using ASEReadCounter and matched read counts to maternal and paternal alleles. We identified significant ASE using a beta-binomial test comparing the maternal and paternal counts at each gene transcript with the R package MBASED (70). A transcript was considered to show ASE if it showed significant ASE in all F1 hybrid samples generated from the same breeding pair and did not show significant ASE in purebred F1 offspring from the same parental populations.

\section{Acknowledgements}

409 This study was funded by the University of North Carolina at Chapel Hill, the Miller Institute for 410 Basic Research in the Sciences, NSF CAREER Award 1749764, and NIH/NIDCR R01

411 DE027052 to CHM. Travel was supported by an SSE Rosemary Grant Award to JAM. We thank 412 Aaron Comeault, Chris Willett, and Jennifer Coughlan for helpful comments on the manuscript;

413 Daniel Matute, Emilie Richards, Michelle St. John, Bryan Reatini, and Sara Suzuki for valuable 414 discussion; The Vincent J. Coates Genomics Sequencing Laboratory at the University of 415 California, Berkeley for performing RNA library prep and Illumina sequencing; the Gerace 416 Research Centre for logistics; and the Bahamian government BEST Commission for permission 417 to conduct this research.

\section{Data Availability}

420 All transcriptomic raw sequence reads are available as zipped fastq files on the NCBI BioProject 421 database. Accession: PRJNA391309. Title: Craniofacial divergence in Caribbean Pupfishes. All $422 \mathrm{R}$ and Python scripts used for pipelines are available on Git (github.com/joemcgirr/fishfASE).

424 1. Schluter D (2000) The Ecology of Adaptive Radiation (Oxford University Press, Oxford). 
2. Nosil P (2012) Ecological Speciation (Oxford University Press, Oxford).

3. Thompson AC, et al. (2018) A novel enhancer near the Pitx1 gene influences development and evolution of pelvic appendages in vertebrates. Elife 7:1-21.

4. Parry JWL, et al. (2005) Mix and match color vision: Tuning spectral sensitivity by differential opsin gene expression in Lake Malawi cichlids. Curr Biol 15(19):1734-1739.

5. Abzhanov A, Protas M, Grant BR, Grant PR, Tabin CJ (2011) Variation of beaks in Darwin's finches. Science 1462(2004):1462-1466.

6. Jones FC, et al. (2012) The genomic basis of adaptive evolution in threespine sticklebacks. Nature 484(7392):55-61.

7. Manceau M, Domingues VS, Mallarino R, Hoekstra HE (2011) The developmental role of Agouti in color pattern evolution. Science 331(6020):1062-5.

8. Mack KL, Nachman MW (2017) Gene regulation and speciation. Trends Genet 33(1):6880.

9. Pavey SA, Nosil P, Rogers SM (2010) The role of gene expression in ecological speciation. Ann N Y Acad Sci 1206:110-129.

10. Orr HA (1996) Anecdotal, historical and critical commentaries on genetics. Genetics 144:1331-1335.

11. Coyne JA, Orr HA (2004) Speciation (Sinauer Assoc., Sunderland)

12. Signor SA, Nuzhdin SV (2018) The evolution of gene expression in cis and trans. Trends Genet 34(7):532-544.

13. Bedford T, Hartl DL (2009) Optimization of gene expression by natural selection. Proc Natl Acad Sci 106(4):1133-1138.

14. Landry CR, Hartl DL, Ranz JM (2007) Genome clashes in hybrids: Insights from gene expression. Heredity 99(5):483-493.

15. Ortíz-Barrientos D, Counterman BA, Noor MAF (2007) Gene expression divergence and the origin of hybrid dysfunctions. Genetica 129(1):71-81.

16. Mack KL, Campbell P, Nachman MW (2016) Gene regulation and speciation in house mice. Genome Res 26(4):451-61.

17. Cutter AD (2012) The polymorphic prelude to Bateson - Dobzhansky - Muller incompatibilities. Trends Ecol Evol 27(4):210-219.

18. Kulmuni J, Westram AM (2017) Intrinsic incompatibilities evolving as a by-product of divergent ecological selection: Considering them in empirical studies on divergence with gene flow. Mol Ecol 26(12):3093-3103.

19. Corbett-detig RB, Zhou J, Clark AG, Hartl DL, Ayroles JF (2013) Genetic incompatibilities are widespread within species. Nature 504(7478):135-137.

20. Schumer M, Brandvain Y (2016) Determining epistatic selection in admixed populations. Mol Ecol 25(11):2577-91.

21. Schumer M, et al. (2014) High-resolution mapping reveals hundreds of genetic incompatibilities in hybridizing fish species. Elife 2014(3):1-21.

22. Barreto FS, Pereira RJ, Burton RS (2015) Hybrid dysfunction and physiological compensation in gene expression. Mol Biol Evol 32(3):613-622. 
23. Renaut S, Nolte AW, Bernatchez L (2009) Gene expression divergence and hybrid misexpression between lake whitefish species pairs (Coregonus spp. Salmonidae). Mol Biol Evol 26(4):925-936.

24. Dobzhansky T (1951) Genetics and the Origin of Species (Columbia University Press, New York).

25. Schluter D, Conte GL (2009) Genetics and ecological speciation. Proc Natl Acad Sci 106:9955-9962.

26. Martin CH, Wainwright PC (2013) A remarkable species flock of Cyprinodon pupfishes endemic to San Salvador Island, Bahamas. Bull Peabody Museum Nat Hist 54(2):231241.

27. Martin CH, Wainwright PC (2013) Multiple fitness peaks on the adaptive landscape drive adaptive radiation in the wild. Science 339(6116):208-11.

28. St John ME, Martin CH (2019) Scale-eating specialists evolved adaptive feeding kinematics within a microendemic radiation of San Salvador Island pupfishes. bioRxiv doi.org/10.1101/648451 (24 May 2019).

29. Kimura M (1983) The Neutral Allele Theory of Molecular Evolution (Cambridge University Press, Cambridge).

30. Whitehead A, Crawford DL (2006) Neutral and adaptive variation in gene expression. Proc Natl Acad Sci 103(14):5425-5430.

31. Lencer ES, McCune AR (2018) An embryonic staging series up to hatching for Cyprinodon variegatus: An emerging fish model for developmental, evolutionary, and ecological research. J Morphol 279(11):1559-1578.

32. Coolon JD, et al. (2014) Tempo and mode of regulatory evolution in Drosophila. Genome Res 24(5):797-808.

33. McGirr JA, Martin CH (2018) Parallel evolution of gene expression between trophic specialists despite divergent genotypes and morphologies. Evol Lett 2(2):62-75.

34. Chen DH, Wu QW, Li XD, Wang SJ, Zhang ZM (2017) SYPL1 overexpression predicts poor prognosis of hepatocellular carcinoma and associates with epithelial-mesenchymal transition. Oncol Rep 38(3):1533-1542.

35. Kang P, Svoboda KKH (2005) Epithelial-mesenchymal transformation during craniofacial development. J Dent Res. 84(8):678-90.

36. Huang S, Zhang W, Chang X, Guo J (2019) Overlap of periodic paralysis and paramyotonia congenita caused by SCN4A gene mutations. Channels 13(1):110-119.

37. Otto GP, Wu MY, Kazgan N, Anderson OR, Kessin RH (2004) Dictyostelium macroautophagy mutants vary in the severity of their developmental defects. J Biol Chem 279(15):15621-15629.

38. Stadel D, et al. (2015) TECPR2 cooperates with LC3C to regulate COPII-dependent ER export. Mol Cell 60(1):89-104. increased aggression lead to scale-eating in pupfishes? Behav Ecol 30(2):557-569. isolation in a species flock of pupfish (Cyprinodon spp) in the Bahamas. Ethology 121(8):793-800. 
41. Zhou X, Carbonetto P, Stephens M (2013) Polygenic modeling with bayesian sparse linear mixed models. PLoS Genet 9(2):e1003264.

42. Fritz DI, Johnston JM, Chishti AH (2019) MPP1/p55 gene deletion in a hemophilia A patient with ectrodactyly and severe developmental defects. Am J Hematol 94(1):E29E32.

43. Svensson A, Libelius R, Tågerud S (2008) Semaphorin 6C expression in innervated and denervated skeletal muscle. J Mol Histol 39(1):5-13.

44. Malone JH, Michalak P (2008) Gene expression analysis of the ovary of hybrid females of Xenopus laevis and X. muelleri. BMC Evol Biol 8(1). doi:10.1186/1471-2148-8-82.

45. Maheshwari S, Barbash DA (2012) Cis-by-trans regulatory divergence causes the asymmetric lethal effects of an ancestral hybrid incompatibility gene. PLoS Genet 8(3):e1002597.

46. Coyne JA, Orr HA (1989) Patterns of speciation in Drosophila. Evolution 43(2):362-381.

47. Turissini DA, McGirr JA, Patel SS, David JR, Matute DR (2018) The rate of evolution of postmating-prezygotic reproductive isolation in Drosophila. Mol Biol Evol 35(2):312334.

48. Arnegard ME, et al. (2014) Genetics of ecological divergence during speciation. Nature 511(7509):307-311.

49. McGirr JA, Martin CH (2019) Hybrid gene misregulation in multiple developing tissues within a recent adaptive radiation of Cyprinodon pupfishes. PLoS One 14(7):e0218899.

50. Martin CH (2016) Context-dependence in complex adaptive landscapes: frequency and trait-dependent selection surfaces within an adaptive radiation of Caribbean pupfishes. Evolution 70(6):1265-82.

51. Servedio MR, Doorn GS Van, Kopp M, Frame AM, Nosil P (2011) Magic traits in speciation: "magic" but not rare? Trends Ecol Evol 26(8):389-397.

52. Tulchinsky AY, Johnson NA, Watt WB, Porter AH (2014) Hybrid incompatibility arises in a sequence-based bioenergetic model of transcription factor binding. Genetics 198(3):1155-1166.

53. Johnson NA, Porter AH (2000) Rapid speciation via parallel, directional selection on regulatory genetic pathways. J Theor Biol 205(4):527-542.

54. Martin CH, Feinstein LC (2014) Novel trophic niches drive variable progress towards ecological speciation within an adaptive radiation of pupfishes. Mol Ecol 23(7):18461862.

55. Larson EL, et al. (2018) The evolution of polymorphic hybrid incompatibilities in house mice. 209:845-859.

56. Reed LK, Markow TA (2004) Early events in speciation: Polymorphism for hybrid male sterility in Drosophila. 101(24):9009-9012.

57. Lencer ES, Warren WC, Harrison R, McCune AR. 2017. The Cyprinodon variegatus genome reveals gene expression changes underlying differences in skull morphology among closely related species. BMC Genomics 18(1):424.

58. Li H, Durbin R (2009) Fast and accurate short read alignment with Burrows-Wheeler transform. Bioinformatics 25(14):1754-60.

59. Dobin A, et al. (2013) STAR: ultrafast universal RNA-seq aligner. 29(1):15-21. 
60. DePristo MA, et al. (2011) A framework for variation discovery and genotyping using next-generation DNA sequencing data. Nat Genet 43(5):491-8.

61. Van De Geijn B, Mcvicker G, Gilad Y, Pritchard JK (2015) WASP: Allele-specific software for robust molecular quantitative trait locus discovery. Nat Methods 12(11):1061-1063.

62. Degner JF, et al. (2009) Effect of read-mapping biases on detecting allele-specific expression from RNA-sequencing data. Bioinformatics 25(24):3207-3212.

63. Stamatakis A (2014) RAxML version 8: a tool for phylogenetic analysis and postanalysis of large phylogenies. Bioinformatics 30(9):1312-1313.

64. Paradis E, Schliep K (2019) Ape 5.0: an environment for modern phylogenetics and evolutionary analyses in R. Bioinformatics 35(3):526-528. detection of selective sweeps in thousands of genomes. Mol Biol Evol 30(9):2224-2234.

Fig. 1. Caribbean-wide patterns of gene expression and misregulation across sympatric and allopatric populations of Cyprinodon pupfishes. A) Maximum likelihood tree estimated from

66. Ge SX, Jung D (2018) ShinyGO: a graphical enrichment tool for animals and plants. biorXiv doi.org/10.1101/315150 (4 May 2018).

67. Liao Y, Smyth GK, Shi W (2014) Sequence analysis featureCounts: an efficient general purpose program for assigning sequence reads to genomic features. Bioinformatics 30(7):923-930.

68. Love MI, Huber W, Anders S (2014) Moderated estimation of fold change and dispersion for RNA-seq data with DESeq2. Genome Biol 15(12):550.

69. Benjamini Y, Hochberg Y (1995) Controlling the false discovery rate: a practical and powerful approach to multiple testing. J Royal Statistical Soc B 57(1):289-300.

70. Mayba O, et al. (2014) MBASED: Allele-specific expression detection in cancer tissues and cell lines. Genome Biol 15(8):1-21. species (100\% bootstrap support indicated at nodes). B) Geographic distance separating populations was associated with differential gene expression levels in embryos at 2 days post fertilization ( $2 \mathrm{dpf}$; phylogenetic least squares $P=0.02$, dotted regression line). C) In whole larvae at $8 \mathrm{dpf}$ differential expression was not associated with geographic distance (PGLS; $P=$ 0.18 ) and was higher between sympatric specialists (red) than between allopatric generalists separated by 300 and $1000 \mathrm{~km}$ (black). D and E) Hybrid misregulation for sympatric crosses at 8 dpf than 2 dpf. Geographic distance was not associated with hybrid misregulation at either developmental stage (PGLS; 2 dpf $P=0.17 ; 8 \mathrm{dpf} P=0.38$ ). Percentages in B-E were measured using Crescent Pond crosses. 
generalist $\times$ scale-eater crosses $(\mathrm{E}-\mathrm{H})$, and generalist $\times$ molluscivore crosses $(\mathrm{I}-\mathrm{L})$. Genes misregulated in F1 hybrids are shown in blue. In comparisons involving reciprocal crosses (D, J, and L), we only show genes misregulated in a single cross direction. A total of 716 genes (purple) were differentially expressed between species and also misregulated in their F1 hybrids. Purple Venn diagrams show overlap between lake population comparisons; 4 genes showed differential expression and misregulation in both lake comparisons.

\section{Fig. 3. Genes showing parallel expression divergence in specialists are misregulated in} specialist hybrids. Genes differentially expressed between generalists and molluscivores (green) were compared to the set of genes differentially expressed between generalists and scale-eaters (dark blue). A-D) Significantly more genes showed differential expression in both specialist comparisons (light blue) than expected by chance in both lakes at both developmental stages (Fisher's exact test, $\mathrm{P}<2.7 \times 10^{-5}$ ). E) A neutral model of gene expression evolution would predict that only $50 \%$ of genes should show the same direction of expression in specialists relative to generalists (yellow). F) Instead, 96.6\% of genes showed the same direction of expression in specialists, suggesting significant parallel expression divergence in specialists (Binomial exact test; $P<1.0 \times 10^{-16}$ ). Consistent with incompatible regulatory mechanisms underlying parallel expression in specialists, 45 of these genes were misregulated in specialist F1 hybrids, including $\mathrm{G}$ ) sypll and $\mathrm{H}$ ) scn $4 a$ which showed extreme misregulation: expression levels outside the range of all other Caribbean populations examined.

Fig. 4. Ecological divergence causes hybrid gene misregulation. A) 14 selected gene ontology (GO) terms relevant to trophic specialization were significantly enriched for the set of 125 genes in highly differentiated genomic regions that showed differential expression between species and misregulation in F1 hybrids. Consistent with muscle development and nitrogen metabolism enrichment, B) adductor mandibulae muscle mass tends to be larger in specialists and C) stable nitrogen isotope ratios $(\delta 15 \mathrm{~N})$ are significantly higher in scale-eaters, indicating that they occupy a higher trophic level (Tukey post-hoc test: $P<0.001^{* * *}$ ). D) The gene mppl is controlled by cis-regulatory divergence as shown by E) allele specific expression in F1 hybrids and F) differential expression between Crescent Pond generalists vs. scale-eaters and misregulation in their F1 hybrids. G) The gene mppl (light blue band) is near 170 SNPs fixed between Crescent Pond generalists vs. scale-eaters (black points), shows high absolute divergence between species $\left(D_{x y}\right)$, low within-species diversity $(\pi)$, signatures of a hard selective sweep (Tajima's D and SweeD composite likelihood ratio (CLR)), and is significantly associated with oral jaw length (PIP; GEMMA genome-wide association mapping). 
Fig 1.
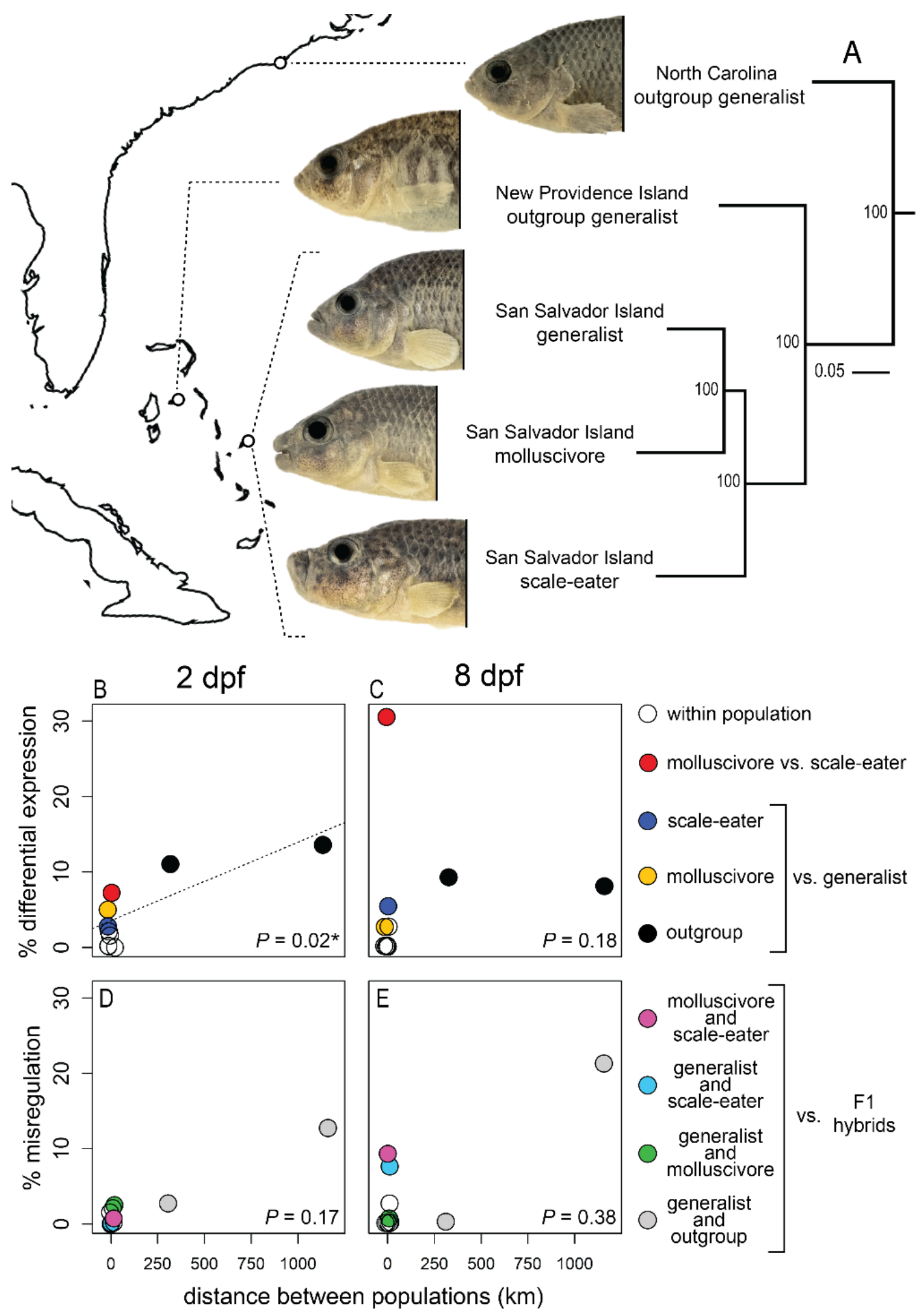
bioRxiv preprint doi: https://doi.org/10.1101/717025; this version posted July 28,2019 . The copyright holder for this preprint (which was not certified by peer review) is the author/funder, who has granted bioRxiv a license to display the preprint in perpetuity. It is made available under aCC-BY 4.0 International license.

Fig. 2.

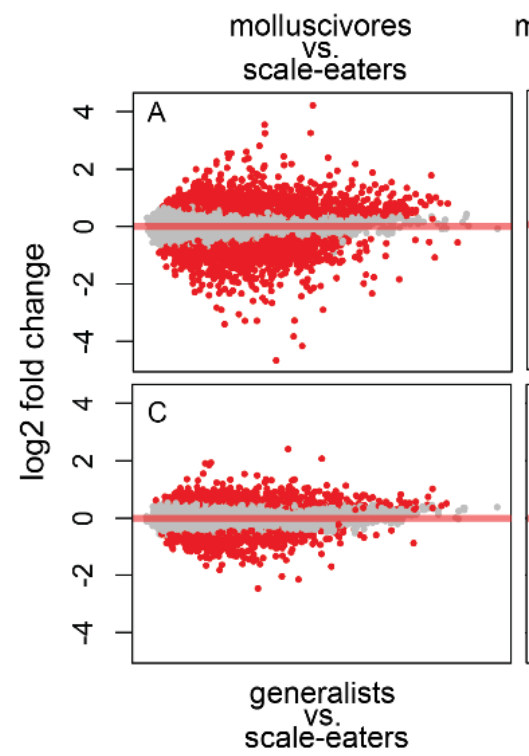

molluscivores and scale-eaters

differential hybrid F1 hybrids

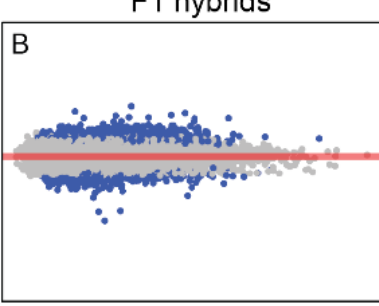

expression misregulation
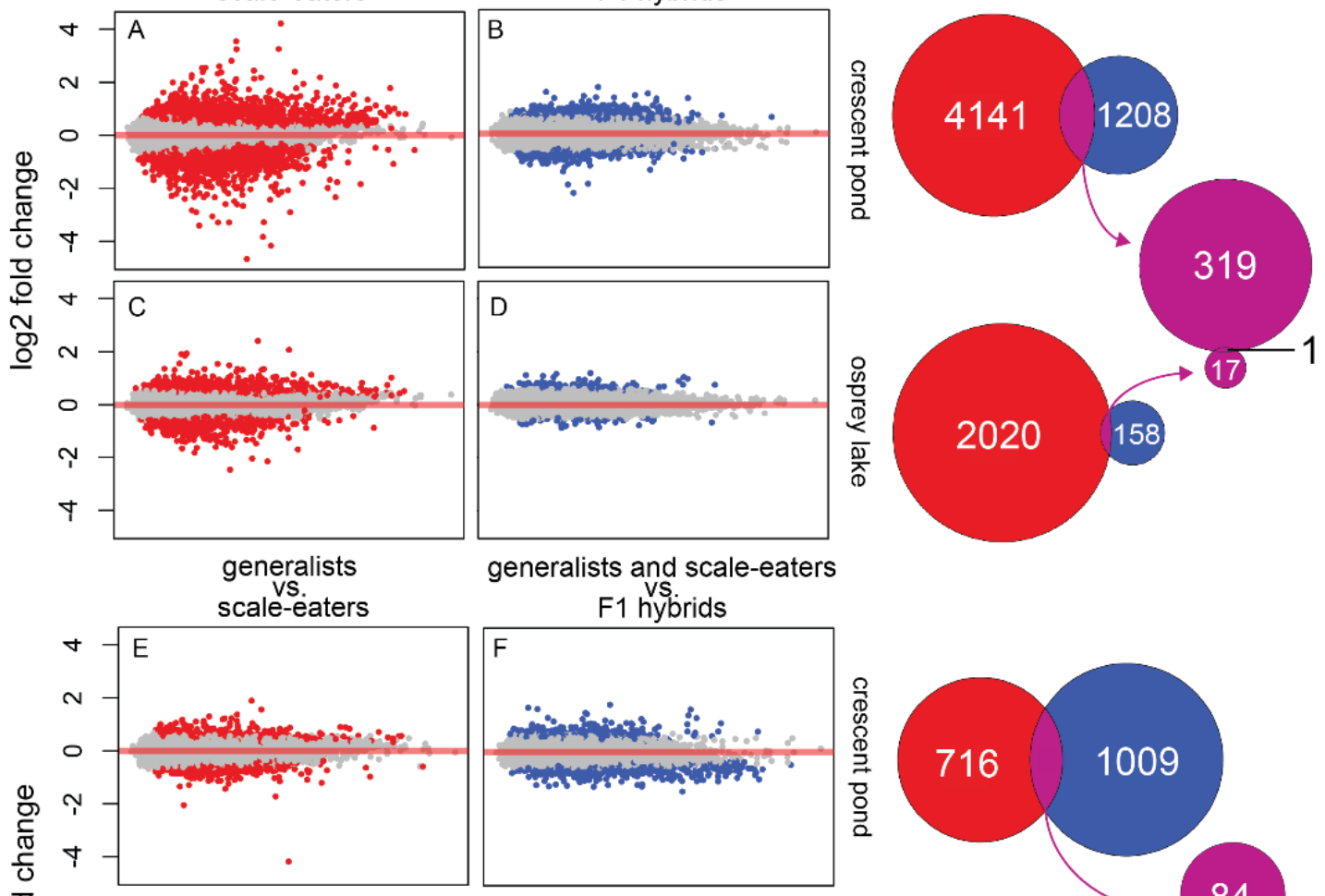

F1 hybrids
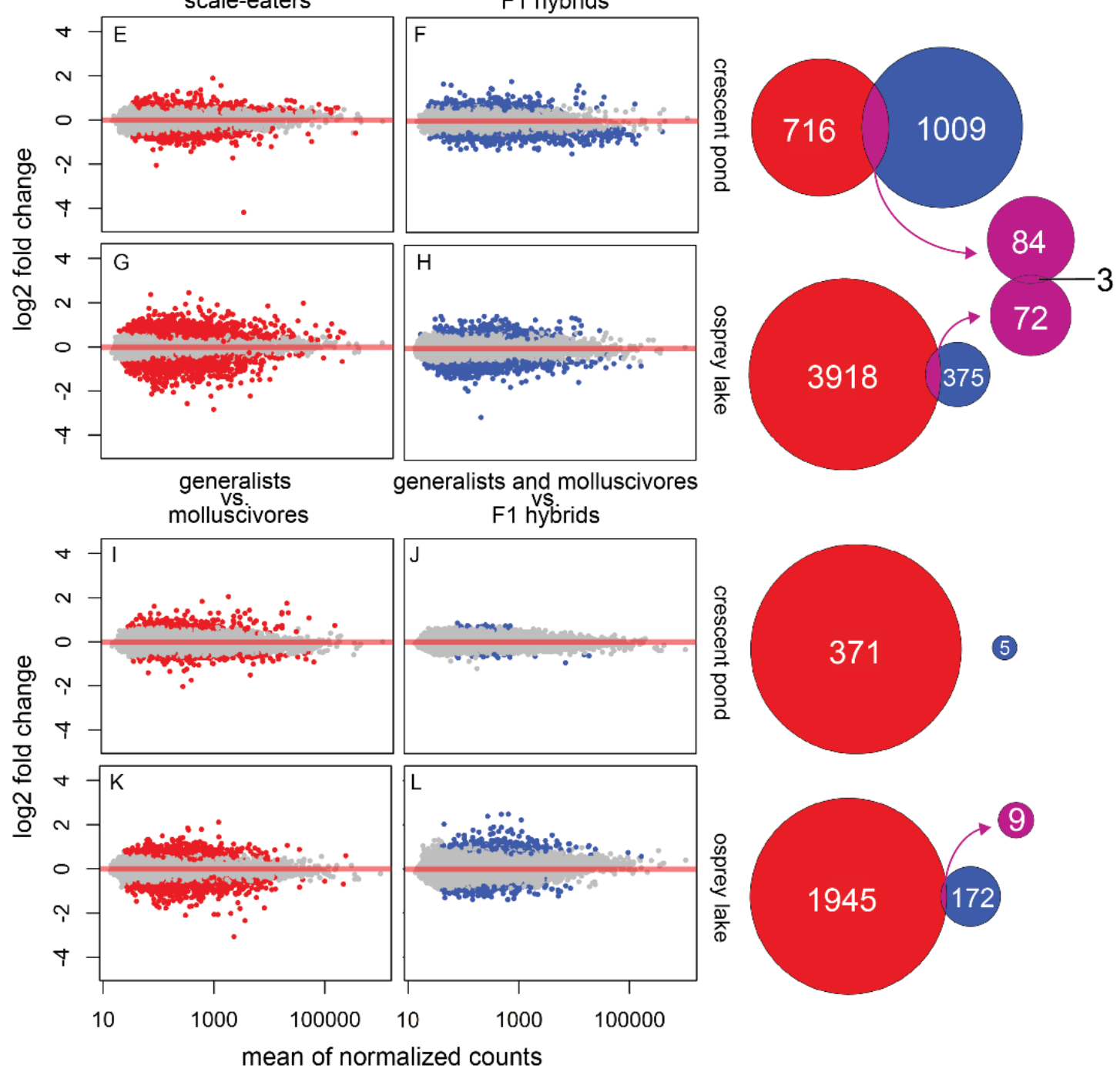
Fig. 3.
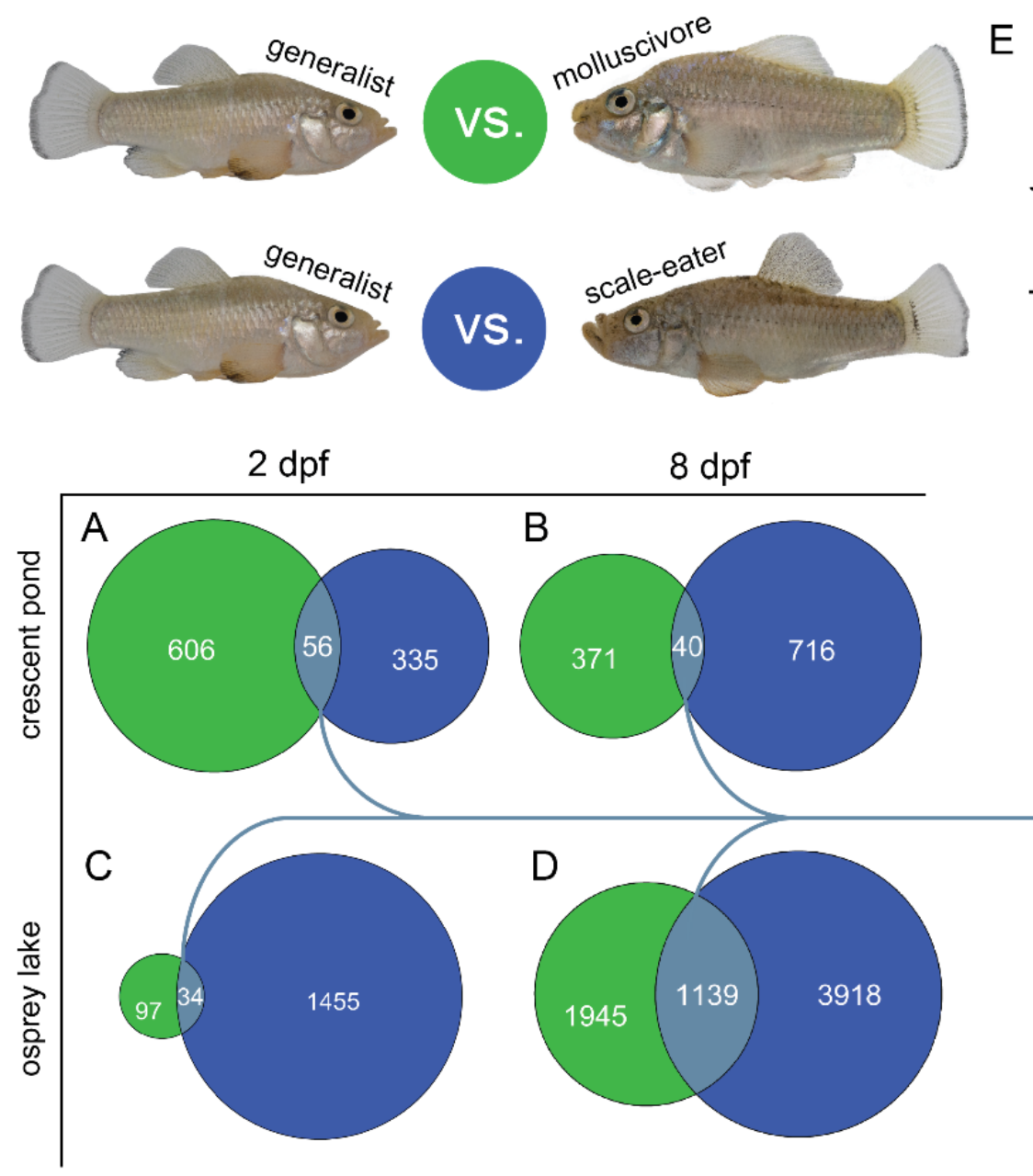

E $\square$ generalist $\square$ molluscivore $\square$ scale-eater
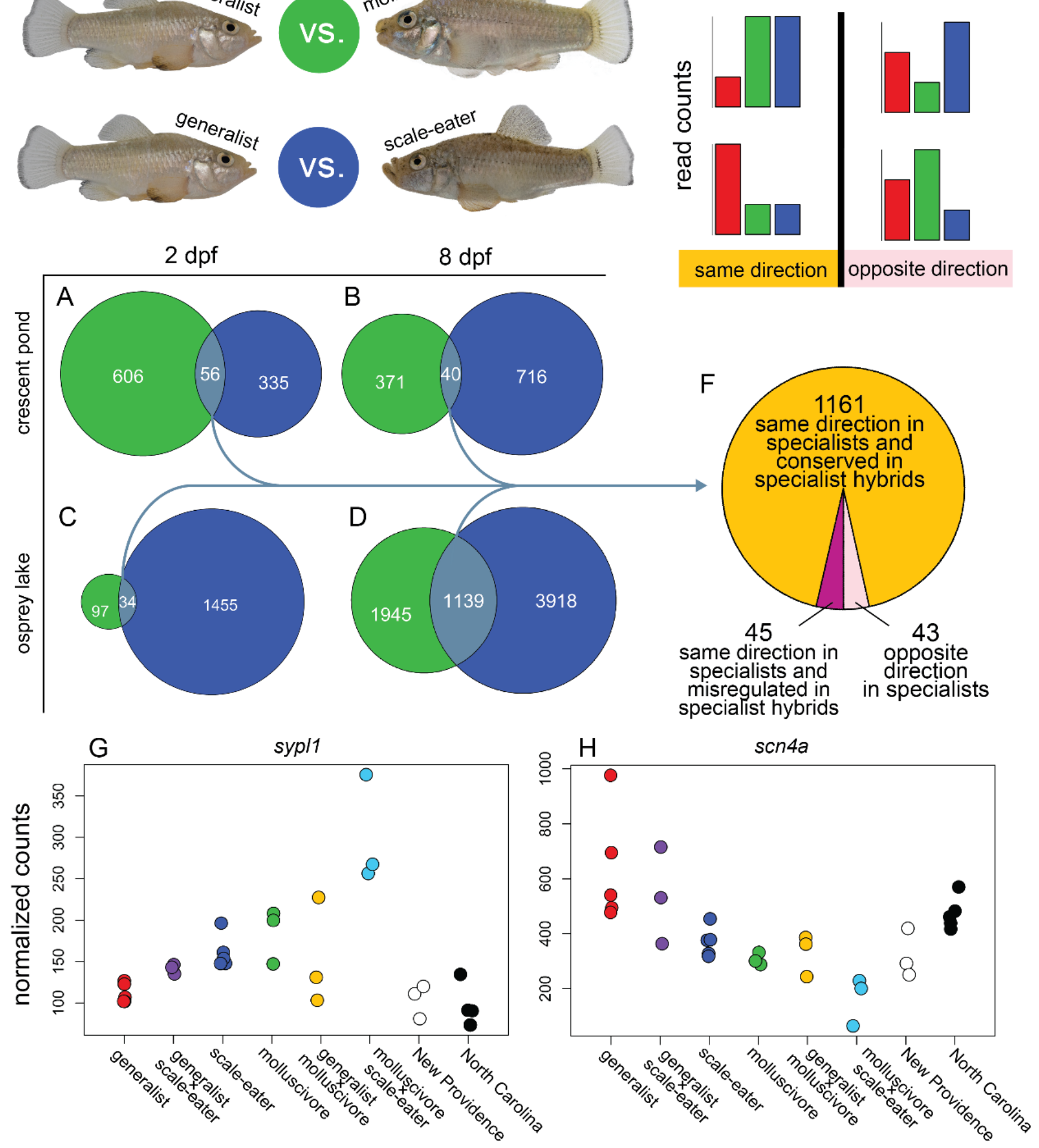
bioRxiv preprint doi: https://doi.org/10.1101/717025; this version posted July 28, 2019. The copyright holder for this preprint (which was not certified by peer review) is the author/funder, who has granted bioRxiv a license to display the preprint in perpetuity. It is made available under aCC-BY 4.0 International license.

Fig. 4.
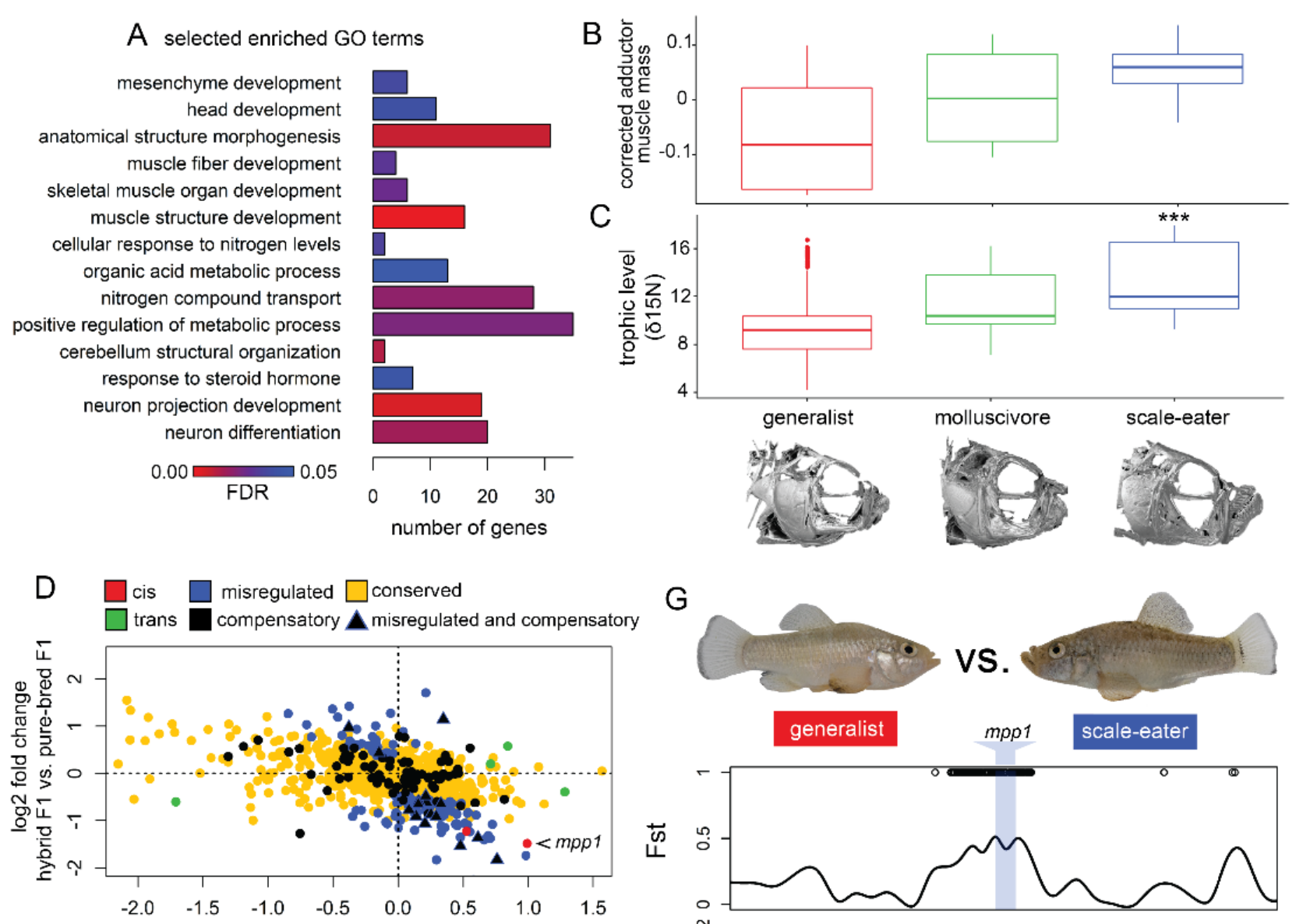

$\log 2$ fold change generalists vs. scale-eaters
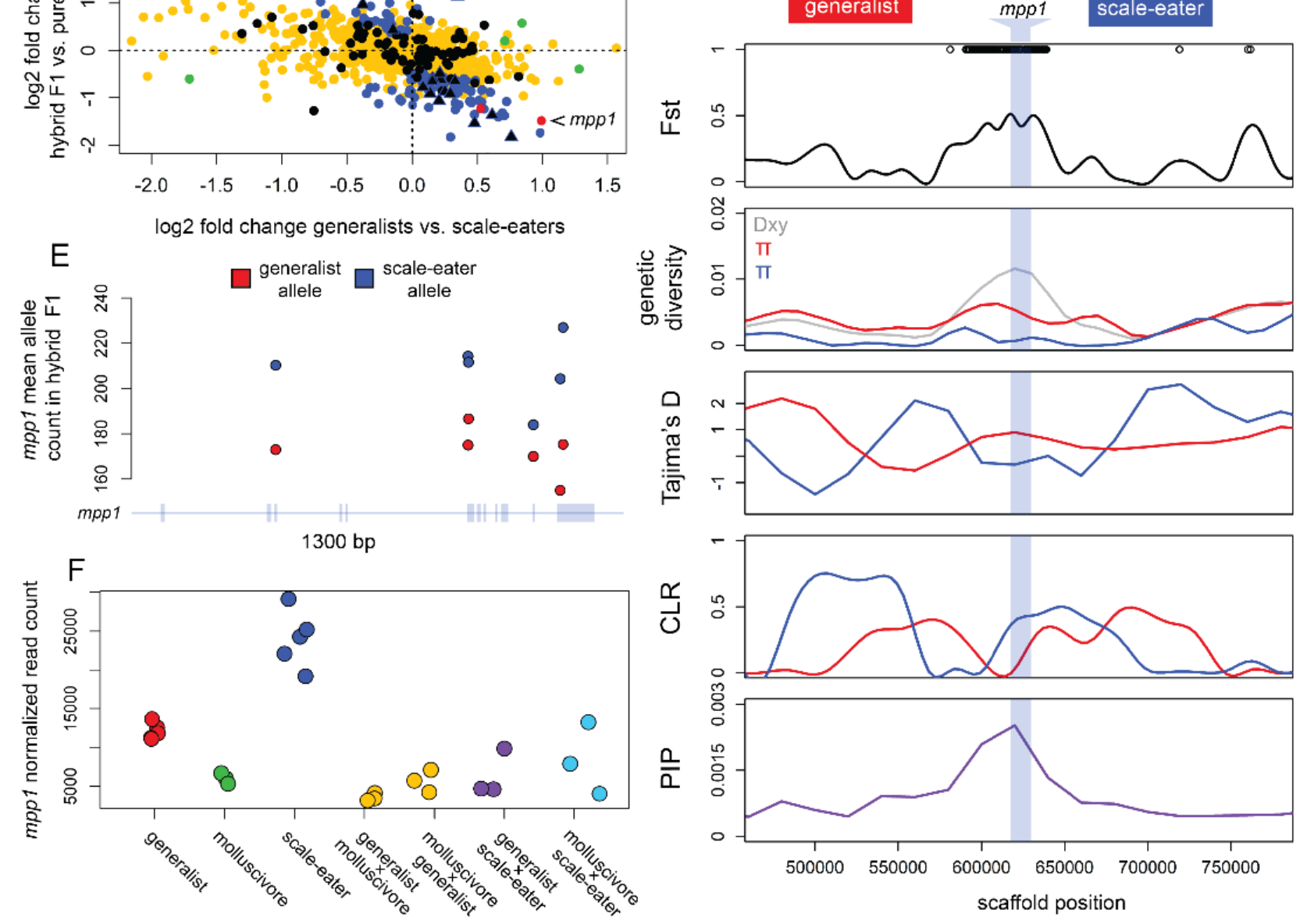


\section{Supplemental Methods}

\section{Study system and sample collection}

631 We collected 51 wild-caught individuals from nine isolated hypersaline lakes on San Salvador

632 Island, Bahamas (Great Lake, Stout's Lake, Oyster Lake, Little Lake, Crescent Pond, Moon

633 Rock, Mermaid's Pond, Osprey Lake, Pigeon Creek) between 2011 and 2018 using seine-nets

634 and hand nets. 18 scale-eaters (Cyprinodon desquamator) were sampled from six lake

635 populations; 15 molluscivores (C. brontotheroides) were sampled from four populations; and 18

636 generalists (C. variegatus) were sampled from nine populations. The genomic dataset also

637 included two C. laciniatus from Lake Cunningham, New Providence Island, Bahamas, one $C$.

638 bondi from Etang Saumautre lake in the Dominican Republic, one C. variegatus from Fort

639 Fisher, North Carolina, one C. diabolis from Devils Hole, Nevada, and captive-bred individuals

640 of C. simus and C. maya from Laguna Chicancanab, Quintana Roo, Mexico. Sampling is further

641 described in $(1,2)$. Fish were euthanized in an overdose of buffered MS-222 (Finquel, Inc.)

642 following approved protocols from the University of California, Davis Institutional Animal Care

643 and Use Committee (\#17455), the University of California, Berkeley Animal Care and Use

644 Committee (AUP-2015-01-7053), and the University of North Carolina Institutional Animal

645 Care and Use Committee (18-061.0). Samples were stored in 95-100\% ethanol.

646 Our total mRNA transcriptomic dataset consisted of 124 Cyprinodon exomes from

647 embryos collected between 2017 and 2018. We collected fishes for breeding from two

648 hypersaline lakes on San Salvador Island, Bahamas (Osprey Lake, and Crescent Pond), Lake

649 Cunningham, New Providence Island, Bahamas, and Fort Fisher, North Carolina, United States..

650 Wild-caught parents were reared in breeding tanks at $25-27^{\circ} \mathrm{C}, 10-15 \mathrm{ppt}$ salinity, $\mathrm{pH} 8.3$, and

651 fed a mix of commercial pellet foods and frozen foods. All purebred F1 offspring were collected

652 from breeding tanks containing multiple F0 breeding pairs. All F1 offspring from crosses

653 between species and populations were collected from individual F0 breeding pairs that were

654 subsequently sequenced in our genomic dataset.

655 Methods for collecting and raising embryos were similar to previously outlined methods

$656(3,4)$. All F1 embryos were collected from breeding mops within one hour of spawning and

657 transferred to petri dishes incubated at $27^{\circ} \mathrm{C}$. Embryo water was treated with Fungus Cure (API

658 Inc.) and changed every 48 hours. Embryos were inspected for viability and sampled either $47-$ 
49 hours post fertilization (hereafter 2 days post fertilization ( 2 dpf)) or 190-194 hours (eight

660 days) post fertilization (hereafter $8 \mathrm{dpf}$ ). These early developmental stages are described as stage

$66123(2 \mathrm{dpf})$ and $34(8 \mathrm{dpf})$ in a recent embryonic staging series of $C$. variegatus (5). The $2 \mathrm{dpf}$

662 stage is comparable to the Early Pharyngula Period of zebrafish, when multipotent neural crest

663 cells have begun migrating to pharyngeal arches that will form the oral jaws and most other

664 craniofacial structures (6-8). Embryos usually hatch six to ten days post fertilization, with

665 similar variation in hatch times among species $(3,7)$. While some cranial elements are ossified

666 prior to hatching, the skull is largely cartilaginous at $8 \mathrm{dpf}$ (5). Embryos from each stage were

667 euthanized in an overdose of buffered MS-222 and immediately preserved in RNA later

668 (Ambion, Inc.) for 24 hours at $4^{\circ} \mathrm{C}$ and then $-20^{\circ} \mathrm{C}$ for up to 9 months following manufacturer's

669 instructions.

671 Hybrid cross design

672 All parents used to generate F1 hybrids were collected from four locations: 1) Crescent Pond, 673 San Salvador, 2) Osprey Lake, San Salvador, 3) Lake Cunningham, New Providence Island, or

674 4) Fort Fisher, North Carolina. In order to understand how varying levels of genetic divergence

675 and ecological divergence between parents affected gene expression patterns in F1 offspring, we

676 performed 11 separate crosses falling into three categories. 1) For purebred crosses, we collected

677 F1 embryos from breeding tanks containing multiple breeding pairs from a single location. 2) For

678 San Salvador species crosses, we crossed a single individual of one species with a single

679 individual of another species from the same lake for all combinations of the three San Salvador

680 species. In order to control for maternal effects on gene expression inheritance, we collected

681 samples from reciprocal crosses for three San Salvador species crosses. 3) For outgroup

682 generalist crosses, we bred a Crescent Pond generalist male with a Lake Cunningham female and 683 a North Carolina female (Table S9).

\section{Genomic sequencing and alignment}

686 All DNA samples were extracted from muscle tissue or caudal fin clips using DNeasy Blood and 687 Tissue kits (Qiagen, Inc.) and quantified on a Qubit 3.0 fluorometer (Thermofisher Scientific, 
Inc.). Sequencing methods for 43 of the 58 individuals in our genomic dataset were previously described $(1,2)$. Briefly, libraries were prepared using Illumina TruSeq DNA PCR-Free kits at the Vincent J. Coates Genomic Sequencing Center (QB3, Berkeley, CA) and samples were pooled on four lanes of Illumina 150PE Hiseq4000. We added 15 new individuals to this dataset

692 that were crossed to generate F1 hybrids. These libraries were prepared at the same facility using

693 TruSeq kits on the automated Apollo 324 system (WaferGen BioSystems, Inc.). Samples were

694 fragmented using Covaris sonication, barcoded with Illumina indices, quality checked using a

695 Fragment Analyzer (Advanced Analytical Technologies, Inc.), and sequenced on one lane of Illumina 150PE Hiseq4000 in June 2018.

We filtered raw reads using Trim Galore (v. 4.4, Babraham Bioinformatics) to remove Illumina adaptors and low-quality reads (mean Phred score <20) and mapped 1,953,034,511 reads to the Cyprinodon reference genome (NCBI, Cyprinodon variegatus annotation release 100; total sequence length $=1,035,184,475$; number of scaffolds $=9,259$; scaffold N50 = 835,301; contig N50 = 20,803; (7)) with the Burrows-Wheeler Alignment Tool (bwa mem; (9)

702 (v. 0.7.12)). The Picard software package (v. 2.0.1) and Samtools (v. 1.9) were used to remove 703 duplicate reads (MarkDuplicates) and create indexes. We assessed mapping and read quality 704 using MultiQC (10).

\section{Transcriptomic sequencing and alignment}

707 We extracted RNA from a total of 348 individuals (whole-embryos and whole-larvae) using

708 RNeasy Mini Kits (Qiagen catalog \#74104). For samples collected at $2 \mathrm{dpf}$, we pooled 5

709 embryos together and pulverized them in a $1.5 \mathrm{ml}$ Eppendorf tube using a plastic pestle washed

710 with RNase Away (Molecular BioProducts). We used the same extraction method for samples

711 collected at $8 \mathrm{dpf}$ but did not pool larvae and prepared a library for each individual separately.

712 Total mRNA sequencing libraries for the resulting 125 samples were prepared at the Vincent J.

713 Coates Genomic Sequencing Center (QB3, Berkeley, CA) using the Illumina stranded Truseq

714 RNA kit (Illumina RS-122-2001). Sequencing was performed on Illumina Hiseq4000 150PE. 72

715 and 53 total mRNA libraries were each pooled across three lanes and sequenced in May 2018

716 and July 2018, respectively. 
We filtered raw reads using Trim Galore (v. 4.4, Babraham Bioinformatics) to remove

718 Illumina adaptors and low-quality reads (mean Phred score $<20$ ) and mapped 1,638,067,612

719 filtered reads to the Cyprinodon reference genome (NCBI, Cyprinodon variegatus annotation

720 release 100; $1.035 \mathrm{~Gb}$; scaffold N50 = 835,301; (7)) using the RNA-seq aligner STAR with

721 default parameters (v. 2.5 (11)). We assessed mapping and read quality using MultiQC (10). We

722 quantified the number of duplicate reads produced during sequence amplification and GC

723 content of transcripts for each sample using RSeQC (12). We also used RSeQC to estimate

724 transcript integrity numbers (TINs) which is a measure of potential in vitro RNA degradation

725 within a sample. TIN is calculated by directly analyzing the uniformity of read coverage across a

726 transcript and is a more reliable measure of degradation compared to RNA integrity number

727 (RIN) which uses ribosomal RNA as a proxy for overall RNA integrity $(12,13)$. We performed

728 one-way ANOVA to determine whether the GC content of reads, read depth across features, total

729 normalized counts, or TINs differed between samples grouped by species and population. We

730 did not find a difference between species or generalist populations for any quality control

731 measure (Fig. S7; ANOVA, $P>0.1$ ), except for a marginal difference in TIN (Fig. S8; ANOVA,

$732 P=0.041$ ) driven by slightly higher transcript quality in North Carolina samples (Tukey multiple

733 comparisons of means; $P=0.043$ ). We found no significant differences among San Salvador

734 Island generalists, molluscivores, scale-eaters, and outgroup generalists in the proportion of reads

735 that map to annotated features of the Cyprinodon reference genome (Fig. S9; ANOVA, $P=$

736 0.17). We did find that more reads mapped to features in 2 dpf samples than 8 dpf samples (Fig.

737 S13; Student's $t$-test, $\left.P<2.2 \times 10^{-16}\right)$.

\section{Variant discovery and population genetic analyses}

740 We followed the best practices guide recommended by the Genome Analysis Toolkit (v. 3.5

741 (14)) in order to call and refine SNP variants across 58 Cyprinodon genomes and across 124

742 Cyprinodon exomes using the Haplotype Caller function. For both datasets, we used

743 conservative hard filtering criteria to call SNPs $(14,15)$ : Phred-scaled variant confidence divided

744 by the depth of nonreference samples $>2.0$, Phred-scaled $P$-value using Fisher's exact test to

745 detect strand bias $>60$, Mann-Whitney rank-sum test for mapping qualities $(\mathrm{z}>12.5)$, Mann-

746 Whitney rank-sum test for distance from the end of a read for those with the alternate allele 
747 ( $\mathrm{z}>8.0)$. We filtered both SNP datasets to include individuals with a genotyping rate above $90 \%$ 748 and SNPs with minor allele frequencies higher than 5\%. Our final filtered genomic SNP dataset 749 included 13,838,603 variants with a mean sequencing coverage of $8.2 \times$ per individual.

We further refined our transcriptomic SNP dataset using the allele-specific software WASP (v. 0.3.3) to correct for potential mapping biases that would influence tests of 752 allele-specific expression (ASE; $(16,17)$ ). While we showed that mapping bias does not significantly affect the proportion of reads mapped to features between species (Fig. S9), even a small number of biased sites would likely account for the majority of significant ASE at an exome-wide scale. WASP identified reads that overlapped sites in our original transcriptomic SNP dataset and re-mapped those reads after swapping the genotype for the alternate allele. Reads that failed to map to exactly the same location were discarded. We re-mapped unbiased reads using methods outlined above to create our final BAM files that were used for all downstream analyses. We re-called SNPs using unbiased BAMs for a final transcriptomic SNP dataset that included 413,055 variants with a mean coverage of 1,060× across gene features per individual.

We analyzed genomic SNPs to measure within-population diversity $(\pi)$, betweenpopulation diversity $\left(D_{x y}\right)$, relative genetic diversity $\left(F_{s t}\right)$, and Tajima's D. We measured $\pi, D_{x y}$, and $F_{s t}$ in $20 \mathrm{~kb}$ windows using the python script popGenWindows.py created by Simon Martin (available on https://github.com/simonhmartin/genomics_general; (18)). 13.8 million SNP variants genotyped by whole genome resequencing of 58 Cyprinodon individuals revealed more population structure between allopatric generalists than between generalists and specialists on San Salvador (genome-wide mean $F_{s t}$ between San Salvador generalists: vs. North Carolina $=$ 0.217; vs. New Providence $=0.155$; vs. scale-eaters $=0.106$; vs. molluscivores $=0.056$ ). We found consistent relationships across a maximum likelihood phylogeny calculated with RAxML,

771 with longer branch lengths separating allopatric populations (Fig. 1, S1).

We calculated Tajima's D in $20 \mathrm{~kb}$ windows and per site $F_{s t}$ for each species and lake

773 population genomic using VCFtools (v. 1.15). We chose to analyze $20 \mathrm{~kb}$ windows given

774 previous estimates of pairwise linkage disequilibrium (measured as $r^{2}$ ) showing that linkage

775 dropped to background levels between SNPs separated by $>20 \mathrm{~kb}\left(r^{2}<0.1\right.$; (1)). Tajima's D

776 statistic compares observed nucleotide diversity to diversity under a null model assuming genetic 
drift, where negative values indicate a reduction in diversity across segregating sites that may be due to positive selection (19). We also looked for evidence of hard selective sweeps using the SweepFinder method first developed by Nielsen et al. (2005) and implemented in the software package SweeD $(20,21)$. SweeD separates scaffolds into 1000 windows of equal size and calculates a composite likelihood ratio (CLR) from a comparison of two contrasting models for each window. The first assumes a window has undergone a recent selective sweep, whereas the second assumes a null model where the site frequency spectrum of the window does not differ from that of the entire scaffold. Windows with a high CLR suggest a history of selective sweeps because the site frequency spectrum is shifted toward low-frequency and high-frequency derived variants $(20,21)$.

We used ancestral population sizes (previously determined by the Multiple Sequentially Markovian Coalescent approach $(1,22)$ to estimate the expected neutral SFS with SweeD, accounting for historical demographic effects on the contemporary shape of the SFS. SweeD identifies regions of a scaffold showing signs of a hard sweep relative to the rest of that scaffold. Thus, we normalized CLR values to be between zero and one to compare the strength of selection across scaffolds. We defined regions showing strong signs of a hard selective sweep as windows that showed CLRs above the $90^{\text {th }}$ percentile for a scaffold (normalized CLR > 0.9) and

794 a negative value of Tajima's D less than the genome-wide $10^{\text {th }}$ percentile (range $=-1.62--0.77$

795 (see table S7 for all population thresholds)). We also visually inspected regions near candidate 796 incompatibility genes to identify CLRs and Tajima's D estimates indicating moderate signs of selection.

\section{Read count abundance and differential expression analyses}

800 We used the featureCounts function of the Rsubread package (23) requiring paired-end and 801 reverse stranded options to generate read counts across 36,511 previously annotated features for 802 the Cyprinodon reference genome (7). We aggregated read counts at the transcript isoform level 803 (36,511 isoforms correspond to 24,952 protein coding genes). component analyses. DESeq2 normalizes read counts by calculating a geometric mean of counts 
806 for each gene across samples, dividing individual gene counts by this mean, and then using the

807 median of these ratios as a size factor for each sample. These sample-specific size factors

808 account for differences in library size and sequencing depth among samples. Gene features

809 showing less than 10 normalized counts in every sample were discarded from analyses. We

810 constructed a DESeqDataSet object in R using a multi-factor design that accounted for variance

811 in F1 read counts influenced by parental population origin and sequencing date (design $=$

812 sequencing_date + parental_breeding_pair_populations). Next, we used a variance stabilizing

813 transformation on normalized counts and performed a principal component analysis to visualize

814 the major axes of variation in $2 \mathrm{dpf}$ and $8 \mathrm{dpf}$ samples (Fig. S15). We removed one $8 \mathrm{dpf}$ outlier

815 so that the final count matrix used for differential expression analyses included 124 samples (2

$816 \mathrm{dpf}=68,8 \mathrm{dpf}=56)$.

DESeq2 fits negative binomial generalized linear models for each gene across samples to

818 test the null hypothesis that the fold change in gene expression between two groups is zero. The

819 program uses an empirical Bayes shrinkage method to determine gene dispersion parameters,

820 which model within-group variability in gene expression and logarithmic fold changes in gene

821 expression. Significant differential expression between groups was determined with Wald tests

822 by comparing normalized posterior log fold change estimates and correcting for multiple testing

823 using the Benjamini-Hochberg procedure with a false discovery rate of 0.05 (Benjamini and

824 Hochberg 1995). We contrasted gene expression in pairwise comparisons between populations

825 grouped by developmental stage. To determine within population levels of expression divergence

826 (Fig. 1B-E), we down-sampled each population to perform every pairwise comparison between

827 samples using the highest sample size possible between groups and calculated the mean number

828 of genes differentially expressed across comparisons.

\section{Hybrid misregulation and inheritance of gene expression patterns}

831 We generated F1 hybrid offspring from crosses between populations and generated purebred F1

832 offspring from crosses within populations. We compared expression in hybrids to expression in

833 purebred offspring to determine whether genes showed additive, dominant, or transgressive

834 patterns of inheritance in hybrids. To categorize hybrid inheritance for F1 offspring generated 
835 from a cross between a female from population $A$ and a male from population $B\left(F 1_{(A \times B)}\right)$, we

836 conducted four pairwise differential expression tests with DESeq2:

842 between parental populations and significantly different between parental populations.

843 Inheritance was dominant if hybrid expression was significantly different from one parental

844 population but not the other. Genes showing misregulation in hybrids showed transgressive

845 inheritance, meaning hybrid gene expression was significantly higher (overdominant) or lower

846 (underdominant) than both parental species (Fig. S10-12). All comparisons were conducted

847 between groups sampled at the same developmental stage ( $2 \mathrm{dpf}$ or $8 \mathrm{dpf}$ ).

\section{Parallel changes in gene expression in specialists}

850 Parallel evolution of gene expression is often associated with convergent niche specialization, 851 but parallel changes in expression may also underlie divergent specialization (4). We looked at

852 the intersection of genes differentially expressed between generalists versus molluscivores and 853 generalists versus scale-eaters to determine whether specialists showed parallel changes in 854 expression relative to generalists. We compared expression between generalists and each 855 specialist grouping samples by lake population and developmental stage.

856 We also examined the direction of expression divergence for each gene to evaluate the 857 significance of parallel expression evolution (Fig 3E). Specifically, we wanted to know whether 858 the fold change in expression for genes tended to show the same sign in both specialists relative 859 to generalists (either up-regulated in both specialists relative to generalists or down-regulated in 860 both specialists). Under a neutral model of gene expression evolution, half of the genes 861 differentially expressed between generalists versus molluscivores and generalists versus scale862 eaters would show fold changes in the same direction and half would show fold changes in 
863 opposite directions (Fig. 3E). Remarkably, 1,206 (96.6\%) of the genes showing expression

864 divergence between generalists versus molluscivores and generalists versus scale-eaters showed

865 the same direction of expression divergence in specialists. These results provide robust evidence

866 for parallel changes in expression underlying divergent trophic adaptation and support previous

867 findings based on a smaller sample size (3).

We wanted to determine whether significant parallelism at the level of gene expression in specialists was mirrored by parallel regulatory mechanisms. We predicted that genes showing parallel changes in specialists would show conserved expression levels in specialist hybrids if

871 they were controlled by the same (or compatible) regulatory mechanisms, but would be

872 misregulated in specialist hybrids if expression was controlled by different and incompatible

873 regulatory mechanisms. We identified genes showing conserved levels of expression in specialist

874 hybrids (no significant difference in expression between purebred specialist F1s and specialist

875 hybrid F1s) and genes showing misregulation in specialist hybrids. We also identified genes

876 showing extreme Caribbean-wide misregulation in specialists. These genes were differentially

877 expressed in specialist hybrids relative to all other samples in our dataset from across the

878 Caribbean (North Carolina to New Providence Island, Bahamas).

Allele specific expression and mechanisms of regulatory divergence

881 We partitioned hybrid gene expression divergence into patterns that could be attributed to cis-

882 regulatory variation in cases where linked genetic variation affected proximal gene expression

883 levels, and trans-regulatory variation in cases where genetic variation in unlinked factors bound

884 to cis-regulatory elements affected gene expression levels. It is possible to identify mechanisms

885 of gene expression divergence between parental species by bringing cis elements from both

886 parents together in the same trans environment in F1 hybrids and quantifying allele specific

887 expression (ASE) of parental alleles at heterozygous sites (25, 26). A gene showing ASE in F1

888 hybrids that is differentially expressed between parental species is expected to result from $c i s-$

889 regulatory divergence. Trans-regulatory divergence can be determined by comparing the ratio of

890 gene expression in parents with the ratio of allelic expression in F1 hybrids. Cis and trans

891 regulatory variants often interact to affect expression divergence of the same gene (26-28). 
Our genomic variant dataset included every parent used to generate F1 hybrids between populations $(n=15)$. We used the VariantsToTable function of the Genome Analysis Toolkit

894 (14) to output genotypes across 13.8 million variant sites for each parent and overlapped these

895 sites with the 413,055 variant sites identified across F1 transcriptomes (corrected for mapping

896 bias). To categorize mechanisms of regulatory divergence between two populations, we used

897 custom R and python scripts (https://github.com/joemcgirr/fishfASE) to identify SNPs that were

898 alternatively homozygous in breeding pairs and heterozygous in their F1 offspring. We counted

899 reads across heterozygous sites using ASEReadCounter (-minDepth 20 --minMappingQuality 10

900 --minBaseQuality 20 -drf DuplicateRead) and matched read counts to maternal and paternal

901 alleles. We calculated the significance of ASE per gene transcript. We identified significant ASE

902 using a beta-binomial test comparing the maternal and paternal counts at each transcript with the

903 R package MBASED (29). For each F1 hybrid sample, we performed a 1-sample analysis with

904 MBASED using default parameters run for 1,000,000 simulations to identify transcripts showing

905 significant ASE $(P<0.05)$. Finally, we quantified allele counts across all heterozygous sites for

906 each purebred F1 sample and ran the same analyses in MBASED to identify transcripts showing

907 ASE in parental populations. A transcript was considered to show ASE if it showed significant

908 ASE in all F1 hybrid samples generated from the same breeding pair and did not show

909 significant ASE in purebred F1 offspring generated from the same parental populations.

910 In order to determine regulatory mechanisms controlling expression divergence between

911 parental species, a transcript had to be included in differential expression analyses and ASE

912 analyses. We were able to classify regulatory categories for more transcripts if breeding pairs

913 were more genetically divergent because we could analyze more heterozygous sites in their

914 hybrids (mean number of informative transcripts across crosses $=1,914$; range $=812-3,543$ ).

915 For each hybrid sample and each transcript amenable to both types of analyses, we calculated $\mathrm{H}$

916 - the ratio of maternal allele counts compared to the number of paternal allele counts in F1

917 hybrids, and $\mathrm{P}$ - the ratio of normalized read counts in purebred F1 offspring from the maternal

918 population compared to read counts in purebred F1 offspring from the paternal population. We

919 performed a Fisher's exact test using $\mathrm{H}$ and $\mathrm{P}$ to determine whether there was a significant trans-

920 contribution to expression divergence, testing the null hypothesis that the ratio of read counts in

921 the parental populations was equal to the ratio of parental allele counts in hybrids $(26,28,30$,

$92231)$. 
We classified expression divergence due to cis-regulation if a transcript showed

924 significant ASE, significant differential expression between parental populations of purebred F1

925 offspring, and no significant trans- contribution. We identified expression divergence due to

926 trans-regulation if transcripts did not show ASE, were differentially expressed between parental

927 populations of purebred F1 offspring, and showed significant trans-contribution. We found

928 compensatory regulatory divergence (cis- and trans-regulatory factors had opposing effects on

929 expression) in cases where a transcript showed ASE and was not differentially expressed

930 between parental populations of purebred F1 offspring (Fig. S2-S4).

\section{Phylogenetic analyses}

933 Gene expression evolves under the combined forces of selection and drift, and is expected to

934 diverge linearly with increasing phylogenetic distance between closely related species (32). The

935 magnitude of F1 hybrid misregulation likely also depends on phylogenetic distance between

936 parental species (33). In order to determine the relationship between expression divergence,

937 hybrid misregulation, and phylogenetic distance, we constructed a maximum likelihood tree

938 using RAxML. We excluded all missing sites and sites with more than one alternate allele from

939 our genomic SNP dataset, leaving 1,737,591 variants across 58 individuals for analyses. We

940 performed ten separate searches with different random starting trees under the GTRGAMMA

941 model. Node support was estimated from 1,000 bootstrap samples. We used branch lengths from

942 the best fitting tree as a measure of phylogenetic distance between populations.

943 We tested whether isolation by distance (kilometers separating populations) was a

944 significant predictor of gene expression divergence between populations. We also tested whether

945 isolation by distance explained patterns of misregulation in hybrids generated by inter-population

946 crosses. Gene expression levels between species cannot be considered to be independent and

947 identically distributed random variables (34). We used phylogenetic generalized least-squares

948 (PGLS) models in R, using the packages ape (35) and nlme to assess whether gene expression

949 patterns were predicted by distance between populations (measured in kilometers) after

950 accounting for phylogenetic relatedness. We excluded Osprey Lake populations from these

951 analyses because outgroup generalist hybrid crosses only involved Crescent Pond generalists.

952 We used lake diameter as the distance between populations for sympatric comparisons. 


\section{Morphometrics}

955 We used digital calipers to measure upper oral jaw length and body length from external

956 landmarks on ethanol-preserved tissue specimens. Upper jaw length was measured from the

957 quadroarticular joint to the tip of the most anterior tooth on the dentigerous arm of the

958 premaxilla. Body length was measured from the midline of the posterior margin of the caudal

959 peduncle to the tip of the lower jaw. We used this measure of body length rather than standard

960 length to account for size variation because the nasal protrusion on some molluscivore samples

961 extended beyond the upper jaw. One scale-eater specimen was removed from the analysis

962 because the caudal region was missing, preventing an accurate measure of body length. All jaw

963 length measurements were log-transformed and regressed against log-transformed body length to

964 remove the effects of size variation among specimens. Size-corrected residuals were used for

965 genome-wide association mapping

Association mapping

968 We employed a Bayesian Sparse Linear Mixed Model (BSLMM) implemented in the GEMMA

969 software package ((36) v. 0.94.1) to identify genomic regions associated with variation in upper

970 oral jaw length. We previously used this program to identify candidate genes influencing jaw

971 size (1). Here, we used the same methods adding 15 individuals to our genomic dataset. Briefly,

972 the BSLMM uses Markov Chain Monte Carlo sampling to estimate the proportion of phenotypic

973 variation explained by every SNP included in the analysis (PVE), the proportion of phenotypic

974 variation explained by SNPs of large effect (PGE), which are defined as SNPs with a non-zero

975 effect on the phenotype, and the number of large-effect SNPs needed to explain PGE (nSNPs;

976 Fig. S5). GEMMA also estimates an effect size coefficient ( $\beta$ ) and a posterior inclusion

977 probability (PIP) for each SNP. We used PIP (the proportion of iterations in which a SNP is

978 estimated to have a non-zero effect on phenotypic variation $(\beta \neq 0))$ to assess the significance of

979 regions associated with jaw size variation. Because these statistics are difficult to interpret for

980 causal SNPs tightly linked to neutral SNPs, we summed $\beta$ and PIP parameters across 20-kb

981 windows to avoid dispersion of the posterior probability density across SNPs in linkage 
982 disequilibrium (LD). Pairwise LD $\left(r^{2}\right)$ drops to background levels of LD between SNPs

983 separated by more than $20 \mathrm{~kb}$ (1). GEMMA controls for background population structure by

984 estimating and incorporating a kinship relatedness matrix as a covariate in the regression model.

985 We performed 10 independent runs of the BSLMM for 57 individuals (following (37)) using a

986 step size of 100 million with a burn-in of 50 million steps. Independent runs were consistent in

987 reporting the strongest associations for the same $20 \mathrm{~kb}$ windows. Windows that showed PIP

988 values above the 99th percentile (0.00175) were considered to be strongly associated with oral

989 jaw size variation within Caribbean pupfishes. Our PIP estimates for strongly associated

990 windows suggest that jaw length may be controlled by several loci of moderate effect (see

991 bimodal PGE distribution, Fig. S5B). Indeed, a linkage mapping analysis of phenotypic diversity

992 in an $F_{2}$ intercross between specialists estimated four QTL with moderate effects on oral jaw size

993 explaining up to $15 \%$ of the variation (38). Encouragingly, the window that showed the strongest

994 association with jaw size (PIP = 0.1043; Fig. S5) contained a single gene associated with

995 craniofacial deformities in humans (samd12; (39)). Additionally, clk2, gpr119, doc2b, rapgef4,

996 were also within the top four windows showing the highest PIP values.

\section{Gene ontology enrichment analyses}

999 We performed a gene ontology (GO) enrichment analysis for the 125 genes in differentiated

1000 genomic regions showing differential expression between species and misregulation in hybrids

1001 using ShinyGo v.0.51 (40). The RefSeq genome records for the Cyprinodon reference genome

1002 were annotated by the NCBI Eukaryotic Genome Annotation Pipeline, an automated pipeline

1003 that annotates genes, transcripts and proteins. Gene symbols for orthologs identified by this

1004 pipleline largely match human gene symbols. Thus, we searched for enrichment across biological

1005 process ontologies curated for human gene functions. We also determined whether genes sets

1006 showing other interesting patterns of expression were annotated for effects on cranial skeletal

1007 system development (GO:1904888). 


\section{References}

1012

1013

1014

1015

1016

1017

1018

1019

1020

1021

1022

1023

1024

1025

1026

1027

1028

1029

1030

1031

1032

1033

1034

1035

1036

1037

1038

1039

1040

1041

1042

1043

1044

1045

1046

1047

1048

1049

1050

1051

1052

1. McGirr JA, Martin CH (2017) Novel candidate genes underlying extreme trophic specialization in Caribbean pupfishes. Mol Biol Evol 34(4):873-888.

2. Richards EJ, Martin CH (2017) Adaptive introgression from distant Caribbean islands contributed to the diversification of a microendemic adaptive radiation of trophic specialist pupfishes. PLoS Genetics 13(8):e1006919.

3. McGirr JA, Martin CH (2018) Parallel evolution of gene expression between trophic specialists despite divergent genotypes and morphologies. Evol Lett 2(2):62-75.

4. McGirr JA, Martin CH (2019) Hybrid gene misregulation in multiple developing tissues within a recent adaptive radiation of Cyprinodon pupfishes. PLoS One 14(7):e0218899.

5. Lencer ES, McCune AR (2018) An embryonic staging series up to hatching for Cyprinodon variegatus: An emerging fish model for developmental, evolutionary, and ecological research. J Morphol 279(11):1559-1578.

6. Schilling TF, Kimmel CB (1994) Segment and cell type lineage restrictions during pharyngeal arch development in the zebrafish embryo. Development 120(3):483-94.

7. Lencer ES, Warren WC, Harrison R, McCune AR (2017) The Cyprinodon variegatus genome reveals gene expression changes underlying differences in skull morphology among closely related species. BMC Genomics 18(1):424.

8. Furutani-Seiki M, Wittbrodt J (2004) Medaka and zebrafish, an evolutionary twin study. Mech Dev 121(7-8):629-637.

9. Li H, Durbin R (2009) Fast and accurate short read alignment with Burrows-Wheeler transform. Bioinformatics 25(14):1754-60.

10. Ewels P, Lundin S, Max K (2016) Data and text mining MultiQC: summarize analysis results for multiple tools and samples in a single report. Bioinformatics 32:3047-3048.

11. Dobin A, et al. (2013) STAR: ultrafast universal RNA-seq aligner. Bioinformatics 29(1):15-21.

12. Wang L, Wang S, Li W (2012) RSeQC: quality control of RNA-seq experiments. Bioinformatics 28(16):2184-5.

13. Wang L, et al. (2016) Measure transcript integrity using RNA-seq data. $B M C$ Bioinformatics 17(1):1-16.

14. DePristo MA, et al. (2011) A framework for variation discovery and genotyping using next-generation DNA sequencing data. Nat Genet 43(5):491-8.

15. Marsden CD, et al. (2014) Diversity, differentiation, and linkage disequilibrium: prospects for association mapping in the malaria vector Anopheles arabiensis. G3 4(1):121-31.

16. Van De Geijn B, Mcvicker G, Gilad Y, Pritchard JK (2015) WASP: Allele-specific software for robust molecular quantitative trait locus discovery. Nat Methods 12(11):1061-1063.

17. Degner JF, et al. (2009) Effect of read-mapping biases on detecting allele-specific expression from RNA-sequencing data. Bioinformatics 25(24):3207-3212.

18. Martin SH, et al. (2013) Genome-wide evidence for speciation with gene flow in Heliconius butterflies. Genome Res 23(11):1817-1828. 
1053

1054

1055

1056

1057

1058

1059

1060

1061

1062

1063

1064

1065

1066

1067

1068

1069

1070

1071

1072

1073

1074

1075

1076

1077

1078

1079

1080

1081

1082

1083

1084

1085

1086

1087

1088

1089

1090

1091

1092

1093

19. Tajima F (1989) Statistical method for testing the neutral mutation hypothesis by DNA polymorphism. Genetics 123(3):585-95.

20. Nielsen R, et al. (2005) Genomic scans for selective sweeps using SNP data. Genome Res. 15(11):1566-75.

21. Pavlidis P, Živković D, Stamatakis A, Alachiotis N (2013) SweeD: Likelihood-based detection of selective sweeps in thousands of genomes. Mol Biol Evol 30(9):2224-2234.

22. Schiffels S, Durbin R (2014) Inferring human population size and separation history from multiple genome sequences. Nat Genet 46(8):919-925.

23. Liao Y, Smyth GK, Shi W (2014) Sequence analysis featureCounts: an efficient general purpose program for assigning sequence reads to genomic features. Bioinformatics 30(7):923-930.

24. Love MI, Huber W, Anders S (2014) Moderated estimation of fold change and dispersion for RNA-seq data with DESeq2. Genome Biol 15(12):550.

25. Cowles CR, Hirschhorn JN, Altshuler D, Lander ES (2002) Detection of regulatory variation in mouse genes. Nat Genet 32(3):432-437.

26. Wittkopp PJ, Haerum BK, Clark AG (2004) Evolutionary changes in cis and trans gene regulation. Nature 430(6995):85-8

27. Landry CR, et al. (2005) Compensatory cis-trans evolution and the dysregulation of gene expression in interspecific hybrids of drosophila. Genetics 171(4):1813-1822.

28. McManus CJ, et al. (2010) Regulatory divergence in Drosophila revealed by mRNA-seq. Genome Res 20(6):816-825.

29. Mayba O, et al. (2014) MBASED: Allele-specific expression detection in cancer tissues and cell lines. Genome Biol 15(8):1-21.

30. Goncalves A, et al. (2012) Extensive compensatory cis-trans regulation in the evolution of mouse gene expression. Genome Res 22(12):2376-2384.

31. Mack KL, Campbell P, Nachman MW (2016) Gene regulation and speciation in house mice. Genome Res 26(4):451-61.

32. Whitehead A, Crawford DL (2006) Variation within and among species in gene expression: Raw material for evolution. Mol Ecol 15(5):1197-1211.

33. Coolon JD, et al. (2014) Tempo and mode of regulatory evolution in Drosophila. Genome Res 24(5):797-808.

34. Felsenstein J (1985) Phylogenies and the Comparative Method. Am Nat 125(1):1-15.

35. Paradis E, Schliep K (2019) Ape 5.0: an environment for modern phylogenetics and evolutionary analyses in R. Bioinformatics 35(3):526-528.

36. Zhou X, Carbonetto P, Stephens M (2013) Polygenic modeling with bayesian sparse linear mixed models. PLoS Genet 9(2):e1003264.

37. Comeault A et al. (2014) Genome-wide association mapping of phenotypic traits subject to a range of intensities of natural selection in Timema cristinae. Am Nat 183(5):711-27.

38. Martin CH, Erickson PA, Miller CT (2017) The genetic architecture of novel trophic specialists: larger effect sizes are associated with exceptional oral jaw diversification in a pupfish adaptive radiation. Mol Ecol 26(2):624-638. 
1094

1095

1096

1097

1098

1099

1100

39. Oliver GR, et al. (2019) RNA-Seq detects a SAMD12-EXT1 fusion transcript and leads to the discovery of an EXT1 deletion in a child with multiple osteochondromas. $\mathrm{Mol}$ Genet Genomic Med 7(3):1-13.

40. Ge SX, Jung D (2018) ShinyGO: a graphical enrichment tool for animals and plants. biorXiv doi.org/10.1101/315150 (4 May 2018). 
1101 Table S1. San Salvador Island population genomic statistics measured across 13.8 million SNPs.

1102 Statistics for the top three rows were calculated for all San Salvador individuals of each species

1103 (see Fig. S1). The remaining rows are comparisons separated by lake populations used to

1104 generate samples for RNAseq (CP = Crescent Pond, OL = Osprey Lake).

1105

\begin{tabular}{llllllll} 
population 1 & $\mathbf{n}$ & population 2 & $\mathbf{n}$ & mean $\boldsymbol{D}_{\boldsymbol{x} \boldsymbol{y}}$ & $\boldsymbol{D}_{\boldsymbol{x y}}$ 90th percentile & mean $\boldsymbol{F}_{\boldsymbol{s t}}$ & \# fixed SNPs \\
\hline all generalists & 8 & all molluscivores & 10 & 0.0047 & 0.0076 & 0.0564 & 179 \\
all generalists & 8 & all scale-eaters & 9 & 0.0047 & 0.0080 & 0.1065 & 5,331 \\
all molluscivores & 10 & all scale-eaters & 9 & 0.0049 & 0.0085 & 0.1357 & 36,335 \\
CP generalists & 5 & CP molluscivores & 5 & 0.0042 & 0.0075 & 0.0740 & 11,015 \\
CP generalists & 5 & CP scale-eaters & 5 & 0.0046 & 0.0082 & 0.1356 & 109,072 \\
CP molluscivores & 5 & CP scale-eaters & 5 & 0.0048 & 0.0093 & 0.1839 & 559,728 \\
OL generalists & 3 & OL molluscivores & 5 & 0.0049 & 0.0084 & 0.0964 & 47,356 \\
OL generalists & 3 & OL scale-eaters & 4 & 0.0049 & 0.0084 & 0.1130 & 108,813 \\
OL molluscivores & 5 & OL scale-eaters & 4 & 0.0049 & 0.0087 & 0.1347 & 168,192 \\
CP generalists & 5 & OL generalists & 3 & 0.0049 & 0.0082 & 0.0759 & 19,582 \\
CP molluscivores & 5 & OL molluscivores & 5 & 0.0045 & 0.0082 & 0.1169 & 92,317 \\
CP scale-eaters & 5 & OL scale-eaters & 4 & 0.0035 & 0.0073 & 0.0983 & 86,367 \\
\hline
\end{tabular}


1121 Table S2. Percentage of genes controlled by different regulatory mechanisms for each hybrid

1122 cross. Informative genes are those containing heterozygous sites in hybrids that were

1123 alternatively homozygous in parents. The final column is the percentage of misregulated genes

1124 showing no difference in expression between parental populations and allele-specific expression

1125 in F1 hybrids, consistent with compensatory regulatory divergence. $\mathrm{NC}=$ North Carolina, NP =

1126 New Providence, $\mathrm{CP}=$ Crescent Pond, $\mathrm{OL}=$ Osprey Lake.

1127

\begin{tabular}{llllllllll}
\hline mother & father & stage & $\begin{array}{l}\text { informative } \\
\text { genes }\end{array}$ & conserved & cis & trans & compensatory & $\begin{array}{l}\text { misregulated } \\
\text { showing } \\
\text { compensatory }\end{array}$ \\
\hline NC generalist & CP generalist & 2dpf & 2182 & 61.18 & 2.66 & 0.37 & 19.98 & 15.81 & 32.75 \\
NP generalist & CP generalist & 2dpf & 2359 & 79.57 & 0.34 & 0.42 & 16.45 & 3.22 & 11.84 \\
CP generalist & CP molluscivore & 2dpf & 2703 & 60.82 & 0.18 & 0.26 & 33.70 & 5.03 & 37.50 \\
CP generalist & CP scale-eater & 2dpf & 1764 & 83.50 & 0.17 & 0.17 & 15.87 & 0.28 & 40.00 \\
CP molluscivore & CP scale-eater & 2dpf & 1645 & 69.79 & 1.64 & 0.55 & 26.38 & 1.64 & 33.33 \\
CP molluscivore & CP generalist & 2dpf & 2193 & 62.79 & 0.14 & 0.05 & 36.07 & 0.96 & 57.14 \\
OL generalist & OL molluscivore & 2dpf & 3114 & 46.66 & 0.03 & 0.06 & 34.20 & 19.04 & 38.95 \\
OL generalist & OL scale-eater & 2dpf & 1934 & 62.77 & 0.05 & 0.52 & 22.75 & 13.91 & 18.96 \\
OL scale-eater & OL molluscivore & 2dpf & 3485 & 74.09 & 1.03 & 0.69 & 23.39 & 0.80 & 21.43 \\
OL molluscivore & OL generalist & 2dpf & 2915 & 59.79 & 0.03 & 0.03 & 37.29 & 2.85 & 38.55 \\
OL scale-eater & OL generalist & 2dpf & 2377 & 57.72 & 0.21 & 0.59 & 29.66 & 11.82 & 31.32 \\
\hline NC generalist & CP generalist & 8dpf & 2995 & 60.13 & 1.40 & 0.07 & 8.41 & 29.98 & 13.47 \\
NP generalist & CP generalist & 8dpf & 1406 & 93.24 & 0.21 & 0.71 & 5.41 & 0.43 & 50.00 \\
CP generalist & CP molluscivore & 8dpf & 819 & 87.06 & 0.12 & 0.12 & 9.77 & 2.93 & 20.83 \\
CP generalist & CP scale-eater & 8dpf & 1147 & 81.17 & 0.26 & 0.44 & 6.63 & 11.51 & 13.64 \\
CP molluscivore & CP scale-eater & 8dpf & 1027 & 78.87 & 1.85 & 2.04 & 4.48 & 12.76 & 8.40 \\
CP molluscivore & CP generalist & 8dpf & 1327 & 88.55 & 0.08 & 0.15 & 10.55 & 0.68 & 33.33 \\
OL generalist & OL molluscivore & 8dpf & 1322 & 75.26 & 0.45 & 0.61 & 7.19 & 16.49 & 9.63 \\
OL generalist & OL scale-eater & 8dpf & 1273 & 85.62 & 0.24 & 1.57 & 3.38 & 9.19 & 13.68 \\
OL scale-eater & OL molluscivore & 8dpf & 984 & 90.24 & 0.81 & 0.61 & 6.20 & 2.13 & 14.29 \\
OL scale-eater & OL generalist & 8dpf & 1087 & 73.60 & 0.18 & 1.10 & 2.21 & 22.91 & 5.62 \\
\hline
\end{tabular}

1128

1129

1130

1131

1132

1133

1134

1135 
1137 Table S3. Number of genes showing differential expression (DE) between species and

1138 misregulation in F1 hybrids. Lines separate cross type (top: specialists, middle: generalist and

1139 scale-eater, bottom: generalist and molluscivore).

1140

\begin{tabular}{lllllll}
\hline maternal population & paternal population & $\begin{array}{l}\text { informative } \\
\text { genes }\end{array}$ & $\begin{array}{l}\text { DE between } \\
\text { species }\end{array}$ & $\begin{array}{l}\text { misregulated } \\
\text { in F1 }\end{array}$ & DE and misregulated & stage \\
\hline CP molluscivore & CP scale-eater & 11718 & 862 & 88 & 10 & $2 \mathrm{dpf}$ \\
OL scale-eater & OL molluscivore & 11820 & 1900 & 150 & 32 & $2 \mathrm{dpf}$ \\
CP molluscivore & CP scale-eater & 13013 & 4141 & 1208 & 320 & $8 \mathrm{dpf}$ \\
OL scale-eater & OL molluscivore & 13225 & 2020 & 158 & 18 & $8 \mathrm{dpf}$ \\
\hline CP generalist & CP scale-eater & 11671 & 335 & 7 & 0 & $2 \mathrm{dpf}$ \\
OL generalist & OL scale-eater & 11650 & 1455 & 1453 & 362 & $2 \mathrm{dpf}$ \\
CP generalist & CP scale-eater & 13300 & 716 & 1009 & 87 & $8 \mathrm{dpf}$ \\
OL generalist & OL scale-eater & 13254 & 3918 & 1088 & 244 & $8 \mathrm{dpf}$ \\
OL scale-eater & OL generalist & 11650 & 1455 & 1283 & 38 & $2 \mathrm{dpf}$ \\
OL scale-eater & OL generalist & 13254 & 3918 & 2016 & 72 & $8 \mathrm{dpf}$ \\
\hline CP generalist & CP molluscivore & 12202 & 606 & 536 & 37 & $2 \mathrm{dpf}$ \\
OL generalist & OL molluscivore & 12207 & 97 & 2142 & 4 & $2 \mathrm{dpf}$ \\
CP generalist & CP molluscivore & 13594 & 371 & 168 & 13 & $8 \mathrm{dpf}$ \\
OL generalist & OL molluscivore & 13697 & 1945 & 1780 & 194 & $8 \mathrm{dpf}$ \\
CP molluscivore & CP generalist & 11814 & 606 & 69 & 4 & $2 \mathrm{dpf}$ \\
OL molluscivore & OL generalist & 12099 & 97 & 256 & 0 & $2 \mathrm{dpf}$ \\
CP molluscivore & CP generalist & 13768 & 371 & 31 & 0 & $8 \mathrm{dpf}$ \\
OL molluscivore & OL generalist & 13694 & 1945 & 443 & 25 & $8 \mathrm{dpf}$ \\
\hline
\end{tabular}


1151 Table S4. Genes differentially expressed between species and misregulated in hybrids that were

1152 common to both 8dpf Crescent Pond (CP) and Osprey Lake (OL) comparisons.

1153

\begin{tabular}{lllllll}
\hline cross & transcript & gene & $\begin{array}{l}\text { log2 fold } \\
\text { change } \\
\text { CP } \\
\text { mother vs } \\
\text { CP father }\end{array}$ & $\begin{array}{l}\text { log2 fold } \\
\text { change OL } \\
\text { mother vs } \\
\text { OL father }\end{array}$ & $\begin{array}{l}\text { log2 fold } \begin{array}{l}\text { log2 fold } \\
\text { change CP } \\
\text { parents vs. CP } \\
\text { hybrids }\end{array} \\
\text { change OL } \\
\text { parents vs. OL } \\
\text { hybrids }\end{array}$ \\
\hline $\begin{array}{l}\text { generalist } \times \text { scale-eater } \\
\text { generalist } \times \text { scale-eater }\end{array}$ & XM_015396529.1 & trim47 & -1.332 & 0.547 & -1.332 & -1.278 \\
$\begin{array}{l}\text { generalist } \times \text { scale-eater } \\
\text { scale-eater } \times\end{array}$ & XM_015405031.1 & krt13 & -1.184 & -1.181 & -1.183 & -1.229 \\
molluscivore & XM_015396195.1 & elovl7 & 0.784 & -0.641 & -0.978 & -0.905 \\
\hline
\end{tabular}


1173 Table S5. 360 significantly enriched gene ontology terms for 125 genes showing differential 1174 expression between species and misregulation in F1 hybrids found within highly differentiated 1175 regions of the genome.

\begin{tabular}{|c|c|c|}
\hline GO term & $\begin{array}{l}\text { Enrichment } \\
\text { FDR }\end{array}$ & $\begin{array}{l}\text { Genes } \\
\text { in list }\end{array}$ \\
\hline Muscle structure development & 0.000347 & 16 \\
\hline Muscle organ development & 0.000673 & 12 \\
\hline Neuron projection development & 0.000673 & 19 \\
\hline Cellular component biogenesis & 0.000673 & 39 \\
\hline Neuron development & 0.002059 & 19 \\
\hline Response to stress & 0.002071 & 43 \\
\hline Response to abiotic stimulus & 0.002071 & 19 \\
\hline Anatomical structure morphogenesis & 0.002071 & 31 \\
\hline Animal organ development & 0.002071 & 38 \\
\hline System development & 0.002071 & 47 \\
\hline Cellular response to organic cyclic compound & 0.002071 & 13 \\
\hline Tissue development & 0.002589 & 26 \\
\hline Hindbrain structural organization & 0.002632 & 2 \\
\hline Cerebellum structural organization & 0.002632 & 2 \\
\hline Cellular response to stress & 0.002632 & 26 \\
\hline Negative regulation of neuron differentiation & 0.002632 & 8 \\
\hline Response to external stimulus & 0.002697 & 29 \\
\hline Striated muscle tissue development & 0.002697 & 10 \\
\hline Neuron differentiation & 0.002697 & 20 \\
\hline Cellular response to nutrient levels & 0.002697 & 8 \\
\hline Organic substance transport & 0.002996 & 32 \\
\hline Generation of neurons & 0.003242 & 21 \\
\hline Muscle tissue development & 0.003242 & 10 \\
\hline Cell development & 0.003307 & 26 \\
\hline Regulation of neuron projection development & 0.00339 & 11 \\
\hline Cardiac muscle contraction & 0.003875 & 6 \\
\hline Negative regulation of cell development & 0.003926 & 9 \\
\hline Cellular response to external stimulus & 0.003926 & 9 \\
\hline Cellular response to extracellular stimulus & 0.004413 & 8 \\
\hline Cellular component assembly & 0.005139 & 33 \\
\hline Nitrogen compound transport & 0.005139 & 28 \\
\hline Neurogenesis & 0.005335 & 21 \\
\hline Regulation of anatomical structure morphogenesis & 0.005335 & 16 \\
\hline Cell differentiation & 0.005335 & 40 \\
\hline Protein-containing complex subunit organization & 0.005335 & 27 \\
\hline Anatomical structure arrangement & 0.005335 & 3 \\
\hline Regulation of multicellular organismal development & 0.005335 & 24 \\
\hline Negative regulation of neuron projection development & 0.005397 & 6 \\
\hline Response to organic cyclic compound & 0.005695 & 15 \\
\hline Negative regulation of neurogenesis & 0.005782 & 8 \\
\hline Regulation of neuron differentiation & 0.005898 & 12 \\
\hline Lateral motor column neuron migration & 0.005898 & 2 \\
\hline Response to oxygen-containing compound & 0.005898 & 21 \\
\hline Regulation of plasma membrane bounded cell projection organization & 0.006627 & 12 \\
\hline Regulation of cell projection organization & 0.007269 & 12 \\
\hline Striated muscle cell development & 0.007269 & 6 \\
\hline Ribosome biogenesis & 0.007398 & 8 \\
\hline
\end{tabular}


Negative regulation of nervous system development

0.007398

Striated muscle contraction

0.00753

Fructose catabolic process

0.007713

Positive regulation of metabolic process

0.007713

0.007713

0.007713

Cellular protein-containing complex assembly

0.007713

Fructose catabolic process to hydroxyacetone phosphate and glyceraldehyde-3-

0.007713

Spinal cord motor neuron migration

0.007955

Regulation of cellular response to heat

0.008043

Ribonucleoprotein complex biogenesis

0.008242

Regulation of nervous system development

0.00842

Negative regulation of cell projection organization

0.008537

Cellular developmental process

0.008827

0.009003

0.009559

Plasma membrane bounded cell projection organization

0.009846

Regulation of cell development

Skeletal muscle organ development

Cellular response to heat

Chaperone-mediated protein folding

RRNA metabolic process

0.009846

0.010074

0.010116

Negative regulation of intracellular signal transduction

0.010443

0.010511

0.010661

Regulation of developmental process

Protein-containing complex assembly

Cell projection organization

0.010772

0.011215

Muscle cell differentiation

0.011641

Motor neuron migration

Movement of cell or subcellular component

0.011641

Muscle fiber development

Response to nitrogen compound

Response to organic substance

Nervous system development

Neuron projection morphogenesis

Cellular response to nitrogen compound

0.011646

0.012324

0.012511

0.012613

0.013067

0.013067

0.013067

0.013121

Striated muscle cell differentiation

Response to organonitrogen compound

0.013435

Actin filament-based movement

0.013435

Anterior/posterior axon guidance

0.013435

Cardiac muscle cell development

0.013962

0.014449

Plasma membrane bounded cell projection morphogenesis

0.014635

Cell projection morphogenesis

Response to mechanical stimulus

Regulation of biological quality

Monosaccharide metabolic process

0.014808

0.014808

0.015408

0.015572

G1 to G0 transition

0.01575

0.016095

0.016709

Cellular response to organonitrogen compound

0.016796

Cell part morphogenesis

Positive regulation of developmental process

0.017118

0.01717

Muscle filament sliding

0.01717

Regulation of microtubule polymerization or depolymerization

0.017257

Desmosome organization

0.01743

6 
RRNA processing

Response to wounding

Regulation of neuron maturation

Aggrephagy

Cellular response to chemical stimulus

Regulation of keratinocyte differentiation

Circulatory system development

Cellular response to starvation

Endonucleolytic cleavage involved in rRNA processing

Endonucleolytic cleavage of tricistronic rRNA transcript (SSU-rRNA, 5.8S rRNA, LSU-rRNA)

Protein folding

Post-embryonic development

Cerebellum morphogenesis

Monocarboxylic acid metabolic process

Regulation of cell differentiation

Axon development

Regulation of response to stress

Regulation of protein modification by small protein conjugation or removal

Intracellular receptor signaling pathway

Cellular response to epidermal growth factor stimulus

Heart contraction

Dendrite development

Microtubule depolymerization

Cellular response to nitrogen starvation

Cellular response to nitrogen levels

Negative regulation of cell morphogenesis involved in differentiation

Organic acid biosynthetic process

Carboxylic acid biosynthetic process

Regulation of response to stimulus

Regulation of developmental growth

Regulation of multicellular organismal process

Cellular response to abiotic stimulus

Cellular response to environmental stimulus

Response to cAMP

Heart process

Purine nucleoside diphosphate metabolic process

Purine ribonucleoside diphosphate metabolic process

Response to heat

Hexose metabolic process

Hindbrain morphogenesis

Positive regulation of organ growth

Response to epidermal growth factor

Ribonucleoside diphosphate metabolic process

Regulation of response to external stimulus

Negative regulation of cell differentiation

RNA processing

Response to peptide hormone

Skeletal muscle tissue development

Embryo implantation

Positive regulation of developmental growth

Muscle contraction

Heart development

Response to acid chemical

Positive regulation of cellular metabolic process

Fructose metabolic process
$0.01743 \quad 6$

$0.01743 \quad 11$

$0.01743 \quad 2$

$0.01743 \quad 2$

$0.018149 \quad 31$

$0.018299 \quad 3$

$0.018299 \quad 14$

$0.018748 \quad 5$

$0.019353 \quad 2$

$0.019353 \quad 2$

$0.019353 \quad 6$

$0.019353 \quad 4$

$0.019353 \quad 3$

$0.019353 \quad 10$

$0.019353 \quad 20$

$0.019353 \quad 9$

$0.019353 \quad 18$

$0.019353 \quad 6$

$0.01975 \quad 7$

$0.020014 \quad 3$

$0.020237 \quad 6$

$0.020502 \quad 6$

$0.02085 \quad 3$

$0.021155 \quad 2$

$0.021155 \quad 2$

$0.02142 \quad 4$

$0.02142 \quad 8$

$0.02142 \quad 8$

$0.02142 \quad 38$

$0.02142 \quad 7$

$0.02142 \quad 29$

$0.02142 \quad 7$

$0.02142 \quad 7$

$0.021439 \quad 4$

$0.021812 \quad 6$

$0.021812 \quad 4$

$0.021812 \quad 4$

$0.021812 \quad 5$

$0.021812 \quad 6$

$0.021812 \quad 3$

$0.021812 \quad 3$

$0.021812 \quad 3$

$0.02307 \quad 4$

$0.02307 \quad 12$

$0.02314 \quad 11$

$0.023278 \quad 13$

$0.023278 \quad 8$

$0.023395 \quad 5$

$0.023395 \quad 3$

$0.024272 \quad 5$

$0.024451 \quad 7$

$0.024451 \quad 9$

$0.026233 \quad 7$

$0.026233 \quad 30$

$0.026609 \quad 2$ 
Animal organ morphogenesis

0.026609

0.026609

Skeletal muscle thin filament assembly

0.026643

Cell-cell adhesion

0.027027

Response to inorganic substance

0.02784

Macromolecule localization

0.02784

Regulation of axonogenesis

0.02784

Cellular macromolecule localization

0.02784

Myotube differentiation

Hexose catabolic process

0.027946

0.027946

Cellular component morphogenesis

0.027946

Cellular localization

0.027946

Mesenchyme development

0.027946

Cellular response to endogenous stimulus

0.027946

Cellular response to organic substance

0.028515

Axonogenesis

0.029032

Tube development

0.029032

Response to drug

0.029032

Positive regulation of neuron differentiation

0.029032

Cellular response to oxygen-containing compound

0.029032

Carboxylic acid metabolic process

0.029103

Regulation of cellular component organization

0.029382

Cardiac muscle cell differentiation

0.029515

Response to starvation

Cellular response to steroid hormone stimulus

Positive regulation of neuron projection development

0.029555

0.029555

Head development

0.02975

0.02975

Response to insulin

0.030109

NAD biosynthetic process

Coenzyme metabolic process

Nucleoside diphosphate metabolic process

0.030452

0.031917

0.031917

Skeletal myofibril assembly

Supramolecular fiber organization

0.032288

0.032357

0.032357

Polyol metabolic process

Microtubule polymerization or depolymerization

0.033638

0.033638

Regulation of epidermal cell differentiation

Positive regulation of cell projection organization

0.033638

0.033969

Female pregnancy

Response to muscle stretch

Neural retina development

Carbohydrate metabolic process

0.034504

0.034504

0.03529

0.03529

Glucose metabolic process

0.03529

Protein localization to nucleus

Nucleic acid transport

RNA transport

Membrane organization

0.03529

0.03529

0.03529

0.03529

0.035338

Negative regulation of metabolic process

0.035338

Negative regulation of cell-substrate adhesion

Regulation of protein ubiquitination

Response to nutrient levels

Monosaccharide catabolic process

0.035338

0.035338

0.035338

0.035338

0.035338

Cardiac muscle fiber development

Maternal process involved in female pregnancy

0.035338

13

2

4

12

9

29

5

20

4

3 
Positive regulation of protein modification by small protein conjugation or

0.035338

removal

Establishment of RNA localization

$0.035735 \quad 5$

Negative regulation of cell adhesion

0.036136

0.036136

Regulation of cell morphogenesis

0.036136

Lipoprotein metabolic process

Organic acid transmembrane transport

Carboxylic acid transmembrane transport

0.036136

Regulation of nitric oxide biosynthetic process

0.036136

0.03672

Cardiac muscle tissue development

Cleavage involved in rRNA processing

0.03672

Glyceraldehyde-3-phosphate metabolic process

0.036849

Muscle cell cellular homeostasis

Negative regulation of cellular component organization

0.036849

0.036849

Regulation of cell morphogenesis involved in differentiation

0.036849

Cellular response to nutrient

0.037187

Maturation of 5.8S rRNA from tricistronic rRNA transcript (SSU-rRNA, 5.8S

0.037187

rRNA, LSU-rRNA)

Glycerol metabolic process

0.037741

0.037741

0.037741

Cytoskeleton organization

0.037741

Cell adhesion

0.037741

Negative regulation of signal transduction

0.037741

Biological adhesion

Establishment of mitochondrion localization, microtubule-mediated

0.037741

0.037741

Amide transport

Regulation of mRNA stability

0.037741

0.037741

0.037741

Negative regulation of axonogenesis

Negative regulation of ERK1 and ERK2 cascade

0.037741

0.037741

Cellular response to amino acid stimulus

Cardiac muscle cell action potential

Response to peptide

Detection of abiotic stimulus

0.037741

0.037741

0.037741

0.038322

Negative regulation of cellular metabolic process

0.038322

Cellular protein localization

0.038322

Positive regulation of cell differentiation

Response to organophosphorus

Regulation of cell adhesion

0.038322

0.038322

0.038658

Retina layer formation

Response to steroid hormone

Developmental cell growth

Positive regulation of mesonephros development

0.03906

0.03906

0.03906

0.03906

Regulation of cellular response to stress

0.03906

Oxoacid metabolic process

Response to endogenous stimulus

0.040117

0.040319

0.040785

0.040785

Small molecule biosynthetic process

0.041395

Brain development

Regulation of cellular component movement

0.041395

Regulation of cell maturation

Developmental growth

Establishment of protein localization

0.041395

0.041884

0.041903

0.042553

0.042553

0.042553 
Cellular protein modification process

0.042553

Glutamine metabolic process

0.042553

NADH regeneration

0.042553

Nitric oxide biosynthetic process

0.042553

Carbohydrate transport

0.042553

Response to temperature stimulus

0.042553

Response to hormone

0.042553

Regulation of signal transduction

0.042553

Endomembrane system organization

0.042553

Regulation of cell communication

0.042553

Response to purine-containing compound

0.042553

Protein transport

0.042553

Protein import

0.042553

Alditol metabolic process

0.042553

NAD metabolic process

0.042553

Regulation of rhodopsin mediated signaling pathway

0.042553

Regulation of epithelial cell differentiation

0.042553

Membrane raft organization

0.042553

Regulation of response to extracellular stimulus

0.042553

Regulation of response to nutrient levels

0.042553

Maintenance of protein location in cell

0.042553

Cardiocyte differentiation

Protein modification process

0.042553

0.042553

0.042553

Regulation of locomotion

Ribosomal large subunit biogenesis

Regulation of RNA stability

Multi-multicellular organism process

0.042553

0.042553

Decidualization

0.042553

Reproductive structure development

0.042553

0.042553

0.042553

Positive regulation of multicellular organismal process

0.042553

Nucleus localization

Establishment of localization in cell

0.042553

Establishment of mitochondrion localization

0.042553

Positive regulation of nervous system development

0.042553

Regulation of ryanodine-sensitive calcium-release channel activity

0.042553

Canonical glycolysis

0.042553

Glucose catabolic process to pyruvate

Regulation of anion transmembrane transport

0.042553

0.042553

Heterotypic cell-cell adhesion

0.043292

Cellular response to lipid

0.043292

Reproductive system development

0.043576

Cardiac myofibril assembly

0.043663

Regulation of mesonephros development

0.043663

Glycolytic process through fructose-6-phosphate

0.043663

Glycolytic process through glucose-6-phosphate

0.043663

Cellular response to hypoxia

0.044341

Protein localization

0.044752

0.044752

Transport along microtubule

0.044752

Nitric oxide metabolic process

0.044752

Maintenance of location

Microtubule-based transport

Regulation of signaling

0.044752

0.044901

0.045069

Keratinocyte differentiation

0.045277

0.045277 
RNA localization

$0.045277 \quad 5$

Intracellular protein transport

0.045277

0.045277

Cell death

0.045277

Posttranscriptional regulation of gene expression

0.045277

Peptide transport

0.045277

Regulation of fatty acid metabolic process

0.045277

$\mathrm{N}$-terminal protein amino acid modification

0.045277

Regulation of protein modification process

0.045277

Cholesterol homeostasis

0.045277

Macromolecule modification

0.045277

Positive regulation of molecular function

0.045277

Regulation of fatty acid oxidation

0.045277

Positive regulation of lipid biosynthetic process

0.045277

MRNA transport

Sterol homeostasis

0.045277

0.045277

Oxidation-reduction process

0.045277

Regulation of mRNA catabolic process

0.045277

Response to oxygen levels

Cellular response to vitamin

0.045277

Positive regulation of animal organ morphogenesis

0.045277

0.045277

0.045277

Reactive nitrogen species metabolic process

0.045277

0.046773

0.047322

Skin development

Regulation of keratinocyte proliferation

0.047462

Cerebellar Purkinje cell layer development

0.047462

Regulation of microtubule depolymerization

0.047462

Regulation of epidermis development

0.047462

0.047838

Cell-substrate adhesion

Cellular response to decreased oxygen levels

0.048446

Muscle organ morphogenesis

Nucleobase-containing compound transport

0.048446

0.049275

0.049438

Adult walking behavior

0.049438

Rhodopsin mediated signaling pathway

Regulation of axon extension involved in axon guidance

0.049438

Wound healing

0.049438

0.049598 
1185 Table S6. 26 genes showing differential expression between species and misregulation in F1

1186 hybrids found within highly differentiated regions of the genome $\left(F_{s t}=1 ; D_{x y} \geq\right.$ genome-wide

$118790^{\text {th }}$ percentile (values in bold; range $=0.0031-0.0075$; see table S1 for all population

1188 thresholds)) that also show strong signs of a hard selective sweep in specialists (negative

1189 Tajima's $\mathrm{D}<$ genome-wide $10^{\text {th }}$ percentile (values in bold; range $=-1.62--0.77$ (see table S7 for

1190 all population thresholds); SweeD composite likelihood ratio $>90^{\text {th }}$ percentile for scaffold

1191 (values in bold)).

1192

\begin{tabular}{|c|c|c|c|c|c|c|c|c|c|c|c|}
\hline $\begin{array}{l}\text { maternal } \\
\text { population }\end{array}$ & $\begin{array}{l}\text { paternal } \\
\text { population }\end{array}$ & stage & gene & $\begin{array}{l}\text { log2 fold } \\
\text { change } \\
\text { parental } \\
\text { populations } \\
\text { vs. hybrids } \\
\end{array}$ & $\begin{array}{l}\log 2 \\
\text { fold } \\
\text { change } \\
\mathbf{P} \\
\text { value } \\
\end{array}$ & $\begin{array}{l}\text { fixed } \\
\text { SNPs } \\
\text { within } \\
20 \mathrm{~kb}\end{array}$ & $\begin{array}{l}\text { Tajima's D } \\
\text { maternal } \\
\text { population }\end{array}$ & $\begin{array}{l}\text { Tajima's } \\
\text { D paternal } \\
\text { population }\end{array}$ & $\begin{array}{l}\text { CLR } \\
\text { maternal } \\
\text { population }\end{array}$ & $\begin{array}{l}\text { CLR } \\
\text { paternal } \\
\text { population }\end{array}$ & $\begin{array}{l}\text { jaw } \\
\text { length } \\
\text { effect size }\end{array}$ \\
\hline OL generalist & OL scale-eater & $2 \mathrm{dpf}$ & pak3 & 0.804 & 0.017 & 11 & -0.45 & -1.33 & 530.3 & 1241.6 & $-5.70 \mathrm{E}-05$ \\
\hline OL generalist & OL scale-eater & $2 \mathrm{dpf}$ & $m t t p$ & -1.655 & $>0.001$ & 111 & -0.28 & -1.31 & 315.9 & 1011.5 & $-4.55 \mathrm{E}-06$ \\
\hline OL generalist & OL scale-eater & $2 \mathrm{dpf}$ & phgdh & -0.892 & $>0.001$ & 8 & 0.33 & -1.48 & 383.9 & 1076.1 & $-1.51 \mathrm{E}-05$ \\
\hline OL generalist & OL scale-eater & $2 \mathrm{dpf}$ & svil & 1.398 & $>0.001$ & 6 & -0.97 & -1.53 & 3136.0 & 4458.7 & $-6.55 \mathrm{E}-05$ \\
\hline OL generalist & OL scale-eater & $2 \mathrm{dpf}$ & dscam & 1.434 & 0.021 & 8 & -1.03 & -1.34 & 923.7 & 2663.9 & $1.97 \mathrm{E}-05$ \\
\hline OL generalist & OL scale-eater & $2 \mathrm{dpf}$ & $d a b l$ & 0.753 & 0.048 & 24 & -0.04 & -1.51 & 1285.5 & 2755.9 & $-3.34 \mathrm{E}-05$ \\
\hline CP generailst & $\mathrm{CP}$ scale-eater & $8 \mathrm{dpf}$ & $d b i$ & -1.115 & 0.007 & 3 & 0.39 & -1.66 & 337.5 & 1121.7 & 0.000447 \\
\hline OL scale-eater & OL molluscivore & $2 \mathrm{dpf}$ & lctl & 2.091 & 0.045 & 42 & -1.75 & 0.99 & 962.1 & 202.8 & $6.89 \mathrm{E}-06$ \\
\hline $\mathrm{CP}$ molluscivore & $\mathrm{CP}$ scale-eater & $8 \mathrm{dpf}$ & $p d c d 11$ & 1.457 & 0.002 & 52 & -1.62 & -1.41 & 2351.7 & 2208.3 & $9.14 \mathrm{E}-06$ \\
\hline $\mathrm{CP}$ molluscivore & $\mathrm{CP}$ scale-eater & $8 \mathrm{dpf}$ & nup205 & 1.016 & 0.016 & 50 & -1.56 & -0.87 & 1747.5 & 206.1 & $-4.83 \mathrm{E}-05$ \\
\hline $\mathrm{CP}$ molluscivore & $\mathrm{CP}$ scale-eater & $8 \mathrm{dpf}$ & LOC107098071 & 1.168 & 0.002 & 3 & -1.95 & -0.68 & 1289.4 & 754.8 & $-1.89 \mathrm{E}-05$ \\
\hline $\mathrm{CP}$ molluscivore & $\mathrm{CP}$ scale-eater & $8 \mathrm{dpf}$ & $t t n$ & 1.371 & 0.011 & 52 & -1.68 & -1.66 & 5370.8 & 2041.6 & $-1.88 \mathrm{E}-05$ \\
\hline $\mathrm{CP}$ molluscivore & $\mathrm{CP}$ scale-eater & $8 \mathrm{dpf}$ & nup155 & 1.020 & 0.014 & 4 & 0.99 & -1.74 & 201.4 & 1929.8 & $-4.17 \mathrm{E}-05$ \\
\hline $\mathrm{CP}$ molluscivore & $\mathrm{CP}$ scale-eater & $8 \mathrm{dpf}$ & cabp 7 & -0.966 & 0.038 & 8 & -0.14 & -1.61 & 1480.7 & 161.9 & 4.59E-06 \\
\hline $\mathrm{CP}$ molluscivore & CP scale-eater & $8 \mathrm{dpf}$ & ppp $5 c$ & 0.938 & 0.020 & 301 & -1.64 & -1.66 & 163.2 & 130.4 & $1.77 \mathrm{E}-06$ \\
\hline $\mathrm{CP}$ molluscivore & $\mathrm{CP}$ scale-eater & $8 \mathrm{dpf}$ & unc $45 a$ & 1.097 & 0.014 & 66 & -1.68 & -1.66 & 5369.8 & 2042.5 & $-8.92 \mathrm{E}-06$ \\
\hline $\mathrm{CP}$ molluscivore & CP scale-eater & $8 \mathrm{dpf}$ & polr $2 b$ & 0.550 & 0.017 & 183 & -1.27 & -1.71 & 807.3 & 2203.0 & $4.78 \mathrm{E}-05$ \\
\hline $\mathrm{CP}$ molluscivore & $\mathrm{CP}$ scale-eater & $8 \mathrm{dpf}$ & dusp3 & -1.470 & 0.011 & 21 & -1.54 & 0.14 & 17.0 & 60.9 & $-4.58 \mathrm{E}-06$ \\
\hline $\mathrm{CP}$ molluscivore & $\mathrm{CP}$ scale-eater & $8 \mathrm{dpf}$ & ndufa 412 & -0.711 & 0.013 & 19 & -1.39 & -1.77 & 3031.1 & 2809.3 & $6.31 \mathrm{E}-07$ \\
\hline $\mathrm{CP}$ molluscivore & $\mathrm{CP}$ scale-eater & $8 \mathrm{dpf}$ & psmd11 & 1.022 & 0.004 & 13 & -1.58 & 0.94 & 135.8 & 125.8 & $-8.03 \mathrm{E}-06$ \\
\hline $\mathrm{CP}$ molluscivore & $\mathrm{CP}$ scale-eater & $8 \mathrm{dpf}$ & pde6g & -1.308 & 0.027 & 30 & 0.24 & -1.77 & 1530.2 & 1261.4 & $-2.01 \mathrm{E}-06$ \\
\hline $\mathrm{CP}$ molluscivore & $\mathrm{CP}$ scale-eater & $8 \mathrm{dpf}$ & mapls & 0.805 & 0.029 & 7 & 0.16 & -1.75 & 457.8 & 1523.2 & $-1.58 \mathrm{E}-05$ \\
\hline $\mathrm{CP}$ molluscivore & $\mathrm{CP}$ scale-eater & $8 \mathrm{dpf}$ & ptprn2 & -0.670 & 0.015 & 29 & -1.61 & -1.82 & 2211.6 & 1392.6 & $1.73 \mathrm{E}-05$ \\
\hline $\mathrm{CP}$ molluscivore & $\mathrm{CP}$ scale-eater & $8 \mathrm{dpf}$ & $\operatorname{slc} 43 a 1$ & 1.140 & 0.002 & 362 & -1.64 & -1.49 & 809.6 & 662.4 & $-3.60 \mathrm{E}-06$ \\
\hline OL scale-eater & OL molluscivore & $8 \mathrm{dpf}$ & slc38a8 & -1.516 & 0.046 & 62 & -1.48 & -0.13 & 3749.1 & 2435.3 & $3.80 \mathrm{E}-05$ \\
\hline OL scale-eater & OL molluscivore & $8 \mathrm{dpf}$ & semabc & -0.607 & 0.030 & 64 & -0.82 & -1.82 & 2253.9 & 3918.3 & -0.00051 \\
\hline
\end{tabular}


1196 Table S7. San Salvador Island population genomic statistics measured across 13.8 million SNPs.

1197 Statistics for the top three rows were calculated for all San Salvador individuals of each species

1198 (see Fig. S1). The remaining rows are comparisons separated by lake populations used to

1199 generate samples for RNAseq $(\mathrm{CP}=$ Crescent Pond, OL = Osprey Lake).

1200

1201

\begin{tabular}{llll}
\hline population & mean Tajima's D & Tajima's D 10th percentile & mean $\boldsymbol{\pi}$ \\
\hline all generalists & 0.704649 & -0.90273 & 0.003029 \\
all molluscivores & 0.565385 & -1.34112 & 0.002583 \\
all scale-eaters & 0.210182 & -1.62616 & 0.002036 \\
CP generalists & 0.430683 & -1.076 & 0.002806 \\
CP molluscivores & 0.097742 & -1.44811 & 0.00194 \\
CP scale-eaters & -0.01537 & -1.53413 & 0.001385 \\
OL generalists & 0.338391 & -0.77476 & 0.003022 \\
OL molluscivores & 0.227443 & -1.37104 & 0.002458 \\
OL scale-eaters & 0.14957 & -1.31009 & 0.00219 \\
\hline
\end{tabular}

1207

1208

1209

1210

1211

1212

1213

1214

1215

1216

1217

1218

1219

1220

1221

1222

1223

1224 
1225 Table S8. Ecological DMI candidate genes associated with jaw size. Nine genes showing

1226 differential expression between species and misregulation in F1 hybrids found within highly

1227 differentiated regions of the genome $\left(F_{s t}=1 ; D_{x y} \geq\right.$ genome-wide $90^{\text {th }}$ percentile (values in bold;

1228 range $=0.0075-0.0031$; see table $\mathrm{S} 1$ for all population thresholds)) were also in a $20 \mathrm{~kb}$ regions

1229 significantly associated with oral jaw size variation across our Caribbean pupfish samples

1230 (GEMMA PIP $>99^{\text {th }}$ percentile $(0.00175)$ ). Genes in bold are discussed in the main text. The

1231 genes sema6c and $d b i$ (Table S6) also show signs of a hard selective sweep in specialists

1232 (negative Tajima's D $<$ genome-wide $10^{\text {th }}$ percentile; range $=-1.62--0.77$ (see table $\mathrm{S} 7$ for all

1233 population thresholds); SweeD composite likelihood ratio $>90^{\text {th }}$ percentile by scaffold (values in

1234 bold)).

1235

1236

\begin{tabular}{|c|c|c|c|c|c|c|c|c|c|c|c|c|}
\hline $\begin{array}{l}\text { maternal } \\
\text { population }\end{array}$ & $\begin{array}{l}\text { paternal } \\
\text { population }\end{array}$ & stage & gene & $\begin{array}{l}\text { log2 fold } \\
\text { change } \\
\text { parental } \\
\text { populations } \\
\text { vs. hybrids }\end{array}$ & $\begin{array}{l}\text { log2 fold } \\
\text { change } \\
\text { P value }\end{array}$ & $\begin{array}{l}\text { fixed } \\
\text { SNPs } \\
\text { within } \\
20 \mathrm{~kb}\end{array}$ & $\begin{array}{l}\text { Tajima's } \\
\text { D } \\
\text { maternal } \\
\text { population }\end{array}$ & $\begin{array}{l}\text { Tajima's } \\
\text { D paternal } \\
\text { population }\end{array}$ & $\begin{array}{l}\text { CLR } \\
\text { maternal } \\
\text { population }\end{array}$ & $\begin{array}{l}\text { CLR paternal } \\
\text { population }\end{array}$ & PIP & $\begin{array}{l}\text { jaw } \\
\text { length } \\
\text { effect size }\end{array}$ \\
\hline $\mathrm{CP}$ generailst & CP scale-eater & 8 & mpp1 & -1.48472 & 0.001062 & 170 & 0.824871 & -0.57836 & 1181.48 & 1364.328 & 0.00255 & 0.000507 \\
\hline $\mathrm{CP}$ generailst & CP scale-eater & 8 & dbi & -1.11505 & 0.007072 & 3 & 0.390309 & -1.65859 & 337.5028 & 1121.688 & 0.00198 & 0.000447 \\
\hline $\mathrm{CP}$ molluscivore & CP scale-eater & 8 & rcl1 & 0.891616 & 0.004743 & 9 & -0.59334 & -1.19039 & 1028.911 & 433.5589 & 0.00379 & 0.000826 \\
\hline $\mathrm{CP}$ molluscivore & CP scale-eater & 8 & $\operatorname{prpf39}$ & 0.645521 & 0.048885 & 325 & -1.03984 & -1.14611 & 137.0623 & 2474.137 & 0.0025 & -0.00017 \\
\hline $\mathrm{CP}$ molluscivore & CP scale-eater & 8 & LOC 107082296 & -1.43946 & 0.005671 & 2 & -1.07899 & -0.35454 & 289.3542 & 1000.216 & 0.00175 & $-1.24 \mathrm{E}-06$ \\
\hline OL generalist & OL scale-eater & 8 & rcll & 0.971193 & 0.025532 & 3 & -0.46693 & -1.19082 & 654.403 & 1471.226 & 0.00379 & 0.000826 \\
\hline OL scale-eater & OL molluscivore & 8 & sema6c & -0.60673 & 0.030178 & 64 & -0.81823 & -1.81724 & 2253.855 & 3918.334 & 0.00213 & -0.00051 \\
\hline OL scale-eater & OL molluscivore & 8 & mid1ip1 & -0.77486 & 0.016349 & 1 & 0.594817 & -0.27379 & 32.32544 & 1237.023 & 0.00185 & 0.000467 \\
\hline $\mathrm{CP}$ molluscivore & $\mathrm{CP}$ scale-eater & 48 & hbae & 0.934082 & $9.95 \mathrm{E}-06$ & 29 & -1.3977 & 1.87904 & 1218.031 & 41.76962 & 0.00191 & 0.000745 \\
\hline OL generalist & OL scale-eater & 48 & ak3 & -0.64731 & 0.007329 & 4 & -0.79556 & -1.19082 & 797.5076 & 1471.226 & 0.00379 & 0.000826 \\
\hline
\end{tabular}


1249 Table S9. Cross design for 124 transcriptomes. All libraries were prepared with Truseq stranded 1250 mRNA kits and sequenced at the Vincent J. Coates Genomic Sequencing Center in either May

12512018 or June 2018.

\begin{tabular}{|c|c|c|c|}
\hline sample ID & stage & sequencing date & parents \\
\hline CAE1 & $8 \mathrm{dpf}$ & May-18 & Crescent Pond generalists \\
\hline CAE2 & $8 \mathrm{dpf}$ & May-18 & Crescent Pond generalists \\
\hline CAE3 & $8 \mathrm{dpf}$ & May-18 & Crescent Pond generalists \\
\hline CAE4 & $8 \mathrm{dpf}$ & May-18 & Crescent Pond generalists \\
\hline CAE5 & $8 \mathrm{dpf}$ & May-18 & Crescent Pond generalists \\
\hline CME1 & $8 \mathrm{dpf}$ & Jul-18 & Crescent Pond snail eaters \\
\hline CME2 & $8 \mathrm{dpf}$ & Jul-18 & Crescent Pond snail eaters \\
\hline CME5 & $8 \mathrm{dpf}$ & Jul-18 & Crescent Pond snail eaters \\
\hline CPE1 & $8 \mathrm{dpf}$ & May-18 & Crescent Pond scale eaters \\
\hline CPE2 & $8 \mathrm{dpf}$ & May-18 & Crescent Pond scale eaters \\
\hline CPE3 & $8 \mathrm{dpf}$ & May-18 & Crescent Pond scale eaters \\
\hline CPE4 & $8 \mathrm{dpf}$ & May-18 & Crescent Pond scale eaters \\
\hline CPE5 & $8 \mathrm{dpf}$ & May-18 & Crescent Pond scale eaters \\
\hline CQE1 & $8 \mathrm{dpf}$ & Jul-18 & New Providence female x New Providence generalist male \\
\hline CQE2 & $8 \mathrm{dpf}$ & Jul-18 & New Providence female x New Providence generalist male \\
\hline CQE3 & $8 \mathrm{dpf}$ & Jul-18 & New Providence female x New Providence generalist male \\
\hline NCE1 & $8 \mathrm{dpf}$ & May-18 & North Carolina generalists \\
\hline NCE2 & $8 \mathrm{dpf}$ & May-18 & North Carolina generalists \\
\hline NCE3 & $8 \mathrm{dpf}$ & May-18 & North Carolina generalists \\
\hline NCE4 & $8 \mathrm{dpf}$ & May-18 & North Carolina generalists \\
\hline NCE5 & $8 \mathrm{dpf}$ & May-18 & North Carolina generalists \\
\hline OAE1 & $8 \mathrm{dpf}$ & May-18 & Osprey Lake generalists \\
\hline OAE2 & $8 \mathrm{dpf}$ & May-18 & Osprey Lake generalists \\
\hline OAE3 & $8 \mathrm{dpf}$ & May-18 & Osprey Lake generalists \\
\hline OAE4 & $8 \mathrm{dpf}$ & May-18 & Osprey Lake generalists \\
\hline OME1 & $8 \mathrm{dpf}$ & May-18 & Osprey Lake snail eaters \\
\hline OME2 & $8 \mathrm{dpf}$ & May-18 & Osprey Lake snail eaters \\
\hline OME3 & $8 \mathrm{dpf}$ & May-18 & Osprey Lake snail eaters \\
\hline OME4 & $8 \mathrm{dpf}$ & May-18 & Osprey Lake snail eaters \\
\hline OME5 & $8 \mathrm{dpf}$ & May-18 & Osprey Lake snail eaters \\
\hline OPE1 & $8 \mathrm{dpf}$ & May-18 & Osprey Lake scale eaters \\
\hline OPE2 & $8 \mathrm{dpf}$ & May-18 & Osprey Lake scale eaters \\
\hline OPE3 & $8 \mathrm{dpf}$ & May-18 & Osprey Lake scale eaters \\
\hline OPE4 & $8 \mathrm{dpf}$ & May-18 & Osprey Lake scale eaters \\
\hline OPE5 & $8 \mathrm{dpf}$ & May-18 & Osprey Lake scale eaters \\
\hline CPU1 & $8 \mathrm{dpf}$ & Jul-18 & Crescent Pond generalist female x Crescent Pond snail eater male \\
\hline CPU3 & $8 \mathrm{dpf}$ & Jul-18 & Crescent Pond generalist female $\mathrm{x}$ Crescent Pond snail eater male \\
\hline
\end{tabular}




\begin{tabular}{|c|c|c|c|}
\hline CPU5 & $8 \mathrm{dpf}$ & Jul-18 & Crescent Pond generalist female $\mathrm{x}$ Crescent Pond snail eater male \\
\hline CVE1 & $8 \mathrm{dpf}$ & Jul-18 & Crescent Pond generalist female $\mathrm{x}$ Crescent Pond scale eater male \\
\hline CVE2 & $8 \mathrm{dpf}$ & Jul-18 & Crescent Pond generalist female $\mathrm{x}$ Crescent Pond scale eater male \\
\hline CVE5 & $8 \mathrm{dpf}$ & Jul-18 & Crescent Pond generalist female $\mathrm{x}$ Crescent Pond scale eater male \\
\hline CWE2 & $8 \mathrm{dpf}$ & Jul-18 & Crescent Pond snail eater female $\mathrm{x}$ Crescent Pond scale eater male \\
\hline CWE3 & $8 \mathrm{dpf}$ & Jul-18 & Crescent Pond snail eater female $\mathrm{x}$ Crescent Pond scale eater male \\
\hline CWE4 & $8 \mathrm{dpf}$ & Jul-18 & Crescent Pond snail eater female $\mathrm{x}$ Crescent Pond scale eater male \\
\hline CXE2 & $8 \mathrm{dpf}$ & Jul-18 & Crescent Pond snail eater female $\mathrm{x}$ Crescent Pond generalist male \\
\hline CXE3 & $8 \mathrm{dpf}$ & Jul-18 & Crescent Pond snail eater female $\mathrm{x}$ Crescent Pond generalist male \\
\hline CXE4 & $8 \mathrm{dpf}$ & Jul-18 & Crescent Pond snail eater female $\mathrm{x}$ Crescent Pond generalist male \\
\hline NAE1 & $8 \mathrm{dpf}$ & Jul-18 & North Carolina female $\mathrm{x}$ Crescent Pond generalist male \\
\hline NAE2 & $8 \mathrm{dpf}$ & Jul-18 & North Carolina female $\mathrm{x}$ Crescent Pond generalist male \\
\hline NAE4 & $8 \mathrm{dpf}$ & Jul-18 & North Carolina female $\mathrm{x}$ Crescent Pond generalist male \\
\hline OUE1 & $8 \mathrm{dpf}$ & Jul-18 & Osprey Lake generalist female x Osprey Lake snail eater male \\
\hline OUE3 & $8 \mathrm{dpf}$ & Jul-18 & Osprey Lake generalist female x Osprey Lake snail eater male \\
\hline OUE4 & $8 \mathrm{dpf}$ & Jul-18 & Osprey Lake generalist female x Osprey Lake snail eater male \\
\hline OVE1 & $8 \mathrm{dpf}$ & Jul-18 & Osprey Lake generalist female x Osprey Lake scale eater male \\
\hline OVE4 & $8 \mathrm{dpf}$ & Jul-18 & Osprey Lake generalist female x Osprey Lake scale eater male \\
\hline OVE5 & $8 \mathrm{dpf}$ & Jul-18 & Osprey Lake generalist female x Osprey Lake scale eater male \\
\hline OXE2 & $8 \mathrm{dpf}$ & Jul-18 & Osprey Lake snail eater female x Osprey Lake generalist male \\
\hline OYE1 & $8 \mathrm{dpf}$ & May-18 & Osprey Lake scale eater female x Osprey Lake generalist male \\
\hline OYE2 & $8 \mathrm{dpf}$ & May-18 & Osprey Lake scale eater female x Osprey Lake generalist male \\
\hline OYE3 & $8 \mathrm{dpf}$ & May-18 & Osprey Lake scale eater female x Osprey Lake generalist male \\
\hline OYE4 & $8 \mathrm{dpf}$ & May-18 & Osprey Lake scale eater female x Osprey Lake generalist male \\
\hline OYE5 & $8 \mathrm{dpf}$ & May-18 & Osprey Lake scale eater female x Osprey Lake generalist male \\
\hline OZE2 & $8 \mathrm{dpf}$ & Jul-18 & Osprey Lake scale eater female x Osprey Lake snail eater male \\
\hline OZE4 & $8 \mathrm{dpf}$ & Jul-18 & Osprey Lake scale eater female x Osprey Lake snail eater male \\
\hline OZE5 & $8 \mathrm{dpf}$ & Jul-18 & Osprey Lake scale eater female x Osprey Lake snail eater male \\
\hline PAE1 & $8 \mathrm{dpf}$ & Jul-18 & New Providence female $x$ Crescent Pond generalist \\
\hline PAE2 & $8 \mathrm{dpf}$ & Jul-18 & New Providence female $x$ Crescent Pond generalist \\
\hline PAE5 & $8 \mathrm{dpf}$ & Jul-18 & New Providence female $x$ Crescent Pond generalist \\
\hline CAT1 & $2 \mathrm{dpf}$ & May-18 & Crescent Pond generalists \\
\hline CAT2 & $2 \mathrm{dpf}$ & May-18 & Crescent Pond generalists \\
\hline CAT3 & $2 \mathrm{dpf}$ & May-18 & Crescent Pond generalists \\
\hline CMT1 & $2 \mathrm{dpf}$ & Jul-18 & Crescent Pond snail eaters \\
\hline CMT2 & $2 \mathrm{dpf}$ & Jul-18 & Crescent Pond snail eaters \\
\hline CMT3 & $2 \mathrm{dpf}$ & Jul-18 & Crescent Pond snail eaters \\
\hline CPT1 & $2 \mathrm{dpf}$ & May-18 & Crescent Pond scale eaters \\
\hline CPT2 & $2 \mathrm{dpf}$ & May-18 & Crescent Pond scale eaters \\
\hline CPT3 & $2 \mathrm{dpf}$ & Jul-18 & Crescent Pond scale eaters \\
\hline CQT1 & $2 \mathrm{dpf}$ & Jul-18 & New Providence female x New Providence generalist male \\
\hline CQT2 & $2 \mathrm{dpf}$ & Jul-18 & New Providence female $x$ New Providence generalist male \\
\hline NCT1 & $2 \mathrm{dpf}$ & May-18 & North Carolina generalists \\
\hline NCT2 & $2 \mathrm{dpf}$ & May-18 & North Carolina generalists \\
\hline NCT3 & $2 \mathrm{dpf}$ & May-18 & North Carolina generalists \\
\hline
\end{tabular}




\begin{tabular}{|c|c|c|c|}
\hline OAT1 & $2 \mathrm{dpf}$ & May-18 & Osprey Lake generalists \\
\hline OAT2 & $2 \mathrm{dpf}$ & May-18 & Osprey Lake generalists \\
\hline OAT3 & $2 \mathrm{dpf}$ & Jul-18 & Osprey Lake generalists \\
\hline OMT1 & $2 \mathrm{dpf}$ & May-18 & Osprey Lake snail eaters \\
\hline OMT2 & $2 \mathrm{dpf}$ & May-18 & Osprey Lake snail eaters \\
\hline OMT3 & $2 \mathrm{dpf}$ & May-18 & Osprey Lake snail eaters \\
\hline OPT1 & $2 \mathrm{dpf}$ & May-18 & Osprey Lake scale eaters \\
\hline OPT2 & $2 \mathrm{dpf}$ & May-18 & Osprey Lake scale eaters \\
\hline OPT3 & $2 \mathrm{dpf}$ & May-18 & Osprey Lake scale eaters \\
\hline CUT1 & $2 \mathrm{dpf}$ & Jul-18 & Crescent Pond generalist female $\mathrm{x}$ Crescent Pond snail eater male \\
\hline CUT2 & $2 \mathrm{dpf}$ & Jul-18 & Crescent Pond generalist female $\mathrm{x}$ Crescent Pond snail eater male \\
\hline CUT3 & $2 \mathrm{dpf}$ & Jul-18 & Crescent Pond generalist female $\mathrm{x}$ Crescent Pond snail eater male \\
\hline CVT1 & $2 \mathrm{dpf}$ & May-18 & Crescent Pond generalist female $\mathrm{x}$ Crescent Pond scale eater male \\
\hline CVT2 & $2 \mathrm{dpf}$ & May-18 & Crescent Pond generalist female $\mathrm{x}$ Crescent Pond scale eater male \\
\hline CVT3 & $2 \mathrm{dpf}$ & May-18 & Crescent Pond generalist female $\mathrm{x}$ Crescent Pond scale eater male \\
\hline CWT1 & $2 \mathrm{dpf}$ & May-18 & Crescent Pond snail eater female x Crescent Pond scale eater male \\
\hline CWT2 & $2 \mathrm{dpf}$ & May-18 & Crescent Pond snail eater female x Crescent Pond scale eater male \\
\hline CWT3 & $2 \mathrm{dpf}$ & May-18 & Crescent Pond snail eater female x Crescent Pond scale eater male \\
\hline CXT1 & $2 \mathrm{dpf}$ & May-18 & Crescent Pond snail eater female $\mathrm{x}$ Crescent Pond generalist male \\
\hline CXT2 & $2 \mathrm{dpf}$ & May-18 & Crescent Pond snail eater female x Crescent Pond generalist male \\
\hline CXT3 & $2 \mathrm{dpf}$ & May-18 & Crescent Pond snail eater female x Crescent Pond generalist male \\
\hline NAT1 & $2 \mathrm{dpf}$ & May-18 & North Carolina female $\mathrm{x}$ Crescent Pond generalist male \\
\hline NAT2 & $2 \mathrm{dpf}$ & May-18 & North Carolina female $\mathrm{x}$ Crescent Pond generalist male \\
\hline NAT3 & $2 \mathrm{dpf}$ & May-18 & North Carolina female $\mathrm{x}$ Crescent Pond generalist male \\
\hline OUT1 & $2 \mathrm{dpf}$ & Jul-18 & Osprey Lake generalist female x Osprey Lake snail eater male \\
\hline OUT2 & $2 \mathrm{dpf}$ & Jul-18 & Osprey Lake generalist female x Osprey Lake snail eater male \\
\hline OUT3 & $2 \mathrm{dpf}$ & Jul-18 & Osprey Lake generalist female x Osprey Lake snail eater male \\
\hline OVT1 & $2 \mathrm{dpf}$ & May-18 & Osprey Lake generalist female x Osprey Lake scale eater male \\
\hline OVT2 & $2 \mathrm{dpf}$ & May-18 & Osprey Lake generalist female x Osprey Lake scale eater male \\
\hline OVT3 & $2 \mathrm{dpf}$ & May-18 & Osprey Lake generalist female x Osprey Lake scale eater male \\
\hline OXT1 & $2 \mathrm{dpf}$ & Jul-18 & Osprey Lake snail eater female x Osprey Lake generalist male \\
\hline OXT2 & $2 \mathrm{dpf}$ & Jul-18 & Osprey Lake snail eater female x Osprey Lake generalist male \\
\hline OXT3 & $2 \mathrm{dpf}$ & Jul-18 & Osprey Lake snail eater female x Osprey Lake generalist male \\
\hline OYT1 & $2 \mathrm{dpf}$ & May-18 & Osprey Lake scale eater female x Osprey Lake generalist male \\
\hline OYT2 & $2 \mathrm{dpf}$ & May-18 & Osprey Lake scale eater female x Osprey Lake generalist male \\
\hline OYT3 & $2 \mathrm{dpf}$ & May-18 & Osprey Lake scale eater female x Osprey Lake generalist male \\
\hline OZT1 & $2 \mathrm{dpf}$ & Jul-18 & Osprey Lake scale eater female x Osprey Lake snail eater male \\
\hline OZT2 & $2 \mathrm{dpf}$ & Jul-18 & Osprey Lake scale eater female x Osprey Lake snail eater male \\
\hline OZT3 & $2 \mathrm{dpf}$ & Jul-18 & Osprey Lake scale eater female x Osprey Lake snail eater male \\
\hline PAT1 & $2 \mathrm{dpf}$ & May-18 & New Providence female $x$ Crescent Pond generalist \\
\hline PAT2 & $2 \mathrm{dpf}$ & May-18 & New Providence female $x$ Crescent Pond generalist \\
\hline PAT3 & $2 \mathrm{dpf}$ & May-18 & New Providence female $x$ Crescent Pond generalist \\
\hline
\end{tabular}


bioRxiv preprint doi: https://doi org/10.1101/717025: this version posted July 28 2019. The copyright holder for this preprint (which was not certified by peer review) is the author/funder, who has granted bioRxiv a license to display the preprint in perpetuity. It is made available under aCC-BY 4.0 International license.

1280 Fig S1. Maximum likelihood tree generated using RAxML with 1.7 million SNPs showing phylogenetic relationships between 55 Cyprinodon individuals. Relationships for three outgroup individuals that were included in the genomic dataset are not shown. $\mathrm{Red}=$ San Salvador

1283 generalist , green $=$ molluscivore, blue $=$ scale-eater, black $=$ outgroup generalist . 


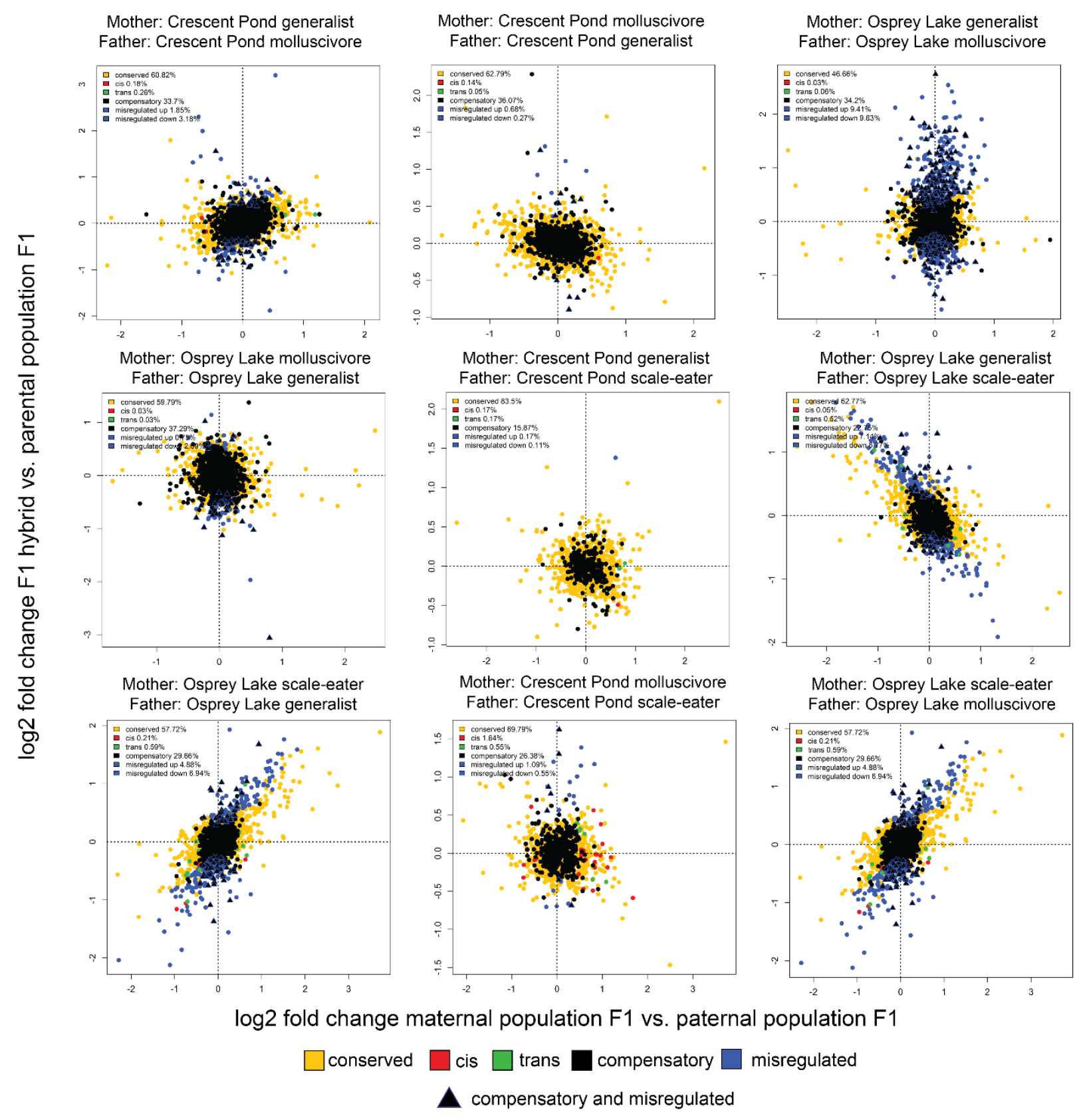

1285 Fig S2. Regulatory mechanisms underlying expression divergence at $2 \mathrm{dpf}$ in San Salvador 1286 crosses. Yellow $=$ conserved (no difference in expression between any group or ambiguous 1287 expression patterns), red $=$ cis (significant ASE in hybrids, significant differential expression 1288 between parental populations of purebred F1 offspring, and no significant trans- contribution), 1289 green = trans (significant ASE in hybrids, significant differential expression between parental 1290 populations of purebred F1 offspring, and significant trans- contribution), black = compensatory 1291 (significant ASE in hybrids, no significant differential expression between parental populations 1292 of purebred F1 offspring), blue = misregulated (significant differential expression between 1293 purebred F1 and hybrid F1), triangle = compensatory and misregulated. 


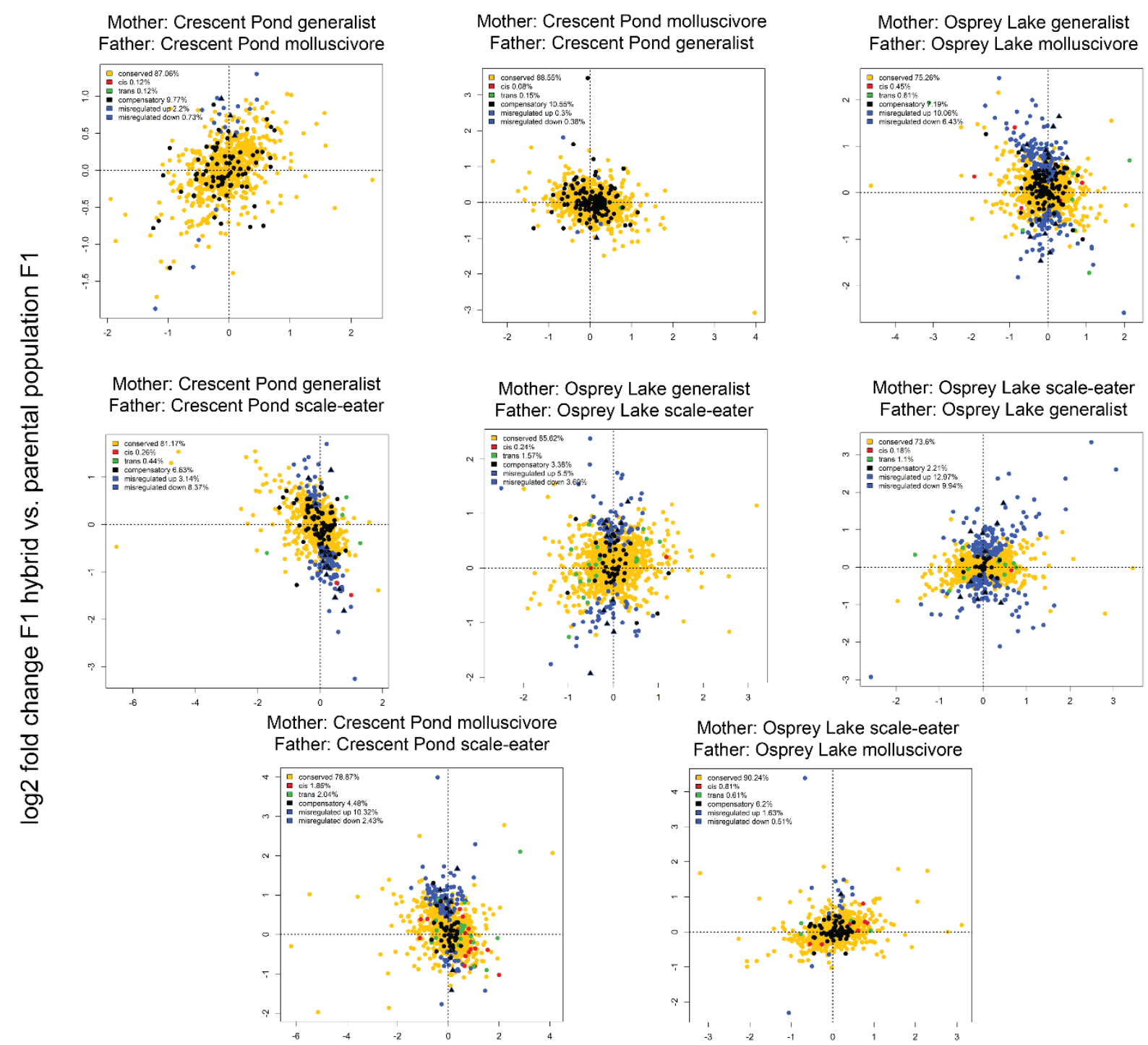

log2 fold change maternal population F1 vs. paternal population F1

conserved $\square$ cis $\square$ trans $\square$ compensatory $\square$ misregulated

A compensatory and misregulated

1296 Fig S3. Regulatory mechanisms underlying expression divergence at 8 dpf in San Salvador crosses. Yellow $=$ conserved (no difference in expression between any group or ambiguous expression patterns), red = cis (significant ASE in hybrids, significant differential expression between parental populations of purebred F1 offspring, and no significant trans-contribution), green = trans (significant ASE in hybrids, significant differential expression between parental populations of purebred F1 offspring, and significant trans-contribution), black = compensatory 1302 (significant ASE in hybrids, no significant differential expression between parental populations of purebred F1 offspring), blue = misregulated (significant differential expression between purebred F1 and hybrid F1), triangle = compensatory and misregulated. 

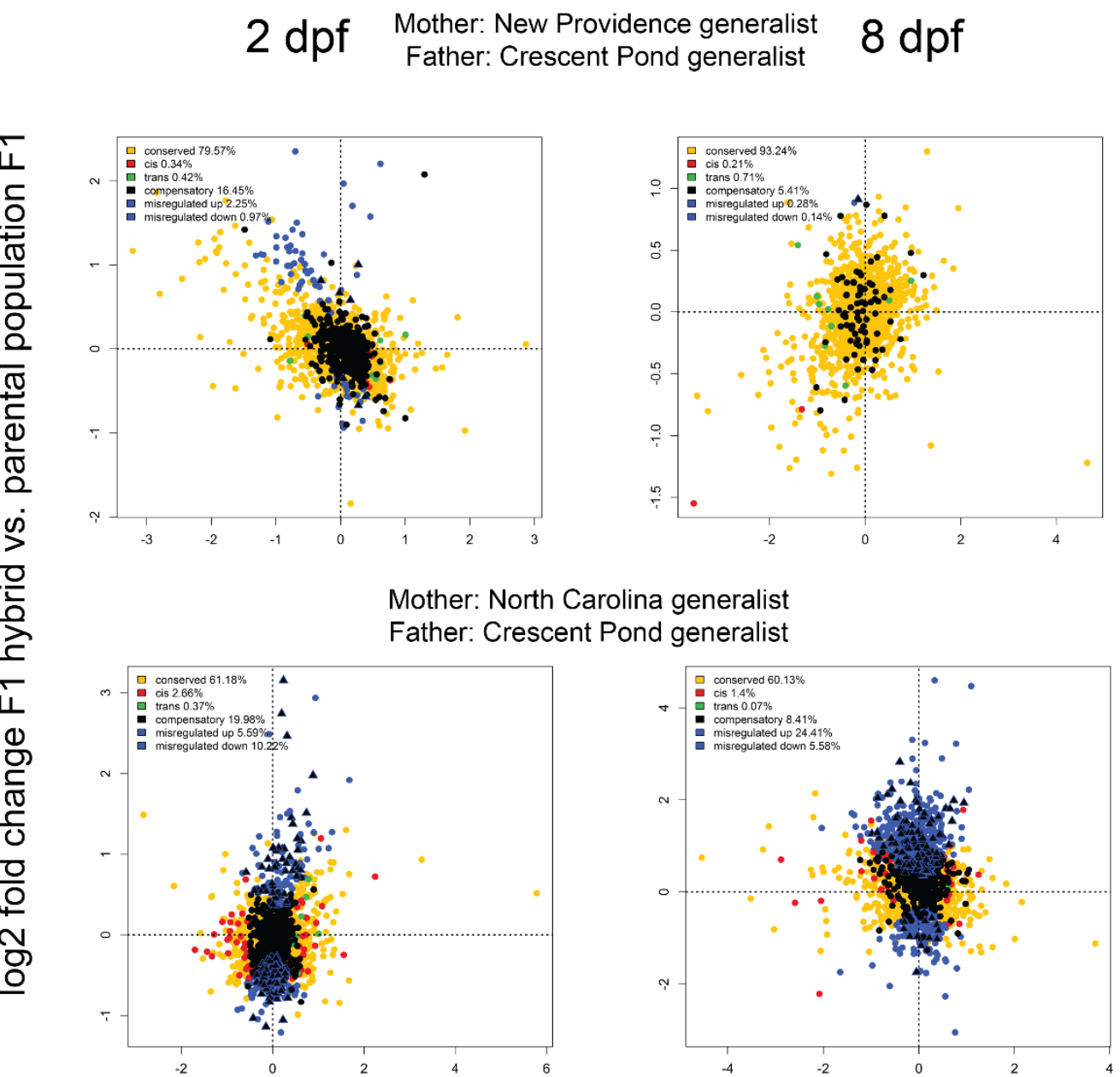

log2 fold change maternal population F1 vs. paternal population F1

conserved $\square$ cis $\square$ trans $\square$ compensatory $\square$ misregulated

\section{A compensatory and misregulated}

Fig S4. Regulatory mechanisms underlying expression divergence in outgroup generalist population crosses. Yellow = conserved (no difference in expression between any group or ambiguous expression patterns), red $=$ cis (significant ASE in hybrids, significant differential expression between parental populations of purebred F1 offspring, and no significant transcontribution), green = trans (significant ASE in hybrids, significant differential expression between parental populations of purebred F1 offspring, and significant trans-contribution), black = compensatory (significant ASE in hybrids, no significant differential expression between parental populations of purebred F1 offspring), blue = misregulated (significant differential expression between purebred F1 and hybrid F1), triangle = compensatory and misregulated. 

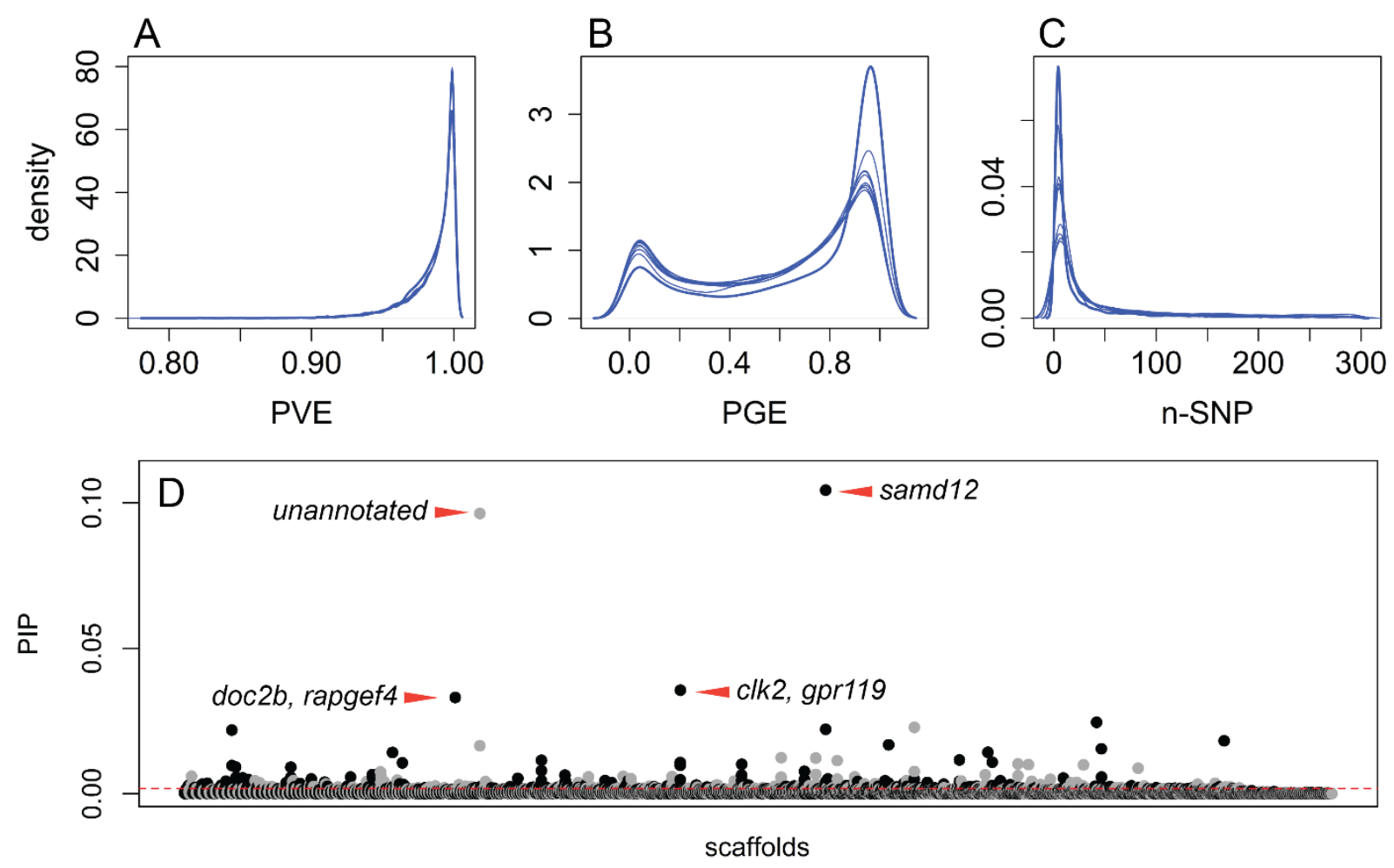

1318 Fig. S5. Genome-wide association mapping. GEMMA implements a Bayesian sparse linear mixed model (BSLMM) that uses MCMC to estimate the proportion of phenotypic variation explained by every SNP included in the analysis (A; PVE), the proportion of phenotypic variation explained by SNPs of large effect (B; PGE), which are defined as SNPs with a nonzero effect on the phenotype, and the number of large-effect SNPs needed to explain PGE (C; nSNPs). Each blue line represents one of ten independent runs of the BSLMM. D) Posterior inclusion probability for $20 \mathrm{~kb}$ windows across all scaffolds (alternating black and grey for each scaffold). Windows that showed PIP values above the 99th percentile (0.00175; dotted red line) were considered to have a significant effect on jaw size variation. Red arrows indicate genes within top four windows (samd12, clk2, gpr119, doc2b, rapgef4). 


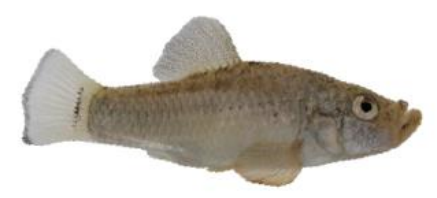

\section{scale-eater}
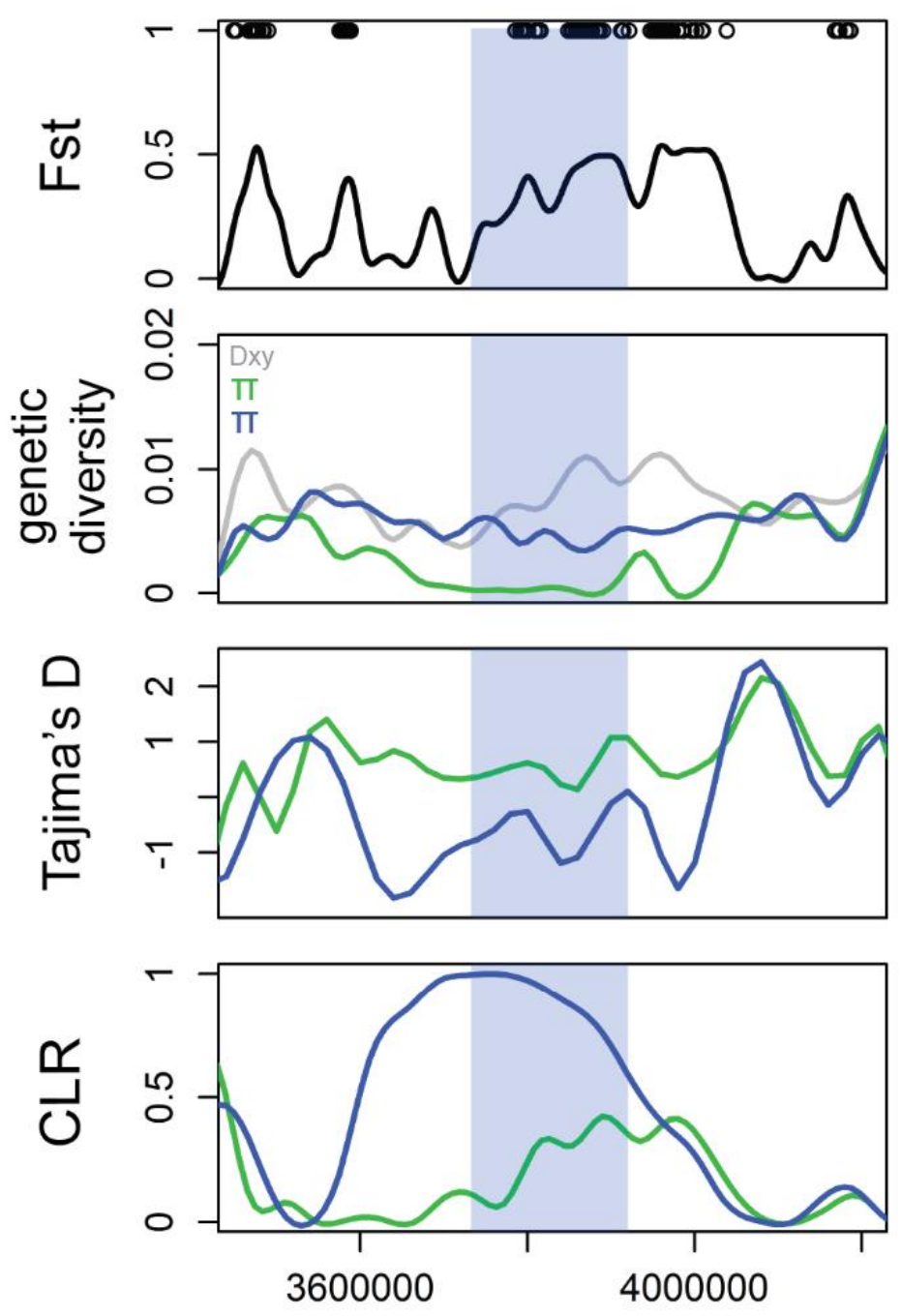

scaffold position

1335 Fig S6. The sema6c gene region (light blue) contains 64 SNPs fixed between Osprey Lake scaleeaters (blue) vs. molluscivores (green), shows strong between-population divergence and low within-population diversity, shows strong signs of a hard selective sweep, and is significantly associated with oral jaw length variation in a genome-wide association analysis using GEMMA 


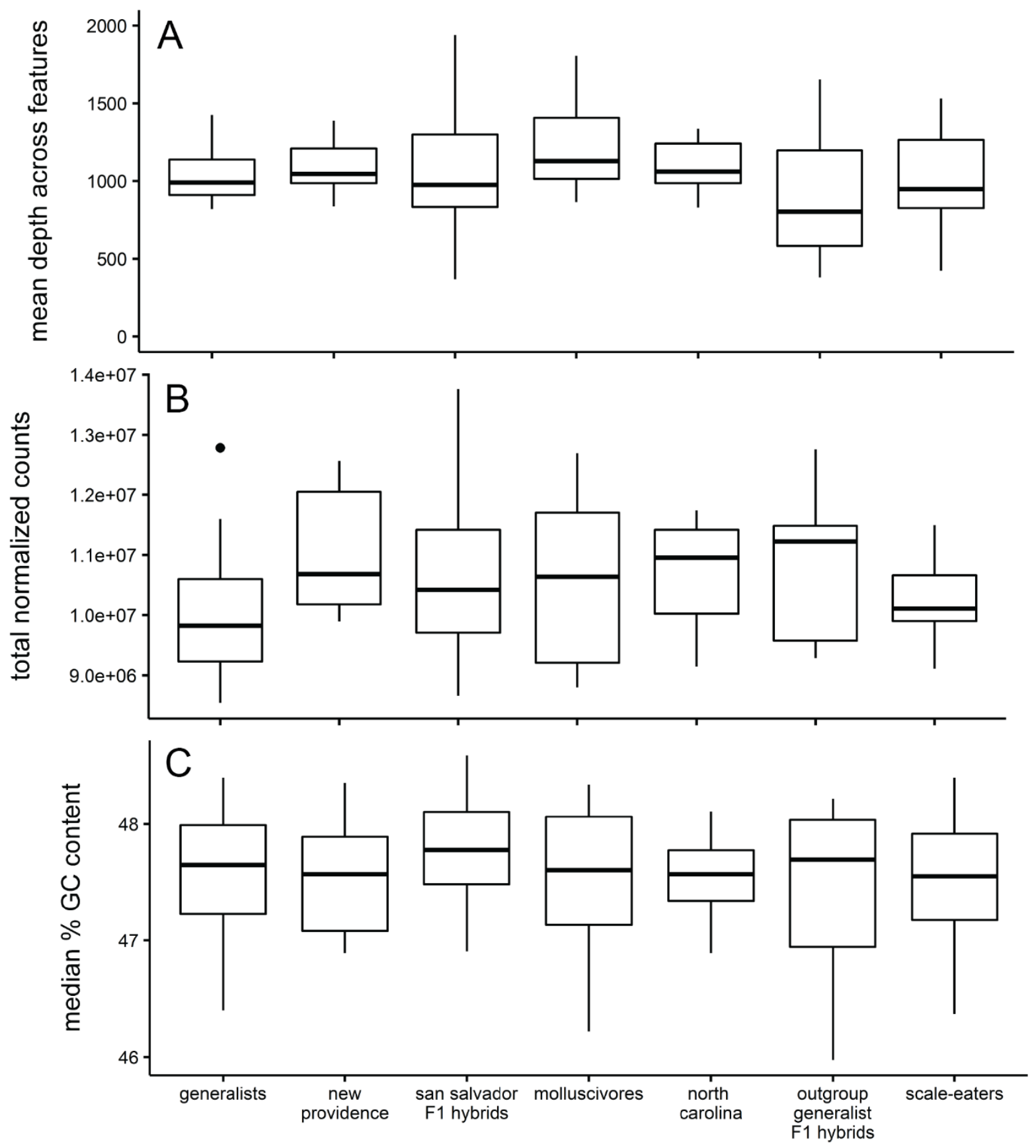

1342 Fig S7. No significant difference among F1 purebred and F1 hybrid samples for A) mean read 1343 depth across annotated features (ANOVA; $P=0.32$ ), B) total normalized read counts (ANOVA; $1344 P=0.16$ ), C) median percent GC content of reads (ANOVA; $P=0.32$ ). 


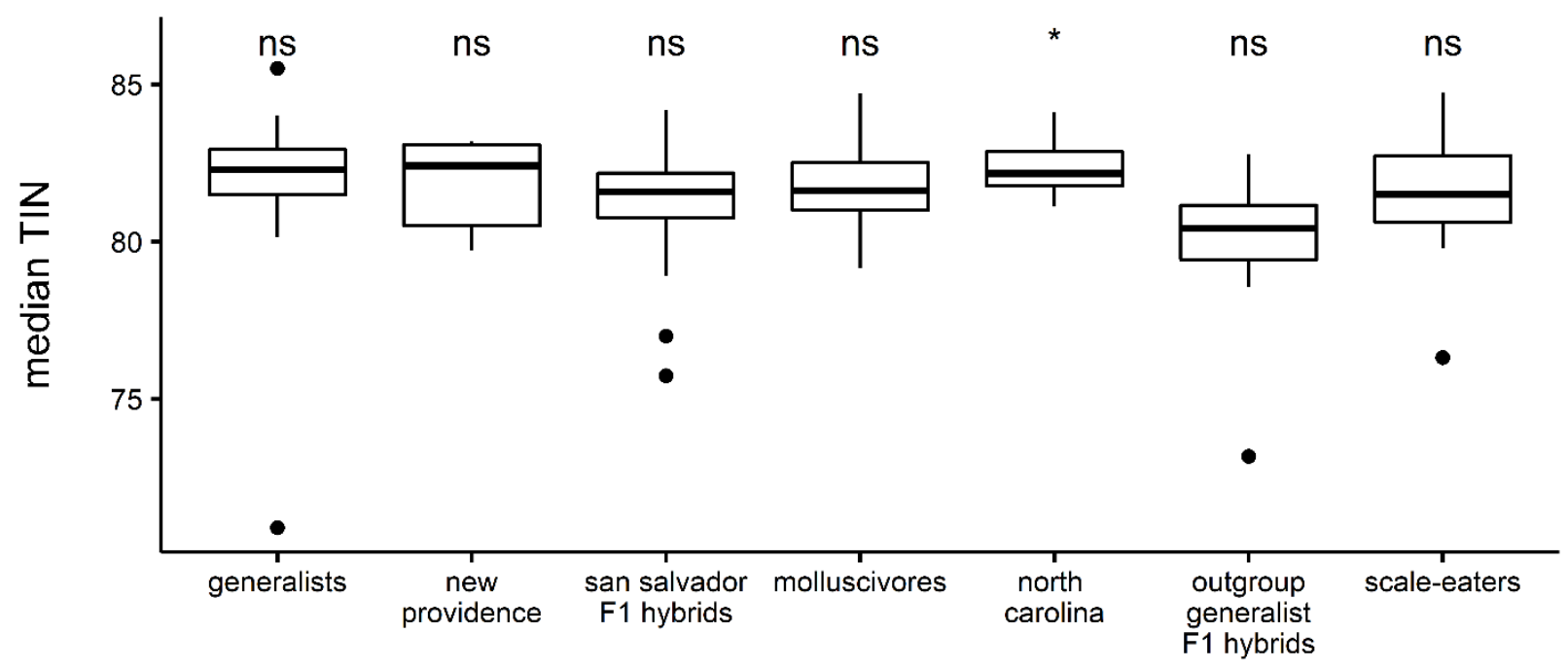

1346 Fig S8. Median transcript integrity numbers for each species and generalist population. Tukey 1347 post-hoc test: $P<0.05=* ; P>0.05=$ ns. 


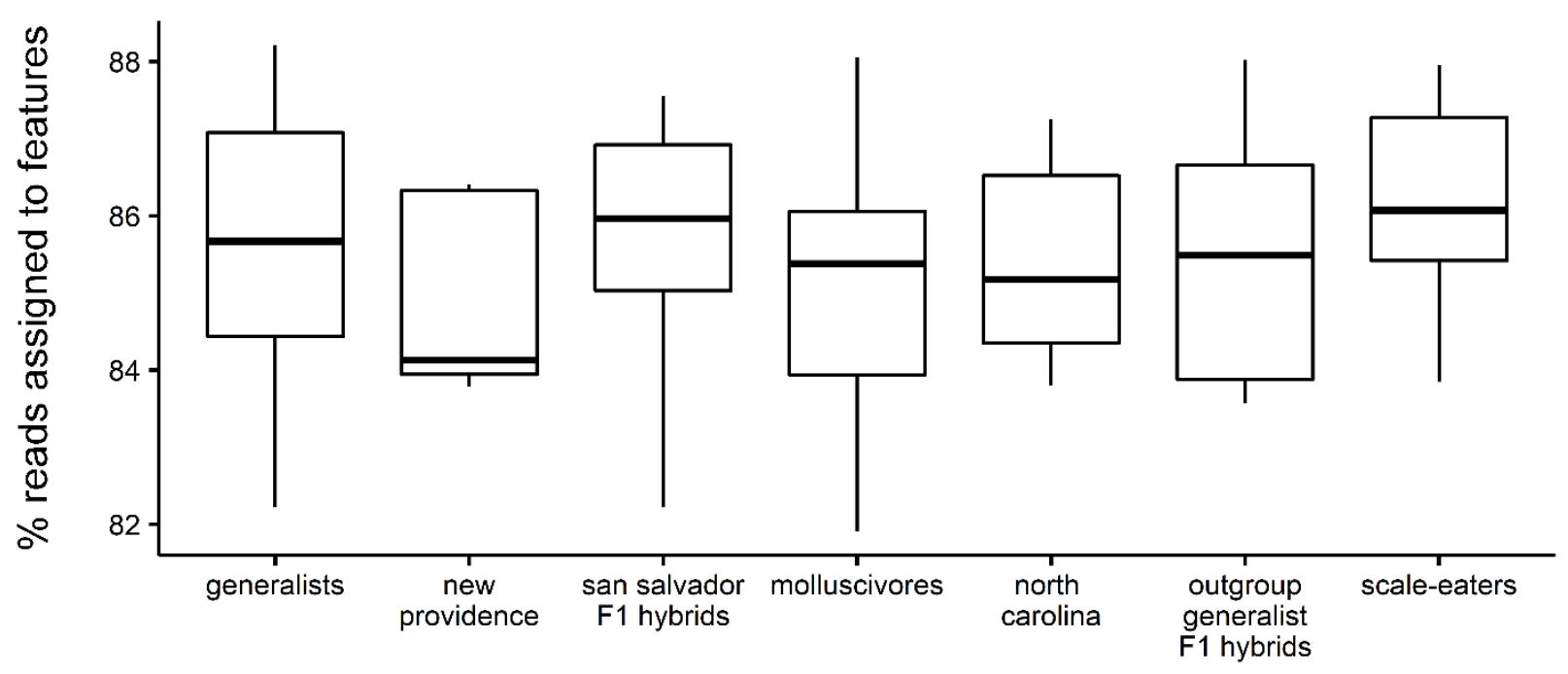

1367 Fig S9. No significant difference in the percentage of reads mapping to annotated features of the 1368 Cyprinodon reference genome among F1 purebred and F1 hybrid samples (ANOVA; $P=0.17$ ). 

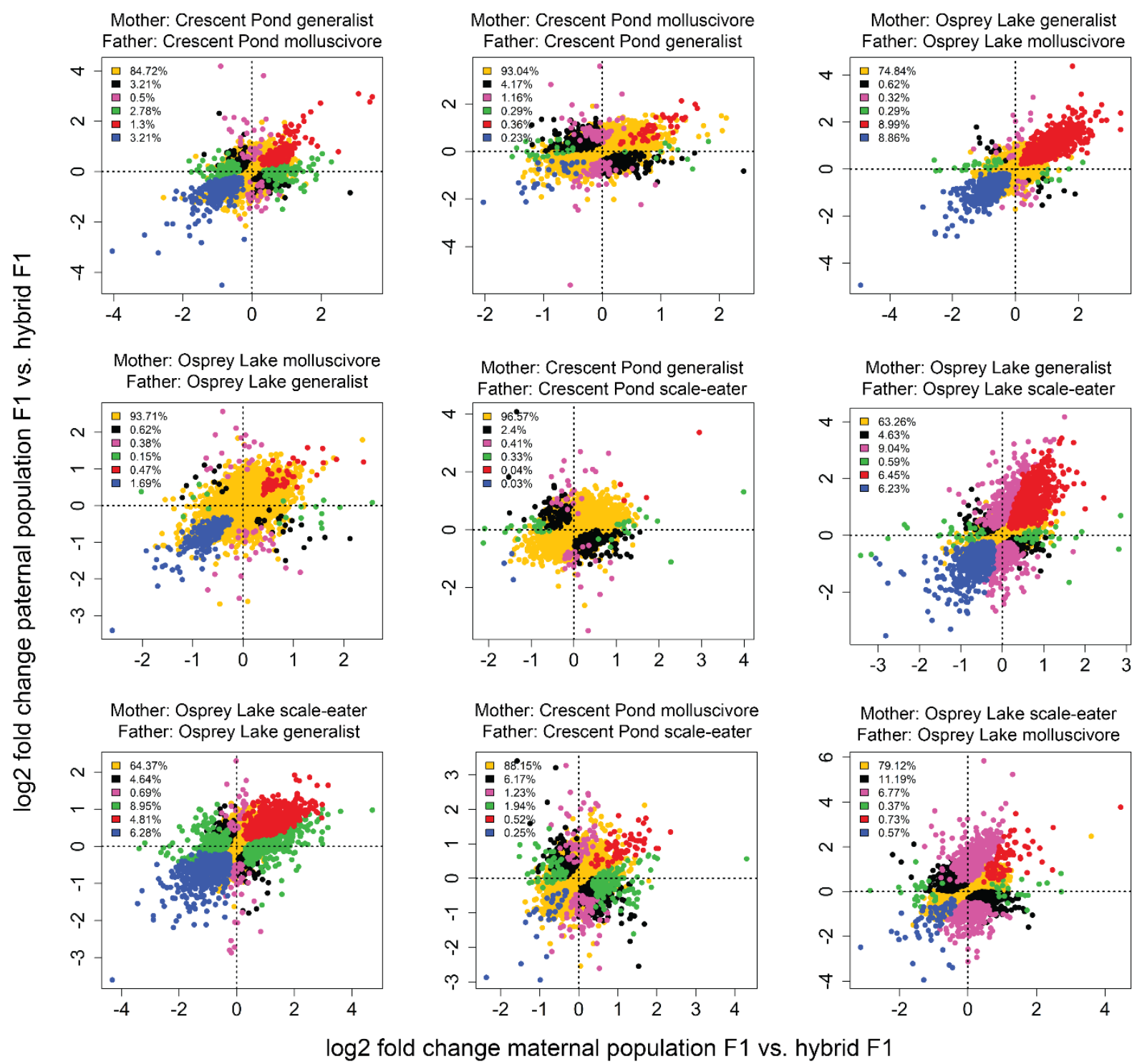

log2 fold change maternal population F1 vs. hybrid F1

1386 Fig S10. Gene expression inheritance for 2 dpf San Salvador hybrid crosses. Yellow = conserved (no difference in expression between groups or ambiguous expression patterns), black = additive

1388 (differential expression between purebred F1 and intermediate expression levels in hybrid F1), pink = maternal dominant (differential expression between purebred F1, differential expression between paternal population purebred F1 and F1 hybrids, no differential expression between maternal population purebred F1 and F1 hybrids), green = paternal dominant (differential expression between purebred F1, differential expression between maternal population purebred $\mathrm{F} 1$ and F1 hybrids, no differential expression between paternal population purebred F1 and F1 hybrids), red = overdominant (F1 hybrid gene expression significantly higher than parental population purebred $\mathrm{F} 1)$, blue = underdominant $(\mathrm{F} 1$ hybrid gene expression significantly lower than parental population purebred F1). 


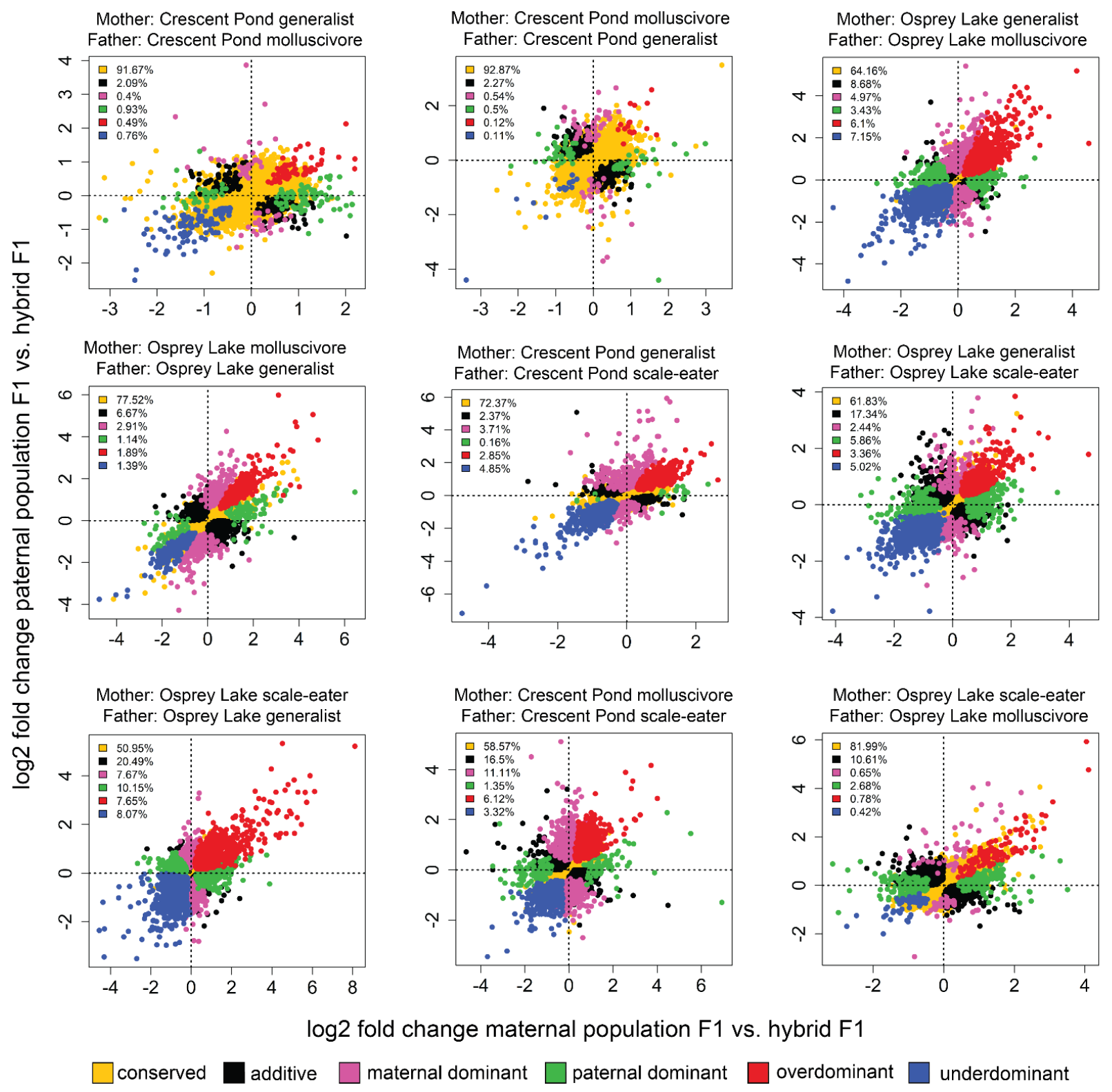

1398 Fig S11. Gene expression inheritance for 8 dpf San Salvador hybrid crosses. Yellow = conserved

1399 (no difference in expression between groups or ambiguous expression patterns), black = additive

1400 (differential expression between purebred F1 and intermediate expression levels in hybrid F1),

1401 pink = maternal dominant (differential expression between purebred F1, differential expression

1402 between paternal population purebred F1 and F1 hybrids, no differential expression between

1403 maternal population purebred F1 and F1 hybrids), green = paternal dominant (differential

1404 expression between purebred F1, differential expression between maternal population purebred

$1405 \quad \mathrm{~F} 1$ and F1 hybrids, no differential expression between paternal population purebred F1 and F1

1406 hybrids), red = overdominant (F1 hybrid gene expression significantly higher than parental

1407 population purebred F1), blue = underdominant (F1 hybrid gene expression significantly lower

1408 than parental population purebred F1). 


\section{$2 \mathrm{dpf} \quad \begin{gathered}\text { Mother: New Providence generalist } \quad 8 \mathrm{dpf} \\ \text { Father: Crescent Pond generalist }\end{gathered}$}
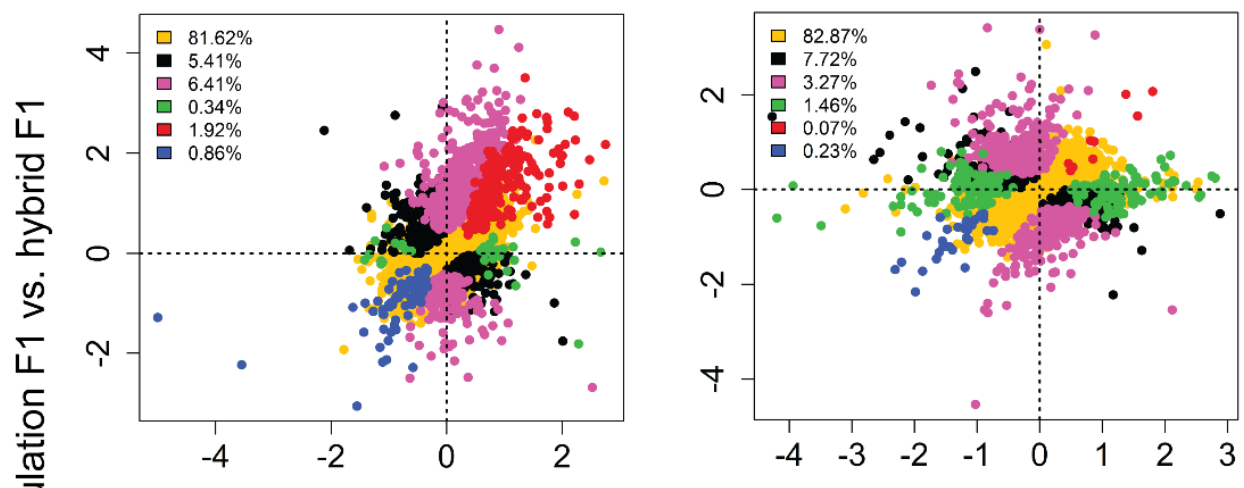

Mother: North Carolina generalist

Father: Crescent Pond generalist

1409 Fig S12. Gene expression inheritance for outgroup generalist population hybrid crosses. Yellow

$1410=$ conserved (no difference in expression between groups or ambiguous expression patterns),

1411 black = additive (differential expression between purebred F1 and intermediate expression levels

1412 in hybrid F1), pink = maternal dominant (differential expression between purebred F1,

1413 differential expression between paternal population purebred F1 and F1 hybrids, no differential

1414 expression between maternal population purebred F1 and F1 hybrids), green = paternal dominant

1415 (differential expression between purebred F1, differential expression between maternal

1416 population purebred F1 and F1 hybrids, no differential expression between paternal population

1417 purebred F1 and F1 hybrids), red = overdominant (F1 hybrid gene expression significantly

1418 higher than parental population purebred F1), blue = underdominant (F1 hybrid gene expression

1419 significantly lower than parental population purebred F1). 


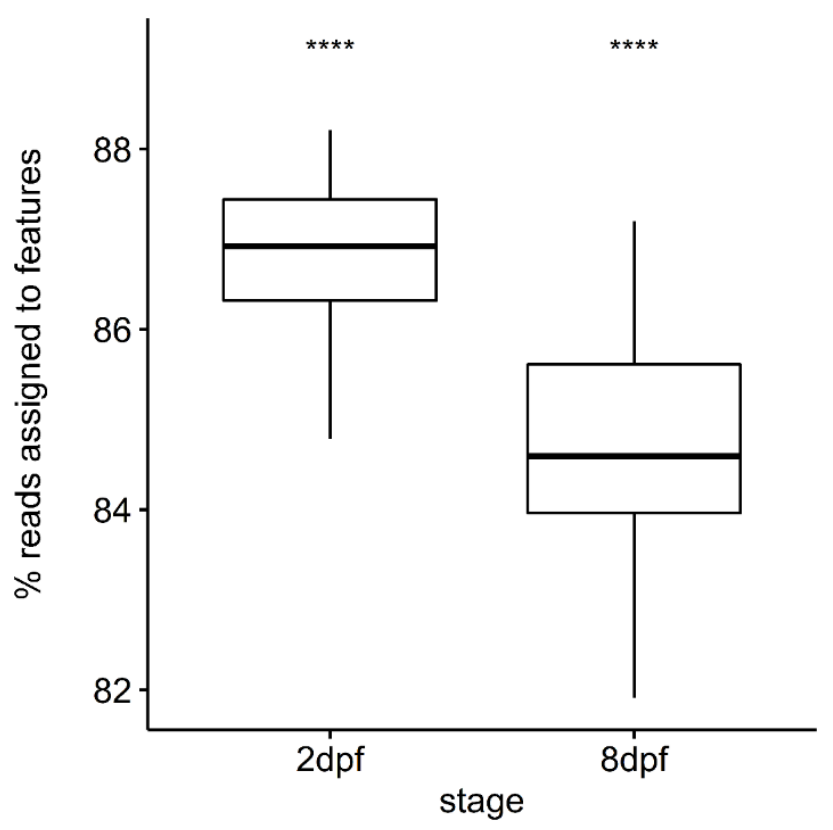


bioRxiv preprint doi: https://doi.org/10.1101/717025: this version posted July 28,2019 . The copyright holder for this preprint (which was not certified by peer review) is the author/funder, who has granted bioRxiv a license to display the preprint in perpetuity. It is made available under aCC-BY 4.0 International license.

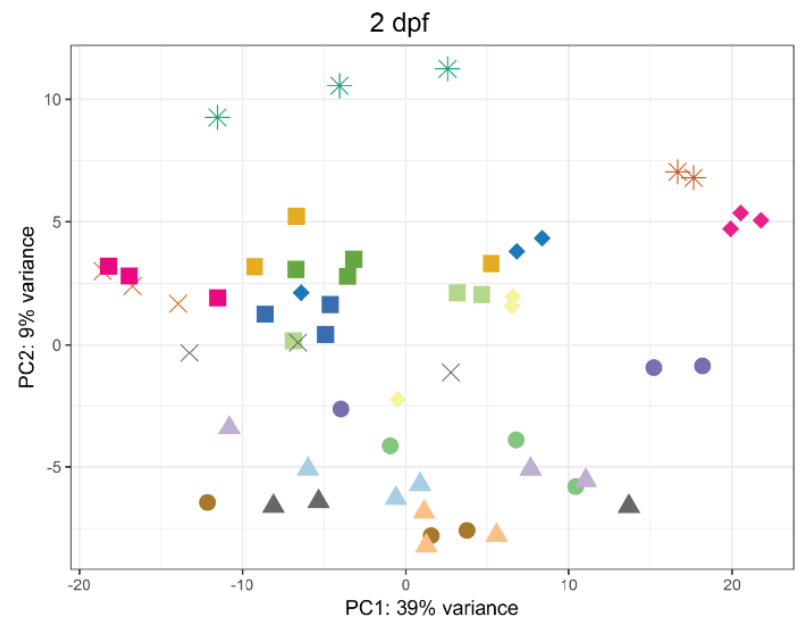

* outgroup generalist pure-bred F1

$X$ outgroup generalist $x$ crescent pond generalist hybrid F1

- crescent pond pure-bred F1

A crescent pond hybrid F1

- osprey pure-bred F1

- osprey hybrid F1

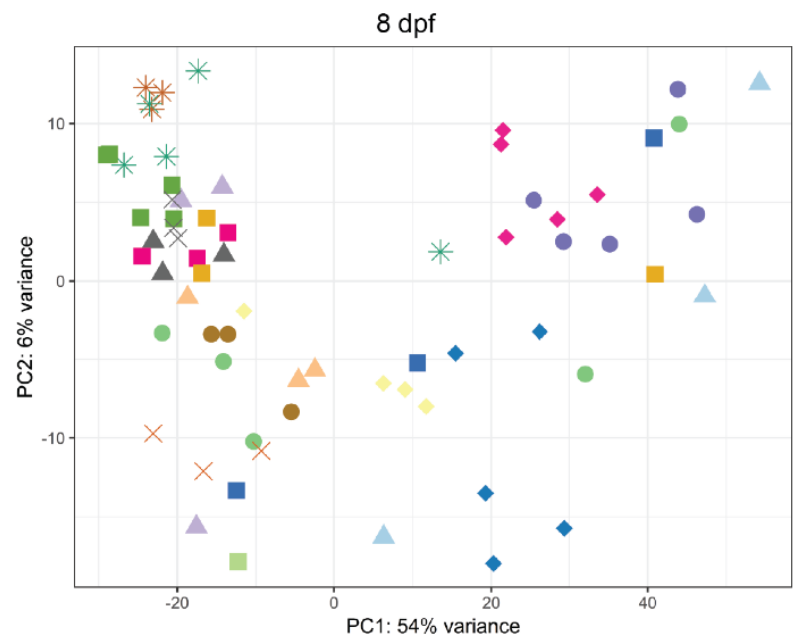

generalist crescent pond

- generalist crescent pond female $\mathrm{x}$ scale eater crescent pond male

generalist crescent pond female $x$ snail eater crescent pond male

generalist osprey

- generalist osprey female $\mathrm{x}$ scale eater osprey male

- generalist osprey female $x$ snail eater osprey male

- new providence female $x$ cunningham generalist male

- new providence female $x$ generalist crescent pond

north carolina

- north carolina female $x$ generalist crescent pond male

- scale eater crescent pond

- scale eater osprey

- scale eater osprey female $\mathrm{x}$ generalist osprey male

- scale eater osprey female $x$ snail eater osprey male

- snail eater crescent pond

- snail eater crescent pond female $x$ generalist crescent pond male

- snail eater crescent pond female $x$ scale eater crescent pond male

- snail eater osprey

- snail eater osprey female $\mathrm{x}$ generalist osprey male

1439 Fig S14. First two principal components explaining $48 \%$ (2 dpf) and 60\% (8 dpf) of the variance across normalized read counts.

1441

1442 